UNIVERSIDADE DE SÃO PAULO

INSTITUTO DE PSICOLOGIA

PAULO FRANCISCO DE CASTRO

CARACTERIZAÇÃO DA PERSONALIDADE DE PACIENTES COM TRANSTORNO DE PÂNICO POR MEIO DO MÉTODO DE RORSCHACH: CONTRIBUIÇÕES DO SISTEMA COMPREENSIVO 


\section{CARACTERIZAÇÃO DA PERSONALIDADE DE PACIENTES COM TRANSTORNO DE PÂNICO POR MEIO DO MÉTODO DE RORSCHACH: CONTRIBUIÇÕES DO SISTEMA COMPREENSIVO}

Tese apresentada ao Instituto de Psicologia da Universidade de São Paulo como parte dos requisitos para a obtenção do título de Doutor em Psicologia.

Área de Concentração: Psicologia Escolar e do Desenvolvimento Humano Orientadora: Profa. Dra. Eda Marconi Custódio 
Castro, Paulo Francisco de.

Caracterização da personalidade de pacientes com transtorno de pânico por meio de método de Rorschach: contribuições do sistema compreensivo / Paulo Francisco de Castro; orientadora Eda Marconi Custódio . -- São Paulo, 2008.

$102 \mathrm{p}$.

Tese (Doutorado - Programa de Pós-Graduação em Psicologia. Área de Concentração: Psicologia Escolar e do Desenvolvimento Humano) - Instituto de Psicologia da Universidade de São Paulo.

1. Teste de Rorschach 2. Avaliação psicológica 3. Psicopatologia 4. Testes psicológicos 5. Distúrbios do pânico I. Título.

BF698.8.R5 


\section{INFORMAÇÃO IMPORTANTE}

Considerando a Lei 4119, de 27 de agosto de 1962, que regulamenta a profissão de psicólogo, no Artigo $13^{\circ}$, $1^{\circ}$ parágrafo dispõe que: “Constitui função privativa do psicólogo o uso de métodos e técnicas para diagnóstico psicológico” e, portanto, não pode ser exercida por outras pessoas, sem essa formação e que não estejam inscritas no Conselho Regional de Psicologia.

E considerando ainda que para complementar esta Lei, o Código de Ética Profissional, publicado em agosto de 2005, referente às Responsabilidades do Psicólogo, dispõe:

- Artigo $1^{\circ}$, que estabelece os deveres fundamentais dos psicólogos, Alínea i, que cabe a todo psicólogo "zelar para que a comercialização, aquisição, doação, empréstimo, guarda e forma de divulgação do material privativo do psicólogo sejam feitas conforme os princípios deste Código";

- Artigo $2^{\circ}$, estabelecendo o que é vedado ao psicólogo, conforme alínea h, impede o profissional de “interferir na validade e fidedignidade de instrumentos e técnicas psicológicas, adulterar seus resultados ou fazer declarações falsas”;

- Artigo $15^{\circ}$, determina que o psicólogo deverá "zelar pelo destino de seus arquivos pessoais, inclusive todo material psicológico (testes)” e

- Artigo $18^{\circ}$ que: “o psicólogo não divulgará, ensinará, cederá, emprestará ou venderá a leigos instrumentos e técnicas psicológicas, que permitam e facilitem o exercício ilegal da profissão”.

Diante do que foi exposto, decidiu-se que a presente versão fosse reduzida para ser disponibilizada na internet. Embora pequena, tal redução foi necessária, pois houve a supressão de qualquer informação que possibilitasse a leigos compreenderem algum componente de aplicação ou interpretação do Método de Rorschach.

Informamos que a versão completa da Tese, disponível para psicólogos ou estudantes de psicologia, encontra-se na Biblioteca do Instituto de Psicologia da Universidade de São Paulo ou diretamente com o autor. 


\section{FOLHA DE APROVAÇÃO}

Paulo Francisco de Castro

Caracterização da personalidade de pacientes com transtorno de pânico por meio do Método de Rorschach: contribuições do sistema compreensivo.

Tese apresentada ao Instituto de Psicologia da Universidade de São Paulo como parte dos requisitos para a obtenção do título de Doutor em Psicologia.

Área de Concentração: Psicologia Escolar e do Desenvolvimento Humano

Aprovado em: 31 de março de 2008.

Banca Examinadora

Professora Doutora Eda Marconi Custódio (Orientadora)

Instituição: Instituto de Psicologia da Universidade de São Paulo

Professora Titular Latife Yagizi

Instituição: Escola Paulista de Medicina - Universidade Federal de São Paulo

Professora Associada Regina Sonia Gattas Fernandes do Nascimento

Instituição: Pontifícia Universidade Católica de São Paulo

Professora Associada Maria Abigail de Souza

Instituição: Instituto de Psicologia da Universidade de São Paulo

Professora Doutora Irai Cristina Boccato Alves

Instituição: Instituto de Psicologia da Universidade de São Paulo 
A meus amados pais, Osny e Rosa, como sinal de reconhecimento e gratidão, por tudo que fizeram para que eu pudesse chegar onde hoje estou.

A minha saudosa avó Dora (in memorian), por tudo que representa até hoje em minha vida.

A meus queridos sobrinhos, Ícaro, Natália, Luigi, Ingra e Mariana, com um forte desejo que, algum dia, eu possa ter a satisfação de poder ler suas teses. 


\section{AGRADECIMENTO ESPECIAL}

Esta tese foi fruto de intenso trabalho, de grande alegria e satisfação. Mas, nada teria sido possível sem a participação fundamental dos colaboradores da pesquisa aos quais agradeço, especialmente, pela disponibilidade em participar do presente estudo e, sobretudo, por não sucumbirem aos seus sofrimentos. Pelo contrário, transformaram suas ansiedades e angústias em material que proporcionou a compreensão do Transtorno de Pânico e o desenvolvimento deste trabalho de pesquisa.

Agradeço o esforço que fizeram para superar seus medos e mostrá-los a mim, demonstrando não só confiança em meu trabalho, mas também consciência de que, de alguma forma, esses conteúdos poderiam servir para auxiliar na compreensão das dificuldades de outras pessoas.

Espero que nosso contato durante meus estudos possa lhes ter trazido algum tipo de benefício, mesmo que pequeno, como forma de gratidão por toda colaboração que me prestaram. 


\section{AGRADECIMENTOS}

Acima de tudo, agradeço a Deus pelas minhas conquistas e pela minha vida ser como é, que eu seja merecedor de tudo que Ele tem me concedido ao longo desses anos.

Ao Instituto de Psicologia da Universidade de São Paulo, que acolheu minha proposta e proporcionou-me a obtenção deste título tão almejado. Aos sábios professores, pelo conhecimento que adquiri no cumprimento dos créditos. Aos dedicados funcionários, que sempre me atenderam com atenção e presteza.

Às Professoras Doutoras que compuseram a banca examinadora, cada qual e a seu modo, fizeram parte de minha trajetória educacional e profissional, constituindo-se como marcos importantes de minha carreira.

À Professora Doutora Eda Marconi Custódio, minha orientadora, que conheci, em 1994, durante o I Encontro do LITEP/USP e, desde então, despertou meu desejo de ser orientado por ela. Agradeço-lhe pela condução deste estudo com tanta competência e conhecimento, pelas discussões e por sua intensa correção de tudo o que eu fazia. Agradeçolhe ainda por sua forma doce e segura de orientar, seu respeito pelas minhas dificuldades e seu constante sorriso acolhedor que tanto sentirei falta.

À Professora Doutora Latife Yazigi, que conheci em 1995, durante o I Encontro da Sociedade Brasileira de Rorschach, em uma conferência que proferiu. Desde esse dia, tem sido um modelo de capacidade, conhecimento e seriedade profissional e científica, um exemplo que pretendo ser capaz de seguir. Além disso, agradeço-lhe pelas valiosas contribuições na realização desta pesquisa.

À Professora Doutora Regina Sonia Gattaz Fernandes do Nascimento, responsável por tudo que sei sobre o sistema compreensivo do Rorschach. Pelo convívio constante de dois anos no período das aulas, que tive a honra de assistir e que despertaram meu interesse para desenvolver o presente estudo. Agradeço-lhe também pela forma competente e segura que conduzia as aulas, pelo apoio e contribuições no desenvolvimento deste projeto.

À Professora Doutora Maria Abigail de Souza, que eu conhecia por seus trabalhos com o Rorschach e que tive a oportunidade de conviver pessoalmente no cumprimento de um crédito sobre essa técnica, oferecendo-me a oportunidade única de saber mais sobre o sistema francês. Agradeço-lhe por oferecer seu conhecimento e suas contribuições na leitura do projeto de tese. 
À Professora Doutora Irai Cristina Boccato Alves, com quem tive o primeiro contato em 1994, durante I Encontro do LITEP/USP que, desde então, tem acompanhado meu desenvolvimento pessoal e profissional. Admiro-a pela competência, seriedade e segurança. Agradeço-lhe por toda atenção que sempre teve comigo, por suas contribuições neste trabalho e em outros tantos que foram realizados, bem como pelo constante incentivo desde minha entrada no programa de pós-graduação.

Ao Professor Doutor Armando Rocha Júnior, “irmão” sempre presente, pelas discussões esclarecedoras, pelo apoio constante, pela leitura deste trabalho, tratando-o com a mesma atenção como se fosse seu. Por tudo isso e por todos os anos de convívio profissional e amizade, divido com você a conquista deste tão importante título.

Aos professores Sonia Maria da Silva e Luis Sérgio Sardinha, especialistas no Método de Rorschach, pelo inestimável apoio em serem juízes no desenvolvimento da pesquisa.

Agradeço o incentivo sempre presente e o apoio emocional de meu irmão, José Fabiano, a cunhada Cristina, a tia Maria Arnone e os primos Roberto e Adriana.

Aos velhos amigos, professores da Universidade Guarulhos, representados aqui por Mara Poltronieri, Tania Maria Justo de Almeida, Silvia Suely de Souza Maia, Eliana Ferrante Pires, Maria Lúcia Marques, Augusto José Fiedler, José Candido Cheque de Moraes e Jumara Van De Velde Vieira, que acompanharam todo meu caminho desde a graduação e que, também, fazem parte de minha história. Agradeço-lhes pelo apoio sempre presente e pelas alegrias que sentimos ao longo desses anos.

Aos novos amigos, professores da Universidade de Taubaté, representados por Ana Cristina Nascimento, Maria Júlia Ribeiro, Marilsa de Souza, Marilza Tadeucci e Paulo Sodré, que compartilharam meus recentes momentos, pelo convívio e incentivo sempre presentes.

Aos amigos Carlos Dias Iema e Georgia Aoki Iema, pelo apoio recebido e incentivo constante.

À psicóloga Lígia Mitsuko Furusawa, pelo apoio recebido, pelos recados que transmitia e os documentos que eu sempre pedia para entregar em algum departamento da Universidade de São Paulo.

Ao Professor Helymar C. Machado (Unicamp), pelo rigoroso tratamento estatístico que subsidiou minhas reflexões.

Às Professoras Ivone Borelli e Mônica de Deus Martins, pela paciente e competente revisão gramatical, cumprindo os exíguos prazos combinados. 


\section{RESUMO}

Castro, P.F. (2008). Caracterização da personalidade de pacientes com transtorno de pânico por meio do Método de Rorschach: contribuições do sistema compreensivo. São Paulo, Tese de Doutorado, Instituto de Psicologia, Universidade de São Paulo, São Paulo.

A presente pesquisa teve como objetivo caracterizar os elementos de personalidade de pacientes com transtorno de pânico a partir dos dados obtidos pelo Método de Rorschach, segundo o sistema compreensivo. Em linhas gerais, o transtorno de pânico pode ser caracterizado pela vivência recorrente de ataques de pânico, em virtude de crises agudas de ansiedade, onde o indivíduo passa por um mal-estar intenso e uma sensação iminente de perigo e ou morte. Participaram do estudo 60 colaboradores divididos igualmente em quatro grupos: pacientes com pânico do sexo feminino, pacientes com pânico do sexo masculino, não pacientes do sexo feminino e não pacientes do sexo masculino. Os participantes do grupo de não pacientes foram avaliados pelo Questionário de Saúde Geral para verificação de seu estado geral de saúde mental e todos os colaboradores submeteram-se ao Método de Rorschach, conforme as especificações técnicas do sistema compreensivo. As respostas foram codificadas por juízes independentes e os índices obtidos foram submetidos à análise estatística por meio do teste de Kruskal-Wallis e do teste post-hoc de Dunn, comparando-se os quatro grupos. Os resultados com diferença estatisticamente significativa apresentados para os colaboradores com transtorno de pânico foram os seguintes: presença do Índice de Depressão ( $\mathrm{p}=0,009)$, indicando depressão e sintomas depressivos ou algum tipo de transtorno afetivo; rebaixamento do Índice Lambda $(p=0,008)$, demonstrando dificuldade na discriminação entre informações importantes e irrelevantes; predomínio de cor acromática e sombreados na Experiência de Base $(\mathrm{p}=0,010)$, caracterizando dor e sofrimento psíquicos em demasia, além de aumento da tensão interna; elevação da Estimulação Sentida ( $\mathrm{p}<$ 0,001), indicando uma vivência de extrema irritação, desconforto e incômodo internos; rebaixamento da Nota $\mathrm{D}(\mathrm{p}<0,001)$, que revela grande vivência de estresse, associado à falta de recursos internos para enfrentá-lo; elevação das determinantes de sombreado com característica de difusão ( $\mathrm{p}<0,001)$, que indica extremo desconforto emocional, sofrimento interno e desamparo emocional; elevação de determinantes mistos de cor e sombreado ( $\mathrm{p}=$ 0,004), que propõe vivências afetivas carregadas de ambivalência e sofrimento e perturbação afetiva; predomínio das respostas empobrecidas de conteúdo humano ( $p=0,011$ ), que demonstra dificuldade de adaptação nas relações sociais; rebaixamento das respostas de movimento cooperativo ( $\mathrm{p}=0,006)$, revelando dificuldade em estabelecer vínculos positivos e construtivos com outros indivíduos. Em síntese, os aspectos de personalidade observados nos colaboradores com pânico mostram tratar-se de indivíduos que internamente apresentam grande sofrimento psicológico, tensão interna e dificuldades afetivas; não possuem recursos de enfrentamento das situações estressantes e ansiógenas, levando-os a dificuldade de relacionamento adequado. Os quadros de pânico são decorrentes dessa estrutura frágil e comprometida. Embora os dados sejam conclusivos, existe a necessidade de constantes investigações para a melhor compreensão desse quadro psicopatológico que tanto causa sofrimento em seus portadores.

Palavras-chave: Avaliação Psicológica; Psicopatologia; Teste de Rorschach; Testes Psicológicos; Transtorno de Pânico. 


\begin{abstract}
Castro, P. F. (2008). Characterization of the personality of patients with panic disorder as assessed by the Rorschach Method: contributions of the comprehensive system. São Paulo, Doctoral Thesis, Instituto de Psicologia, Universidade de São Paulo, São Paulo.

The objective of this research was to characterize the personality elements of patients with panic disorder from data obtained by the Rorschach Method following the comprehensive system. In general terms, the panic disorder can be characterized by the repeated experience of panic attacks due to acute anxiety, in which the individual suddenly develops a severe discomfort or fear of danger and or death. 60 subjects participated in the study, equally divided into four groups: female patients with panic, male patients with panic, female nonpatients and male nonpatients. The nonpatient group was assessed through the General Health Questionnaire for a general mental health assessment, and all subjects were submitted to the Rorschach Method, following the comprehensive system technical specifications. The responses were codified by independent raters and the indices obtained were subjected to statistical analysis using the Kruskal-Wallis test followed by Dunn's post-hoc test, comparing the four groups. The results with statistically significant difference presented regarding subjects com panic disorder were the following: presence of Depression Index ( $p=0.009)$, indicating depression and depressive symptoms or some kind of affective disorder; lower Lambda ( $p=0.008)$, showing difficulty to distinguish between important and irrelevant information; prevalence of achromatic and shading colors in the Experience Base $(p=0.010)$, characterizing overwhelming psychic pain and suffering, in addition to increased inner stress; higher Experienced Stimulation ( $p<0.001$ ), showing an experience of extreme inner irritation, discomfort and uneasiness; lower D Score $(\mathrm{p}<0.001)$, showing great stress experience associated with lack of inner coping resources; increase in the shading with diffusion feature determinants $(\mathrm{p}<0.001)$, indicating extreme emotional discomfort, inner suffering and emotional helplessness; increase in mixed color and shading determinants ( $\mathrm{p}=$ 0.004), suggesting affective experiences full of ambivalence and suffering and affective disturbance; predominance of impoverished human content responses $(p=0.011)$, showing difficulty in adapting to social relationships; fewer cooperative movement responses ( $\mathrm{p}=$ 0.006), showing difficulty in establishing positive and constructive bonds with other individuals. In summary, the personality aspects observed in the subjects with panic show they are individuals presenting deep psychological suffering, inner tension and affective difficulties; they lack coping resources to handle stressful and anxious situations, leading them to difficulty in proper interpersonal relationship. The panic disorder results from this fragile and vulnerable structure. Although data is conclusive, permanent investigation is necessary in order to better understand this psychopathologic condition that causes so much pain to those who suffer from it.
\end{abstract}

Keywords: Psychological Assessment; Psychopathology; Rorschach Test; Psychological Tests; Panic Disorder. 


\section{RÉSUMÉ}

Castro, P. F. (2008). Caractérisation de la personnalité des patients atteints de trouble de panique au moyen de la Méthode de Rorschach: contributions du système intégré. São Paulo, Thèse de Doctorat, Instituto de Psicologia, Universidade de São Paulo, São Paulo.

La présente recherche a pour but de caractériser les éléments de la personnalité des patients porteurs de trouble de panique à partir des données obtenues par la Méthode de Rorschach, selon le système intégré. En général, le trouble de panique peut se caractériser par la survenance récurrente d'attaques de panique, en vertu de crises aiguës d'anxiété, pendant lesquelles l'individu éprouve un mal-être intense et une sensation de danger ou de mort imminents. Soixante (60) personnes, réparties en quatre groupes égaux ont participé à cette étude: patientes de sexe féminin atteintes de panique; patients de sexe masculin atteints de panique; individus sains de sexe féminin et individus sains de sexe masculin. Les participants du groupe des individus sains ont été triés et évalués sur un questionnaire de santé générale permettant d'apprécier leur état général de santé mentale. Outre cela, les participants dans leur ensemble ont accepté de se soumettre à la Méthode de Rorschach, conformément aux spécifications techniques du système intégré. Leurs réponses ont été codifiées par des jurys indépendants et les indicateurs obtenus ont été analysés d'un point de vue statistique au moyen du test de Kruskal-Wallis et du test post-hoc, de Dunn, en comparant les quatre groupes. Les résultats des individus atteints de troubles de panique ont montré des différences statistiques significatives dont, notamment: la présence de l'indicateur de dépression ( $p=0,009$ ), indiquant la dépression et les symptômes dépressifs ou un type de trouble affectif; la baisse de l'indicateur Lambda $(p=0,008)$, démontrant la difficulté de discernement entre les informations importantes et les négligeables; la prédominance de la couleur achromatique et des ombres dans l'Expérience de Base $(\mathrm{p}=0,010)$, révélant un excès de détresse et de souffrance psychiques, outre l'augmentation de la tension intérieure; la hausse de la stimulation sentie ( $\mathrm{p}<0,001)$, révélant un vécu d'irritation extrême, de détresse et d'exaspération intérieures; la baisse de la Note $\mathrm{D}(\mathrm{p}<0,001)$ qui révèle un long vécu de stress associé au manque de ressources intérieures pour le combattre; la hausse des déterminants d'ombres caractéristiques de diffusion ( $\mathrm{p}<0,001$ ), qui indique un malaise émotionnel intense, une souffrance intérieure et un abandon émotionnel; l'augmentation des déterminants mixtes en couleur et d'ombre $(p=0,004)$, qui suggère des vécus affectifs lourds d'ambivalence, de souffrance et de perturbations affectives; la prédominance des réponses pauvres en contenu humain $(\mathrm{p}=0,011)$ qui témoignent d'une difficulté d'adaptation aux rapports sociaux; la baisse des réponses de mouvement coopératif $(\mathrm{p}=0,006)$, révélant la difficulté à établir des liens positifs et constructifs avec les autres individus. En conclusion, les aspects de la personnalité observés chez les personnes porteuses de panique ayant collaboré à notre étude montrent qu'il s'agit d'individus qui, dans leur for intérieur, sont sujets à de grandes souffrances psychologiques, à une tension intérieure et à des difficultés affectives. Par ailleurs, ces patients ne trouvent pas en eux la force d'affronter les situations stressantes et anxiogènes, ce qui les empêche d'avoir des rapports normaux avec les autres. Les cadres des troubles de panique découlent de cette structure fragile et instable. Bien que les résultats soient concluants, il faudra encore mener des recherches constantes pour mieux comprendre ce cadre psychopathologique qui est générateur qu'une grande détresse chez les sujets qui en sont porteurs.

Mots-clés: Évaluation Psychologique; Psychopathologie; Test de Rorschach; Tests Psychologiques; Trouble de Panique. 


\section{RESUMEN}

Castro, P. F. (2008). Caracterización de la personalidad de pacientes con trastorno de pánico por medio del Método de Rorschach: contribuciones del sistema comprensivo. São Paulo, Tesis de Doctorado, Instituto de Psicologia, Universidade de São Paulo, São Paulo.

El objetivo de la presente investigación ha sido caracterizar los elementos de personalidad de pacientes con trastorno de pánico a partir de datos obtenidos por el Método de Rorschach, según el sistema comprensivo. En líneas generales, se puede caracterizar el trastorno de pánico por la vivencia recurrente de ataques de pánico, en virtud de crisis agudas de ansiedad, en las cuales, el individuo pasa por un malestar intenso y una sensación inminente de peligro y/o de muerte. Participaron en el estudio 60 colaboradores, divididos igualmente en cuatro grupos: pacientes del sexo femenino con pánico, pacientes del sexo masculino con pánico, no pacientes del sexo femenino y no pacientes del sexo masculino. Se evaluaron a los participantes del grupo de no pacientes por medio del Cuestionario de Salud General para verificar su estado general de salud mental y todos los colaboradores se sometieron al Método de Rorschach, de conformidad a las especificaciones técnicas del sistema comprensivo. Las respuestas fueron codificadas por jueces independientes y los índices obtenidos fueron objeto de análisis estadístico por medio de la prueba de Kruskal-Wallis y de la prueba post-hoc, de Dunn, comparándose los cuatro grupos. Los resultados con diferencia estadísticamente significativa presentados por los colaboradores con trastorno de pánico fueron los siguientes: presencia del Índice de Depresión ( $p=0,009$ ), que señala depresión y síntomas depresivos o algún tipo de trastorno afectivo; rebajamiento del Índice Lambda $(\mathrm{p}=0,008)$, demostrando dificultad en distinguir informaciones importantes e irrelevantes; predominio de color acromático y sombreados en la Experiencia de Base $(p=0,010)$, caracterizando demasiados dolor y sufrimiento psíquicos, además de aumento de la tensión interna; elevación de la Estimulación Sentida ( $\mathrm{p}<0,001$ ), que señala una vivencia de extremada irritación, incomodidad e indisposición internos; rebajamiento de la Nota $\mathrm{D}(\mathrm{p}<0,001)$, que revela gran vivencia de estrés, aunada a la falta de recursos internos para enfrentarlo; elevación de las determinantes de sombreado con característica de difusión ( $p<0,001)$, que indica extremada incomodidad emocional, sufrimiento interno y desamparo emocional; elevación de determinantes mixtos de color y sombreado $(p=0,004)$, que propone vivencias afectivas cargadas de ambivalencia y sufrimiento y perturbación afectiva; predominio de respuestas empobrecidas de contenido humano ( $\mathrm{p}=0,011)$, que demuestra dificultad de adaptación en las relaciones sociales; rebajamiento de las respuestas de movimiento cooperativo ( $\mathrm{p}=$ 0,006), revelando dificultad de establecer vínculos positivos y constructivos con otros individuos. En síntesis, los aspectos de personalidad observados en los colaboradores con pánico reportan individuos que internamente presentan gran sufrimiento psicológico, tensión interna y dificultades afectivas; no poseen recursos de enfrentamiento a situaciones estresantes y ansiógenas, llevándolos a una dificultad para las relaciones adecuadas. Los cuadros de pánico resultan de esa estructura frágil y comprometida. Aunque los datos sean conclusivos, existe la necesidad de constantes investigaciones para la mejor comprensión de ese cuadro psicopatológico que tanto sufrimiento causa a sus portadores.

Palabras clave: Evaluación Psicológica; Psicopatología; Prueba de Rorschach; Pruebas Psicológicas; Trastorno de Pánico. 


\section{LISTA DE QUADROS}

Quadro 1 Comparação do estilo de descrição dos quadros clínicos das patologias entre a CID-10 e o DSM-IV ............................................. 4

Quadro 2 Dados sobre idade e escolaridade dos participantes da pesquisa...... 46

Quadro 3 Resultados do Questionário de Saúde Geral de Goldberg dos participantes do Grupo de Não pacientes.......................................... 51

Quadro 4 Quantidade de discordância de respostas por protocolo.................... 53

Quadro 5 Síntese das variáveis com diferença estatisticamente significativa.... 84 


\section{LISTA DE TABELAS}

Tabela 1 Levantamento dos trabalhos apresentados nos eventos da SBRo que utilizaram o sistema compreensivo................................................ 26

Tabela 2 Presença de DEPI nos quatro grupos. ............................................... 58

Tabela 3 Incidência de indicadores de DEPI nos quatro grupos. .................... 59

Tabela 4 Presença de CDI nos quatro grupos. ................................................ 60

Tabela 5 Incidência de indicadores de CDI nos quatro grupos. ...................... 61

Tabela $6 \quad$ Valores de L apresentados nos quatro grupos. ................................ 61

Tabela 7 Classificação de EB nos quatro grupos. .......................................... 63

Tabela 8 Valores de EA apresentados nos quatro grupos. ............................... 64

Tabela 9 Valores de EBPer apresentados nos quatro grupos. .......................... 65

Tabela 10 Classificação de eb nos quatro grupos. ............................................... 66

Tabela 11 Valores de es apresentados nos quatro grupos. ................................ 68

Tabela 12 Valores de D apresentados nos quatro grupos. ................................ 69

Tabela 13 Valores de Adj D apresentados nos quatro grupos. ........................ 69

Tabela 14 Valores de FM apresentados nos quatro grupos. ............................. 70

Tabela 15 Valores de $m$ apresentados nos quatro grupos. ............................... 71

Tabela 16 Valores de $\Sigma C^{\prime}$ apresentados nos quatro grupos. ............................. 71

Tabela 17 Valores de $\Sigma \mathrm{V}$ apresentados nos quatro grupos. ............................. 72

Tabela 18 Valores de $\Sigma \mathrm{T}$ apresentados nos quatro grupos. .............................. 73

Tabela 19 Valores de $\Sigma \mathrm{Y}$ apresentados nos quatro grupos............................... 74

Tabela 20 Valores de CorSh apresentados nos quatro grupos............................ 75

Tabela 21 Comparação GHR : PHR nos quatro grupos.................................... 76

Tabela 22 Valores de COP apresentados nos quatro grupos............................ 77

Tabela 23 Valores de $\mathrm{X}+\%$ apresentados nos quatro grupos............................ 78

Tabela 24 Valores de XA\% apresentados nos quatro grupos.............................. 79

Tabela 25 Valores de X-\% apresentados nos quatro grupos............................. 80 


\section{SUMÁRIO}

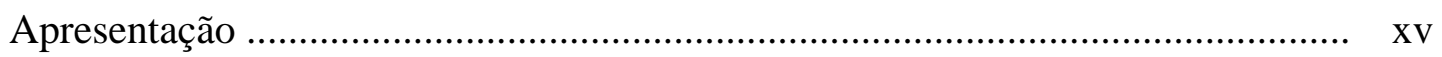

I INTRODUÇÃ

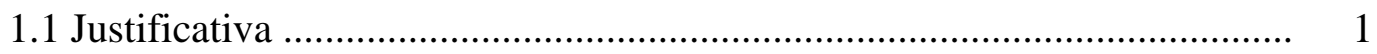

1.2 Transtorno de Pânico ................................................................................ 3

Conceituação e Caracterização Fenomenológica ......................................... 3

Os Manuais de Classificação ...................................................................... 3

Classificação Nosológica do Pânico .......................................................... 4

Ansiedade, Medo e Pânico …………………................................................ 6

Descrição Fenomenológica do Transtorno de Pânico ................................... 9

Conceituação e Caracterização Psicanalítica ............................................... 12

Compreensão Psicanalítica do Fenômeno do Pânico .................................. 13

1.3 Utilização de Técnicas Projetivas e do Método de Rorschach no Diagnóstico Psicológico .............................................................................. 19

Caracterização das Técnicas Projetivas ................................................... 19

O Rorschach como Técnica Projetiva ....................................................... 22

Breve Histórico ….............................................................................. 23

Aspectos Projetivos do Método de Rorschach ........................................... 27

1.4 O Método de Rorshach na Investigação do Pânico .................................... 31

O Rorschach na Investigação de Aspectos Psicopatológicos ..................... 31

O emprego do Rorschach na Investigação da Ansiedade ............................. 34

Estudo do pânico por Técnicas Projetivas e Rorschach ............................... 38

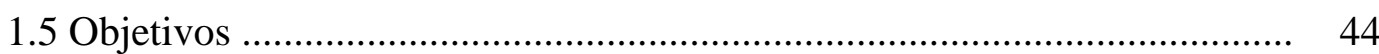


2.1 Colaboradores ….............................................................................. 45

2.2 Material e Instrumentos para a Coleta de Dados .................................. 47

2.3 Procedimentos para a Coleta de Dados ..................................................... 49

2.4 Procedimentos de Análise dos Dados .................................................. 52

III RESULTADOS E DISCUSSÕES ................................................... 57

3.1 Dados Quantitativos ................................................................... 57

Variáveis Principais ........................................................................ 57

Variáveis Secundárias ......................................................................... 75

3.2 Apreciações Qualitativas ................................................................ 81

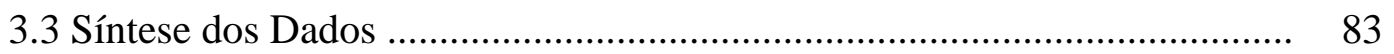

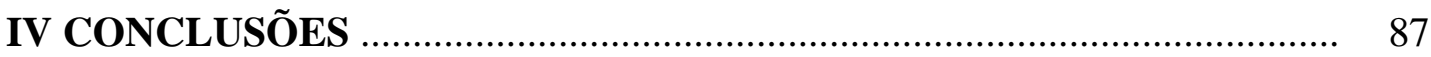

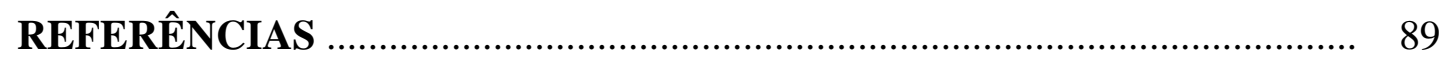

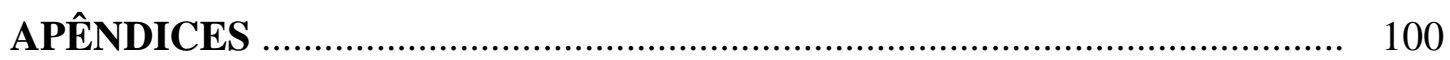




\section{APRESENTAÇÃO}

O desenvolvimento do presente projeto baseia-se em uma descrição teórica inicial e na apresentação de uma proposta metodológica para realização de uma pesquisa empírica sobre a aplicabilidade do Método de Rorschach em pacientes com transtornos de pânico, utilizando o sistema compreensivo.

Desta forma, na primeira parte do capítulo I, apresenta-se um conjunto de justificativas descritas com base no crescimento do interesse pelo teste e em sua aplicação do na investigação do pânico.

Na seção seguinte, os principais conceitos sobre o transtorno de pânico são apresentados, tanto no que se referem à compreensão fenomenológica, baseada nas descrições nosológicas de manuais de grandes instituições normatizadoras, como no que tangem a uma descrição apoiada em fundamentos psicodinâmicos e no funcionamento psíquico dos pacientes.

Após esta exposição, os aspectos teóricos relacionados às técnicas projetivas e ao Rorschach são apresentados. Assim, no próximo tópico, são mostradas as proposições e uma caracterização das técnicas projetivas e sua aplicabilidade clínica em estratégias psicodiagnósticas definidas. A seguir, dá-se uma ênfase ao método de investigação do trabalho, o Rorschach, que é apresentado como técnica projetiva, explicando-se os processos que embasam essa importante técnica, demonstrando sua relevância e principais características.

Depois disso, uma parte é destinada a uma reflexão sobre o Rorschach quando utilizado para investigações clínicas ou pesquisas, envolvendo qualquer funcionamento psicopatológico, enfatizando seu desenvolvimento e sua importância no que se refere ao estudo de diferentes patologias e a aplicação de estratégias de diagnóstico diferencial. No sentido de ilustrar as questões apresentadas e sintetizar as idéias teóricas iniciais, o final desta 
seção propõe-se à apresentação de dados obtidos em material bibliográfico a respeito dos estudos sobre o transtorno de pânico, pautados em técnicas projetivas, dando-se destaque ao Rorschach e à formulação dos objetivos do presente estudo.

No capítulo II, a estratégia metodológica para realização da pesquisa é apresentada, esclarecendo sobre os sujeitos que participaram da pesquisa, descrevendo as características tanto dos pacientes com transtorno de pânico como também as dos grupos de não pacientes, especificando os critérios de inclusão e exclusão para sua participação. Além dos elementos dos sujeitos são apresentados procedimentos que foram utilizados para a coleta dos dados, os cuidados éticos que foram seguidos e as estratégias quantitativas e qualitativas para análise do material coletado.

No item seguinte, capítulo III, estão expressas a apresentação e a discussão dos resultados. Para melhor reflexão dos dados obtidos, os valores quantitativos e as representações qualitativas do estudo foram separados e analisados. Há a apresentação das análises estatísticas aplicadas às variáveis quantitativas e uma apreciação sobre os componentes qualitativos das respostas.

Por fim, no capítulo IV, há a exposição das conclusões da pesquisa pautadas nos objetivos que foram estabelecidos no princípio do texto, esclarecendo sobre o perfil psicológico levantado com base nos dados do Método de Rorschach.

Pautado na divisão estabelecida, espera-se que seja possível a compreensão das idéias e das proposições apresentadas, considerando-se que o presente trabalho tem o intuito de demonstrar a aplicação do Método de Rorschach no contexto do diagnóstico diferencial do Transtorno do Pânico, para poder contribuir na ampliação da possibilidade do uso desse importante instrumento no diagnóstico clínico. 


\section{INTRODUÇÃO}

\subsection{Justificativa}

Muito se discute a respeito dos transtornos de pânico, seus sintomas e diagnóstico, mas em certos casos, é de opinião comum que existe dificuldade para se chegar a uma conclusão precisa, em razão da grande variedade dos sintomas e de sua intensidade. Ao se observar outras patologias, que também apresentam essa característica já estudada pelo Rorschach, levantou-se a idéia e o desejo de se desenvolver este projeto para realizar um estudo sobre a aplicação do Rorschach, a fim de investigar o transtorno de pânico.

Quando se trata de transtorno de pânico, não se pode deixar de citar certa dificuldade diagnóstica e nos relatos de casos (Gentil, 1997a) pode-se verificar que se trata de um quadro em que profissionais tendem a cometer enganos diagnósticos, quer por desconhecimento do conjunto de sintomas, uma vez que o desencadeamento de ataques de pânico envolve mecanismos patológicos complexos, integrando diferentes estruturas biológicas e funcionamentos cognitivos (Ramos, 1995), quer por desconsiderar a gravidade do quadro.

D’Oliveira (1997) apresentou um relato autobiográfico a respeito das dificuldades verificadas em uma longa trajetória até a descoberta do pânico. Citou que sua primeira crise com sinais claros de pânico surgiu, em 1974, aos 25 anos de idade. Recorreu a um clínico geral, teve seu diagnóstico referente a problemas emocionais, sendo encaminhada a uma psicanalista que também não identificou o problema. Relatou seu percurso por vários médicos de diferentes especialidades em um curso de mais de uma década de sofrimento e crises cada vez mais freqüentes, até que, por meio de um artigo de revista, chega a um jovem médico que concluiu o diagnóstico de pânico e, finalmente, foi tratada de maneira adequada. 
A angústia e o estresse desencadeados pela dificuldade em se estabelecer, rapidamente um diagnóstico, agravam o quadro de pânico, fazendo com que este se intensifique e, conseqüentemente, dificulte seu tratamento (Troiano, 2001).

Em termos genéricos, o transtorno de pânico pode ser caracterizado pela incidência recorrente de ataques de pânico, em razão de uma crise aguda de ansiedade, cujo indivíduo vive um mal-estar e sensação iminente de perigo e/ou morte (Gentil, 1997b ; Vieira, 1997).

Assim, nasceu e desenvolveu-se a idéia de utilização do Rorschach em uma pesquisa no pós-graduação, associada ao interesse em perceber se o sistema compreensivo pode possuir índices sensíveis para o diagnóstico de transtornos de pânico.

A relevância deste tema concentra-se na possibilidade de se organizar um conjunto de itens no Rorschach que poderiam identificar o pânico e, assim, seria de extrema valia aos casos de psicodiagnóstico diferencial desta patologia.

O presente trabalho pretende investigar a possibilidade do uso do Método de Rorschach, segundo o Modelo Compreensivo, no psicodiagnóstico diferencial para os distúrbios de pânico. Após a realização da pesquisa, foram descritos os índices quantitativos e os sinais qualitativos no Rorschach que possibilitaram a identificação desse quadro patológico mais detalhadamente. Assim, espera-se ser possível contribuir para um esclarecimento psicodiagnóstico nos casos, cujos sintomas não estejam claros, bem como poder perceber o desenvolvimento do quadro de pânico com antecedência, possibilitando maior rapidez na identificação de seu processo. 


\subsection{Transtorno de Pânico}

\section{Conceituação e Caracterização Fenomenológica}

Em termos fenomenológicos, a descrição das patologias baseia-se em um conjunto detalhado de sintomas e sinais que possam caracterizar, de forma singular, cada uma das doenças catalogadas. Assim, dispõe-se de Manuais de Classificação oficiais que eliminam possíveis dúvidas sobre o diagnóstico descritivo das patologias.

Atualmente, o Transtorno de Pânico, também, faz parte do rol de patologias catalogadas pelos manuais disponíveis.

\section{Os Manuais de Classificação}

A necessidade de uma classificação universal, eliminando as possíveis dúvidas quanto aos quadros clínicos das mais diferentes patologias, há décadas, deu origem aos Manuais de Classificação sob a responsabilidade de grandes agências internacionais de saúde, estes constantemente são revistos, pautados nas novas descobertas empíricas no campo da saúde.

Atualmente, dispõe-se de duas versões oficiais desses Manuais: a décima edição da Classificação Internacional de Doenças - CID-10, publicação sob responsabilidade da Organização Mundial de Saúde e dedicada à descrição nosológica das patologias descritas em todas as áreas (O.M.S., 1992/1993) e a quarta edição do Manual Diagnóstico e Estatístico de Transtornos Mentais - DSM-IV, publicado pela Associação de Psiquiatria Americana, com a apresentação dos sintomas específicos para os quadros de transtornos mentais (A.P.A., 1994/1995).

Os dados do Quadro 1 apresentam as diferenças entre a CID-10 e o DSM-IV, obtidas na comparação proposta por Alarcón (1995). 
Quadro 1. Comparação do estilo de descrição dos quadros clínicos das patologias entre a CID10 e o DSM-IV

\begin{tabular}{|l|l|}
\hline \multicolumn{1}{|c|}{ CID-10 } & \multicolumn{1}{|c|}{ DSM-IV } \\
\hline $\begin{array}{l}\text { Estilo mais narrativo com uma linguagem mais } \\
\text { clínica. }\end{array}$ & $\begin{array}{l}\text { Maior tendência ao detalhamento dos quadros } \\
\text { clínicos, com um caráter mais operacional de } \\
\text { classificação. }\end{array}$ \\
\hline $\begin{array}{l}\text { Descrição mais detalhada das diferenças entre o o } \\
\text { normal e o patológico, expondo mais as } \\
\text { características fronteiriças. }\end{array}$ & $\begin{array}{l}\text { Diferenças mais marcantes no que tange ao } \\
\text { normal e ao patológico. }\end{array}$ \\
\hline Classificação mais flexível e tolerante. & Classificação mais rígida. \\
\hline Uso de algumas terminologias obsoletas & Mais cauteloso na inclusão de novas categorias. \\
\hline
\end{tabular}

Fonte: Alarcón (1995).

É importante pontuar que o DSM-IV fundamenta-se em bases conceituais e instrumentais sob o enfoque de três aspectos: é centralizado em interesses clínicos que permitem a constante investigação por meio de pesquisas, apresenta uniformização de conceitos independente da orientação teórica do profissional e faz uso de códigos precisos e de fácil catalogação. O DSM-IV propõe o agrupamento das patologias por similaridade fenomenológica e organizou os transtornos de pânico como um tipo de transtorno de ansiedade de difícil diagnóstico diferencial por poder estar associado a outros quadros de ansiedade ou fazer parte dos mesmos (Alarcón, 1995).

\section{Classificação Nosológica do Pânico}

Segundo o DSM-IV (A.P.A., 1994/1995), o Transtorno de Pânico é codificado, associando-se o quadro à agorafobia, tendo o código 300.01 para Transtorno de Pânico sem Agorafobia e 300.21 para Transtorno de Pânico com Agorafobia.

A característica essencial do Transtorno de Pânico é a presença de ataques de pânico recorrentes e inesperados, seguidos por pelo menos de um mês de preocupação persistente acerca de ter outro ataque de pânico, preocupação acerca das possíveis implicações ou conseqüências dos ataques de pânico, ou uma alteração comportamental significativa, relacionadas aos ataques. Os ataques de pânico não se devem aos efeitos fisiológicos diretos de uma substância ou de uma condição médica geral (A.P.A., 1994/1995, p. 379). 
Na definição anterior, os sintomas dos Ataques de Pânico são descritos em detalhes pelo DSM-IV. Esta descrição justifica-se uma vez que ataques de pânico surgem em diferentes descrições de quadros clínicos, sobretudo aqueles relacionados a transtornos de ansiedade (A.P.A., 1994/1995). Os critérios estabelecidos para o diagnóstico de um ataque de pânico são os seguintes:

Um período distinto de intenso temor ou desconforto, no qual quatro (ou mais) dos seguintes sintomas desenvolveram-se abruptamente e alcançaram um pico em 10 minutos:

(1) palpitações ou ritmo cardíaco acelerado

(2) sudorese

(3) tremores ou abalos

(4) sensações de falta de ar ou sufocamento

(5) sensações de asfixia

(6) dor ou desconforto torácico

(7) náusea ou desconforto abdominal

(8) sensação de tontura, instabilidade, vertigem ou desmaio

(9) desrealização (sensação de irrealidade) ou despersonalização (estar distanciado de si mesmo)

(10)medo de perder o controle ou enlouquecer

(11) medo de morrer

(12)parestesias (anestesias ou sensações de formigamento)

(13) calafrios ou ondas de calor (A.P.A., 1994/1995, p. 377).

Na CID-10 (O.M.S., 1992/1993), o transtorno de pânico, também denominado ansiedade paroxística episódica, está classificado pelo código F41.0, subcategoria do código F41 - Outros transtornos de ansiedade.

Os aspectos essenciais são ataques recorrentes de ansiedade grave (pânico), os quais não estão restritos a qualquer situação ou conjunto de circunstâncias em particular e que são, portanto, imprevisíveis. Assim como em outros transtornos de ansiedade, os sintomas dominantes variam de pessoa para pessoa, porém início súbito de palpitações, dor no peito, sensações de choque, tontura, e sentimentos de irrealidade (despersonalização ou desrealização) são comuns. Quase invariavelmente há também um medo secundário de morrer, perder o controle ou ficar louco. Os ataques individuais usualmente duram apenas minutos, ainda que às vezes sejam mais prolongados; sua freqüência e o curso do transtorno são, ambos, muito variáveis. Um indivíduo em um ataque de pânico freqüentemente experimenta um crescendo de medo e sintomas autonômicos, o qual resulta em uma saída, usualmente apressada, de onde quer que ele esteja .... De modo similar, ataques de pânico constantes e imprevisíveis produzem medo de ficar sozinho ou ir a lugares públicos. Um ataque de pânico com freqüência é seguido por um medo persistente de ter outro ataque (O.M.S., 1992/1993, p. 137). 
Segundo a CID-10 (O.M.S., 1992/1993), esclarece-se que o transtorno de pânico deve ser o diagnóstico principal somente na ausência de quaisquer outras fobias. Vários ataques graves de ansiedade devem ocorrer em um período de um mês, sem a evidência de perigo objetivo, sem estarem confinados a situações previsíveis e relativamente livres de sintomas ansiosos.

Para Arbona e Arnal (1995), o transtorno de pânico constitui-se, a partir da década de 1980, como uma importante patologia para investigações por se tratar de um grande problema de saúde pública nas sociedades industrializadas. Os autores esclarecem que em razão de sua grande incidência, várias pesquisas preocuparam-se em refletir sobre a etiologia e o tratamento mais adequado nestes quadros, questionando modelos teóricos provenientes tanto da Psiquiatria como da Psicologia como dos estudos sobre ansiedade e seus distúrbios.

Em uma revista de divulgação, observou-se que, na década de 1990, foram realizados estudos que demonstraram que os transtornos de pânico e a incidência de fobias podem atingir 25\% da população dos Estados Unidos da América. Na época, o Brasil, não dispunha de um estudo epidemiológico em escala nacional, porém os indicadores demonstram que a incidência desse tipo de patologia atingia 18\% da população de Brasília, 11\% em São Paulo e 9\% em Porto Alegre, e a incidência era duas vezes maior em mulheres (Poles, 2001). Outro estudo epidemiológico indicou maior incidência de transtornos de ansiedade, inclusive do pânico, em mulheres (Andrade, Viana \& Silveira, 2006).

\section{Ansiedade, Medo e Pânico}

O nascimento marca o início das vivências de ansiedade, caracterizadas, nesse momento inicial de vida, por fome, sede e desconfortos. Essas ansiedades primitivas poderão preparar o indivíduo para a organização adequada da ansiedade comum que a vida 
proporcionará futuramente. Assim, a ansiedade, como patologia, não é uma questão de qualidade, mas sim de quantidade (Grünspun, 1990).

A ansiedade é considerada como uma emoção normal e universal do ser humano, que surge quando o indivíduo antecipa uma situação nova, desconhecida e desafiante ou quando há uma vivência de ameaça ou de perigo. Neste sentido, pode ser considerada como uma emoção benéfica, responsável pela preservação da integridade do ser, preparando-o para o enfrentamento da situação de perigo. Mas como qualquer aspecto emocional, pode apresentar variações patológicas (Gentil Filho, Lotufo Neto \& Maciel, 1995).

Segundo Piotrowski (1974), a ansiedade é um sentimento negativo sem relação direta com a realidade externa, é sempre uma desvantagem para o indivíduo, pois psicologicamente o mutila, fazendo-o sentir um sentimento de extremo desconforto, sem qualquer explicação real ou lógica. É um sentimento amorfo e sem direção objetal. A razão da ansiedade escapa à avaliação, observação e compreensão de outros sujeitos, que não conseguem compreender os motivos pelos quais acontece uma situação ansiosa e acham difícil estimar a intensidade da ansiedade alheia.

Na compreensão dos conceitos de medo e ansiedade, Piotrowski (1974) relata que o medo e a ansiedade são emoções negativas no sentido em que ambas são desejos de dissociação de si, para evitar ou terminar com uma dor imaginária ou real. Percebe o medo como uma inquietação e um desejo de esquivar-se de uma dor mental e/ou física clara e bem definida, resultado de uma vivência particular da realidade objetiva.

Conforme o autor, esses medos podem ser racionais e bem fundamentados e, também, podem ser irracionais ou ilusórios, baseados em uma má avaliação da realidade, porém, de qualquer forma, a realidade é sempre o ponto de referência para a sensação de medo. Por outro lado, o foco da ansiedade é a mente do indivíduo, a ansiedade não tem referência à realidade externa e objetiva, é pura subjetividade. É uma emoção vaga e sem objeto, possui 
um conteúdo ilógico, sem considerar a realidade externa. Sujeitos ansiosos não podem dirigir seu sentimento a nenhum objeto (quer em si mesmo ou em outra pessoa) por causa de sua angústia, que é notadamente interna, e existe independente das relações estabelecidas com os objetos internos ou externos.

O medo é outro aspecto importante. Caso o indivíduo possua uma estrutura psicológica organizada e equilibrada, pode ser controlado e direcionado de forma positiva. Nessa situação, é essencial para a sobrevivência e, particularmente, útil para uma vida produtiva, intensa e completa (Piotrowski, 1974).

Nesse mesmo sentido, Paul (1998) explica que existem dois quadros relacionados diretamente às vivências de ansiedade: o medo e o pânico. A diferença geral encontra-se na intensidade da experiência do sentimento, mas as diferenças são mais marcantes e claras em termos descritivos. Há necessidade de distinção entre medo e pânico para melhor caracterização do quadro e definição do termo.

Segundo o autor, aparentemente, trata-se de uma questão de intensidade, porém o pânico possui sintomas e desdobramentos muito mais significativos do que a vivência de um medo em maiores proporções, pois é um sentimento que surge diante de um determinado objeto, sendo assim estados de medo têm uma relação direta com algum objeto identificado de modo claro pelo indivíduo, com contorno e identidade. Por outro lado, o pânico, além de mais intenso, não se relaciona diretamente a um objeto específico, é a vivência aguda de ansiedade, sem a clareza de objeto observada em estados de medo.

A ansiedade é considerada patológica quando é muito intensa, desproporcional ao estímulo desencadeador ou quando surge sem que haja um motivo aparente para sua vivência. Quando isso ocorre, é sempre acompanhada por sintomas físicos, sobretudo os desencadeados pelo sistema nervoso autônomo, comprometendo o bem-estar do indivíduo (Gentil Filho, Lotufo Neto \& Maciel, 1995). Dependendo de seus desdobramentos e 
intensidade, um distúrbio de ansiedade pode causar desde um desconforto social (Scrof, Schultz, Koerner \& Svetcov, 1999) até o desenvolvimento de fobias gerais ou específicas (Tice, 1990).

Na maior parte dos casos de transtornos de ansiedade, pode haver também um comprometimento cognitivo, afetando funções psíquicas de forma mais intensa: a linguagem pode ser alterada por taquilalia ou gagueira; a memória pode ser afetada, diminuindo-se a capacidade de retenção de informações a curto ou a médio prazos e a concentração dos pacientes pode ser diminuída. Nesses casos, estas alterações levam o paciente a ter dificuldades que podem afetar sua rotina pessoal e profissional (Hindmarch, 1998; Taylor \& Woody, 1997).

\section{Descrição Fenomenológica do Transtorno de Pânico}

Conforme expõem Arbona e Arnal (1995), o termo 'pânico' foi introduzido, pela primeira vez, em 1962 por Klein e Fink ${ }^{1}$, quando os autores substituíram a terminologia ataques de ansiedade por ataques de pânico, reforçando as diferenças entre as crises de ansiedade e a vivência de ansiedade do tipo antecipatória no que se refere à sua etiopatogenia.

Os autores citados explicam que as crises de ansiedade são vivências extremas de ansiedade, sem motivo aparente e, quanto paralisadoras e recorrentes, podem caracterizar o pânico. Em decorrência disso, a ansiedade antecipatória pode surgir diante do temor de novos ataques de pânico. Embora com uma raiz ansiógena comum, as ocorrências são distintas quanto à origem e intensidade e ao momento de sua ocorrência. Com isso, marcaram o início de um movimento de investigações e de descrição de um conjunto de patologias que se associam diretamente aos quadros de ansiedade, sobretudo o Transtorno de Pânico.

\footnotetext{
${ }^{1}$ Referência original: Klein, D.F.; Flink, M. (1962). Psychiatric reaction patterns to imipramine. American Journal of Psychiatry, 2, 14-17.
} 
Como entidade nosológica, o transtorno de pânico atravessou um desenvolvimento como pode ser observado pelo aprimoramento das descrições das patologias nas diferentes versões do DSM.

Durante muitos anos, os ataques de pânico foram classificados baseados na nomenclatura freudiana de neurose de ansiedade. Esta configuração foi mantida até a edição do DSM-II de 1968. Apenas no DSM-III, datado de 1980, o termo pânico surge como descritor nosológico, mas só associado à agorafobia, sendo esta o quadro principal. Em 1987, na edição do DSM-III-R, surge a denominação de transtorno de pânico sem agorafobia, colocando, agora, o pânico como quadro principal. Foi apenas no DSM-IV, publicado em 1994, que o transtorno de pânico foi classificado como quadro principal e isolado de outros sintomas associados a quadros de ansiedade (Arbona \& Arnal, 1995).

Nas versões do DSM, houve o desenvolvimento da definição do Transtorno de Pânico, com base nos desdobramentos de investigações, em que existe um aprofundamento da precisão do quadro pautado em um detalhamento dos sintomas. Ainda nas descrições teóricas, não há uma diferenciação entre crise e ataque de pânico, podendo-se supor que esses dois termos são empregados como sinônimos no que tange ao quadro de pânico. Sendo assim, será respeitada a nomenclatura empregada por autor ou manual nas exposições que seguem.

Para Gentil (1996), um ataque de pânico que, geralmente, é inesperado e intenso, pode ser uma experiência avassaladora. Os sintomas vivenciados pelo paciente e as sensações de fadiga e desconforto sentidas após a crise são extremamente desagradáveis e levam a uma inquietação e temor de outra ocorrência.

Na descrição bibliográfica pesquisada, há uma grande convergência na caracterização da crise de pânico pelos diferentes autores, cujo termo é entendido como um período de intenso medo, apreensão e perigo, freqüentemente, acompanhado de sensação iminente de perigo ou morte. Após a crise, o paciente experimenta um grande desejo de sair do ambiente 
onde a mesma ocorreu (Arbona \& Arnal, 1995; Gentil, 1996 e 1997b; Kaplan \& Sadock, 1991/1993; López, 1995).

Para alguns autores, como Gentil (1997b) e López, (1995), o tempo médio de duração das crises, situa-se em torno de dez minutos e, em geral, dissipa-se em 20 a 40 minutos (Gentil, 1996). Por outro lado, López (1995) descreve casos de episódios de pânico entre 5 minutos e 60 minutos, estabelecendo uma duração média de 45 minutos. Observa-se que não existe uma precisão quanto ao tempo de duração de cada crise de pânico, que depende de diferentes fatores psicológicos.

A dificuldade de uma definição precisa do tempo de duração da crise é decorrente de sua fonte, ou seja, como o tempo de duração é obtido baseado nos relatos dos pacientes e estes ignoram que a crise vai ocorrer. O tempo relatado pode estar sujeito às sensações do paciente e não obedecer a um registro rigoroso de controle.

Segundo López (1995), o critério estabelecido pelo DSM-IV de quatro sintomas ou mais é arbitrário e um ataque de pânico pode ser observado com três sintomas ou mais e, na exposição do manual, não fica claro a intensidade desses mesmos sintomas. No entanto, a vivência extrema da ansiedade caracteriza o pânico, embora, segundo o próprio autor, é muito difícil encontrar uma definição precisa e objetiva do que seja ansiedade extrema.

De qualquer forma, apesar disso, “os ataques de pânico são experiências ambíguas, abertas a interpretações múltiplas e mutáveis” (López, 1995, p.30), em cuja periodicidade pode demonstrar tanto a gravidade do caso como a intensidade do distúrbio (López, 2000).

Em termos orgânicos, o pânico pode ser associado a um grande número de aspectos de ordem biológica como neuroanatômicos, neurofisiológicos, endócrinos, entre outros. (Gentil, 1986; Gentil \& Roso, 1987; Kaplan \& Sadock, 1991/1993; Ramos, 1995; Ventura, 1991). Nesse sentido, as estratégias adotadas para um tratamento farmacológico sempre são discutidas, no sentido de uma busca para uma melhor terapêutica aos pacientes (Andreatini \& 
Galduróz, 1995; Bradwejn, Koszycki \& Zacharlo, 1996; Caetano, 1997; Deakin \& Graeff, 1991; Dias, Del Porto \& Miranda, 1990; Gentil, 1996; Ramos, 1995).

Embora os aspectos orgânicos e farmacológicos relacionados aos transtornos de pânico sejam extremamente importantes em diferentes contextos, sobretudo, nos de pesquisa e clínicos, não serão aprofundados neste texto, em razão do aspecto estabelecido pela proposta da pesquisa que enfoca os recursos psicodiagnósticos de investigação do pânico, em especial, com o uso do Método de Rorschach.

\section{Conceituação e Caracterização Psicanalítica}

Nos últimos anos podem ser observados avanços significativos na compreensão psicanalítica sobre o Transtorno de Pânico, fazendo com que fosse reconhecida como uma importante abordagem teórica para o tratamento desse quadro (Minerbo, 2003),.

Em termos psicanalíticos, o transtorno do pânico é considerado um distúrbio de ansiedade, visto ser um dos afetos mais importantes no desenvolvimento dos conceitos da psicanálise e da teoria psicodinâmica. Embora o pânico apresente sintomas nitidamente físicos, e a maior parte do tratamento envolva psicoterapia e farmacoterapia, a melhora dos pacientes sofre grande interferência de fatores transferenciais. Nestes casos, observa-se uma significativa melhora quando o placebo é administrado, evidenciando que o processo psicoterápico exerce grande importância na melhora do quadro (Gabbard, 1994/1998). Nesse sentido, aspectos psicodinâmicos têm grande relevância no contexto do desenvolvimento dos quadros de pânico.

Gabbard (1994/1998) explica que os pacientes com Transtorno de Pânico apresentam históricos psicodinâmicos de dificuldade para lidar com perdas, sobretudo de figuras representativas de sua infância e, por isso, desenvolvem uma atitude transferencial do tipo paternal com o terapeuta. 
De certa forma, essa perda é significativa e revivenciada por um fator estressante cotidiano, o que, segundo uma visão psicodinâmica, levaria ao surgimento da primeira crise de pânico. Indivíduos sem dificuldade em lidar com perdas, conforme foi descrita, podem atravessar situações igualmente estressantes, vivenciando-as com uma intensidade de ansiedade normal, sem o desenvolvimento de nenhum quadro psicopatológico (Gabbard, 1994/1998).

\section{Compreensão Psicanalítica do Fenômeno do Pânico}

Além da descrição nosológica do pânico, apresentada anteriormente, a psicanálise dedica-se, desde os primórdios freudianos sobre a neurose de angústia, a compreender os elementos inconscientes e dinâmicos que desencadeiam tal quadro.

A seguir, pretende-se realizar uma breve exposição sobre a compreensão dos motivos pelos quais os indivíduos desencadeiam um quadro de pânico, sob as diferentes abordagens psicanalíticas.

Trinca (1997) tece uma relação entre fobia e pânico, considerando o pânico a conseqüência de um estado fóbico, no qual o paciente não teve as condições psíquicas necessárias para sua organização. Para essa relação, utiliza interessantes associações do quadro com o conceito metafórico de buraco negro, no qual, durante o processo de desenvolvimento emocional, o psiquismo organiza-se pautado em uma vivência de solidão e desamparo que culmina com temores e pânico.

O pânico aparece comumente quando o rompimento da relação 'eu-comigo’ alcança consideráveis proporções. É um ponto culminante de perda de relações significativas estruturantes, quando os vínculos com o centro de sustentação interna se acham muito enfraquecidos, desvitalizados ou suprimidos. Corresponde a momentos de incomunicabilidade da pessoa com ela mesma, sentidos como avassaladores e indefensáveis. São também momentos máximos da angústia de dissipação do self (Trinca, 1997, p.34). 
As propostas de compreensão e de leitura psicanalítica são apontadas como uma importante estratégia diagnóstica e de atendimento para pacientes com síndrome do pânico. Schwartzman (1997) aborda o tema da prática psicanalítica para o tratamento de pânico, associando-o à neurose de angústia, estabelecendo uma grande importância no sentido diagnóstico e terapêutico para a vivência da primeira crise, associando o quadro às relações estabelecidas com as figuras parentais. Traça uma relação entre pânico e distúrbios psicossomáticos, por causa dos sintomas do pânico manifestarem-se no âmbito corporal e justifica a psicanálise, como importante recurso teórico por trabalhar diretamente no trânsito psiquismo-corpo.

Conforme relata Schwartzman (1997), os detalhes vividos na primeira crise ficam gravados na memória do paciente e são um marco do funcionamento dos indivíduos com o pânico, levando-os, inclusive, a desenvolver uma fobia secundária originada do temor de uma nova crise.

A autora explica que a crise "surge num momento de ruptura de um certo tipo de rede protetora de ligações afetivas narcísicas” (p.92) quando o indivíduo sente que está absolutamente desprotegido e só ou quando um determinado objeto catexizado positivamente não está presente. Muitos pacientes só se sentem protegidos na companhia de uma determinada pessoa que lhe é importante afetivamente.

Esse aspecto associa-se ao que a autora denominou de “fantasia de anonimato” (p.92) que é o temor de não ser socorrido por ninguém, caso tenha uma crise sozinho na rua ou em algum lugar desconhecido. A situação é observada com grande freqüência após a primeira crise em pacientes com pânico, embora não seja exclusiva desse quadro.

Pela importância e profundidade do conceito de fantasia de anonimato, optou-se por uma transcrição literal da autora: 
Trata-se do medo, mesclado com uma convicção antecipatória de que, se passarem mal na rua, não serão socorridos por ninguém. Mesmo quando a experiência vivida mostra concretamente o contrário, a fantasia continua a atormentá-los, revelando um sentimento de que o mundo é desabitado de pessoas confiáveis, a quem se possa recorrer em hora de necessidade. Essa fantasia encaixa-se perfeitamente no todo do sofrimento do pânico, onde domina uma confusão entre estar perdido em um meio onde ninguém me conhece e sentir-se solto, em um lugar onde ninguém me reconhece. No desamparo da crise, a angústia é a de não ser reconhecido como objeto privilegiado de amor. Daí a urgência de voltar para casa, para junto das pessoas mais próximas” (Schwartzman, 1997, p.92).

Pereira (1997) realiza uma leitura lacaniana do quadro de pânico, associando-o a um desamparo inicial, ou seja, um abalo que ameaça a garantia do reconhecimento simbólico primordial do eu, gerando uma sensação de risco incomensurável de desabamento e traça um paralelo desta leitura com a linguagem, como forma de trabalho psicanalítico com o paciente.

Pânico e cura psicanalítica constituem duas possibilidades subjetivas distintas do sujeito colocar-se frente ao desamparo fundamental dos limites do campo simbólico que ameaçam os alicerces de uma imagem de si estável e imutável. O pânico instala-se quando se revela subitamente ao sujeito aquilo que para este é insuportável: a constatação de que o desamparo é o destino último - e o ponto de partida - de tudo o que se sustenta da linguagem (Pereira, 1997, p.36).

Sob outro ponto de vista teórico, Cartocci (1998) compreende o fenômeno do pânico apoiado na teoria winnicottiana, considerando o quadro como resultado de falhas na relação mãe-bebê, gerando uma grande sensação de desamparo, morte e vazio. Descreve os fenômenos de pânico, pane, queda como uma "falência de uma construção simbólica que, ao menos aparentemente sustenta o sujeito” (p.17). Como se fosse uma ruptura da sustentação individual pautada na vivência ou na sensação de algum conteúdo primitivo que, por um momento ou desencadeado por uma situação ambiental, eclode, ameaçando a existência do sujeito, proporcionando a experiência de uma quebra intensa de sua normalidade, ou seja, “uma explosão direta da angústia” (p.17).

A caracterização psicanalítica do pânico possibilita uma compreensão dos mecanismos psíquicos que envolvem os indivíduos durante a crise e no decorrer de um 
tratamento psicológico. Entretanto, uma consideração muito importante sobre os episódios de pânico, descrita por Schwartzman (1997), deve ser considerada para melhor compreensão do fenômeno. A autora cita que o paciente com pânico sofre de uma neurose normal cujo aparelho psíquico, por ser uma construção ou um processo, apresenta falhas.

A instalação de uma situação de urgência tal como a que se cria na Síndrome do Pânico não deve ser então reduzida a seu aspecto negativo, ao sofrimento que ela produz. Ela constitui-se também numa exigência e numa oportunidade de melhoria dos recursos psíquicos, desde que não seja completamente abafada pelo silenciamento medicamentoso com que a Psiquiatria pretende curá-la (Schwartzman, 1997, p.96).

No estudo do transtorno de pânico, um dos aspectos que merecem atenção é o momento de crise, por se tratar de uma vivência intensa de seus sintomas. Em seus diferentes enfoques, a psicanálise compreende esse momento da seguinte forma:

Segundo Trinca (1997), o ataque de pânico é desencadeado por uma fragilidade que origina um processo mórbido orientado por padrões típicos de temor e ansiedade sentidos pelos pacientes. No início da vida mental dos indivíduos, ocorrem situações que causam a vivência de intensa angústia, tais como: violência, pressão e caos emocional.

Como o bebê não possui estrutura suficiente para elaborar tais sentimentos, utiliza a figura materna, pela identificação projetiva, como instrumento de elaboração dessas vivências, ajudando-o a movimentar seus impulsos vitais e, assim, lidar adequadamente com esses sentimentos sombrios. Caso a mãe não consiga fornecer um suporte emocional eficaz nesse período, não proporcionará holding ao longo do tempo e a criança irá se fragilizar precocemente, fazendo com que respostas internas favoráveis não se desenvolvam (Trinca, 1997).

Essa falha na articulação das respostas internas faz com que esse indivíduo não consiga ter um referencial interno bom e consistente que poderá conter seus medos e dificuldades. Como não elabora internamente esses medos, um sentimento permanente de 
ameaça à vida é constituído, fazendo com que se sinta mais vulnerável às ameaças rotineiras e, por causa de uma falha de configuração de um continente primário elaborado, poderá criar sintomas de pânico diante de uma situação estressante que outro sujeito com um referencial interno mais adaptado elaboraria com mais facilidade (Trinca, 1997).

Nesse sentido, Cartocci (1998) baseia-se no referencial winnicottiano para descrever o processo de pânico, relacionando-o a uma espécie de colapso formado em áreas que não puderam ser exploradas em relação ao mundo e ao outro. "Falhas no processo de constituição e integração do ego estão intimamente relacionadas ao que a mãe pôde ou não proporcionar, desde os cuidados corporais mais básicos, até a capacidade de sonhar” (p. 18-19).

Estas idéias podem ser associadas ao conceito lacaniano de desamparo, pelo qual o bebê vivencia um estágio de insuficiência psicomotora primitiva, levando-o a uma extrema dependência da figura materna, que é a primeira representação do outro para o bebê, mostrando o mundo externo para o pequeno ser humano nesse momento. Ela serve como um espelho, para que o sujeito possa de modo gradativo reconhecer simbolicamente a si como unidade independente de sua mãe (Pereira, 1997).

Para o autor citado (p.32), "qualquer abalo atingindo a garantia de reconhecimento simbólico primordial questiona radicalmente a própria estabilidade da imagem do eu. Aqui intervém um risco terrificante de desabamento”.

Mais tarde, a vivência de tal desabamento poderá, como conseqüência das vivências fálicas, gerar uma sensação do ‘nada’ nas estruturas psíquicas de alguns indivíduos. Segundo Dunker (1997), amparado pelos conceitos lacanianos do nada e da economia neurótica do gozo, o pânico pode ser desenvolvido por pessoas que, de certa forma, vivenciaram uma descontinuidade entre desejo e gozo, criando um lapso abrupto gerado pela identificação ao nada lacaniano como objeto. 
Assim, o quadro da síndrome do pânico é composto por aspectos psicológicos e somáticos.

Os aspectos psicológicos caracterizam a etiologia da síndrome, identificam sua origem e direcionam sua terapêutica. Segundo um ponto de vista psicanalítico, os componentes psíquicos formam as bases do desenvolvimento do pânico. A psicopatologia do desenvolvimento das relações primárias desses indivíduos criou uma predisposição ao surgimento da síndrome.

Os aspectos somáticos identificam a sintomatologia do quadro, visto que os sintomas mais nítidos e identificáveis são os de origem fisiológica. Assim, o estudo dos fatores psicológicos da síndrome do pânico mostra-se muito importante para uma compreensão diagnóstica mais precisa.

No geral, em termos psicanalíticos, observou-se que o pânico é um quadro decorrente de uma falha no desenvolvimento da relação mais primitiva com a figura materna, que promove uma fantasia inconsciente de autodestruição, na qual a sensação de desintegração pode ser desencadeada pelo contato com a fragilidade da relação anteriormente salientada. O medo da morte, que é gerado pela sensação de finitude, está relacionado a uma vivência de abandono e isolamento, oriundo das primeiras relações com a figura materna. 


\subsection{Utilização de Técnicas Projetivas e do Método de Rorschach no Diagnóstico Psicológico}

Cada vez mais observa-se o emprego de técnicas projetivas na investigação psicodiagnóstica de diferentes quadros. Pautado em pesquisas ou levantamentos clínicos, nota-se a grande contribuição que os métodos projetivos de investigação psicodiagnóstica possibilitam para a compreensão dos aspectos psicodinâmicos dos pacientes, assim, proporcionam um excelente material a ser usado na análise desses casos.

\section{Caracterização das Técnicas Projetivas}

As técnicas projetivas ocupam um lugar de destaque no processo psicodiagnóstico, pois constituem um material ambíguo apresentado ao paciente, possibilitando liberdade para que responda ao instrumento oferecido e um bom material para análise e interpretação (Cunha, Minella, Werlang \& Carneiro, 1993).

A ambigüidade que o material das técnicas projetivas apresenta pode proporcionar uma infinidade de material psicológico a ser interpretado, uma vez que a produção psíquica do paciente depende muito mais de seus conteúdos internos do que da estimulação que o material oferece (Cunha et al., 1993). Entende-se aqui como material do paciente as respostas que o mesmo pode emitir diante de borrões de tinta, histórias ou narrativas que expõe a partir de quadros ou figuras, desenhos que o indivíduo produz livremente ou baseado em algum tema proposto, entre outros.

Dessa forma, nas técnicas projetivas, o material para que os conteúdos sejam expressos serve como 'ponte'. Segundo Anderson e Anderson (1951/1978), os testes projetivos não fornecem apenas aspectos de projeção, mas, praticamente todos os 
mecanismos mentais, tanto os expressivos como os de defesa, proporcionando excelente material de análise sobre o paciente.

Em 1939, Franck ${ }^{2}$ introduziu o termo método projetivo que logo se mostrou com ampla difusão e emprego, pois designa um conjunto de procedimentos técnicos, visando ao estudo da personalidade dos indivíduos por meio de estímulos pouco estruturados, nos quais a pessoa pode expressar livremente um sentido particular. Assim, suas respostas serão sempre projetivas e passíveis de uma interpretação de seus processos internos (Van Kolck, 1981).

Por suas propriedades, Anzieu (1961/1984) refere que é difícil uma caracterização específica do Teste de Rorschach. Assim, podem ser tecidas algumas considerações sobre as capacidades do sujeito que estão atuantes durante a execução da prova. Quando se submete ao instrumento, a pessoa relaxa o controle consciente de seus conteúdos, podendo expô-los por meio de suas respostas, baseadas em uma conduta oscilante entre concentração e descontração. Dessa forma, permite a avaliação de suas características mais intrínsecas, bem como o conjunto de defesas que utiliza para poder lidar com elas.

Em razão de suas características, as técnicas projetivas podem ser empregadas em atendimentos com um direcionamento psicodinâmico e visam a "um entendimento dinâmico da personalidade dos pacientes, como conflitos, mecanismos de defesa do ego, estados emocionais, fantasias, traços de caráter e aspectos sadios e patológicos dos sujeitos” (Cunha et al., 1993, p.123).

As propriedades das técnicas projetivas são caracterizadas por vários aspectos comuns a elas: estímulos pouco ou nada estruturados, respostas bastante ou totalmente livres, abordagem indireta de aplicação, origem teórica fundamentada na psicanálise e na psicometria. A avaliação e a interpretação são pautadas em pressupostos psicanalíticos e/ou psicométricos e têm como objetivo a exploração da personalidade em plano mais profundo e

\footnotetext{
${ }^{2}$ Referência original: Franck, L.K. (1939). Projective Methods for the study of personality. Journal of Psychology, 8, 389-413.
} 
abrangente do que as técnicas objetivas e a exploração de dados globais e integrados da personalidade; além disso há uma predominância da aplicação individual que possibilita uma situação trasferencial positiva para melhor compreender os elementos psicológicos dos pacientes (Bell, 1948/1992; Van Kolck, 1981).

Cabe ressaltar que o espaço ocupado pelas técnicas projetivas na psicologia atual é proveniente de constantes estudos que apresentam evidências empíricas e psicométricas de sua capacidade de analisar os elementos psicológicos dos indivíduos. Não se trata de simples aplicação ou transposição da teoria psicanalítica, mas sim fruto da articulação dos pressupostos psicanalíticos com experimentos metodologicamente rigorosos e com comprovações práticas e métricas.

Qualquer técnica de investigação psicológica, projetiva ou não, só terá real validade, quando for planejada com precisão e critérios técnicos e teóricos bem definidos. Dessa forma, o processo psicodiagnóstico ou a pesquisa poderão ter maior definição dos conteúdos psicodinâmicos e psicométricos do quadro (Adrados, 1982).

Após a interpretação de todos os dados e da integração com o conteúdo obtido, podese concluir, de forma consistente e segura, a respeito da personalidade dos indivíduos.

É importante destacar ainda que o emprego de uma técnica projetiva pressupõe um amplo conhecimento do instrumento, apoiado em uma prática constante e atualização permanente quanto às mesmas.

Os princípios de interpretação dos testes projetivos não deixam de ser, portanto, indicadores de sistematização e organização de dados, mantendo uma correspondência analógica com a integração que se realiza no processo psicodiagnóstico visto de sua forma extensa (Becker \& Trinca, 1984, p.83).

É interessante ressaltar a comparação realizada por Niva (1995), quando afirma sobre a aplicação de um instrumento de avaliação psicológica que pode ser análoga ao próprio processo de psicoterapia. Assim, ao se aplicar um instrumento, sobretudo um instrumento 
projetivo, é importante o aplicador atentar aos aspectos comuns entre a vivência da aplicação e a vivência de um processo de psicoterapia breve.

Na maior parte das vezes, surge em mesma escala a exposição de conteúdos transferenciais e contratransferenciais na realização da tarefa proposta, no caso do Rorschach a emissão das respostas. Assim, ao se analisar o conjunto de informações obtidas em uma aplicação de um teste projetivo, é importante que o aplicador atente para estas vivências e as considere no momento de organização dos dados e da devolução de informações. O autor salienta que a experiência de se submeter à avaliação psicológica com um instrumento projetivo pode trazer benefícios por meio da elaboração dos conteúdos, que são eliciados pelas técnicas (Niva, 1995).

Pode-se dizer que os testes projetivos mostram-se como estratégias importantes para a coleta de dados psicodiagnósticos. Servem como meio de comunicação entre os aspectos psicológicos do paciente e o psicólogo com a vantagem de levar à manifestação de conteúdos sem o controle consciente do paciente que desconhece os aspectos técnicos do instrumento, possibilitando uma análise global das características inconscientes e suas conseqüências, como um interlocutor entre o mundo psíquico do paciente e o psicólogo (Grassano, 1977/1996).

\section{O Rorschach como Técnica Projetiva}

O Rorschach é um instrumento psicodiagnóstico de reconhecida validade e profundidade de investigação. Seu material de interpretação possibilita uma análise da personalidade dos indivíduos em termos estruturais e psicodinâmicos, garantindo uma contextualização ímpar do quadro que está sendo investigado.

Por intermédio dos itens de codificação, que permitem um trabalho quantitativo, é possível uma averiguação empírica e estatística de qualquer aspecto da personalidade das 
pessoas, sob o enfoque estrutural. Com base na análise das verbalizações, os aspectos qualitativos da personalidade dos sujeitos podem ser analisados, compreendendo seu funcionamento e relação consigo e com o mundo.

\section{Breve Histórico}

Em diferentes culturas e épocas, o uso da imaginação em brincadeiras populares para interpretar nuvens ou manchas de tinta foi sempre comum. O primeiro registro do emprego de borrões com significado clínico é de 1857, no qual o médico alemão Kerner usava borrões de tinta para caracterizar aspectos de personalidade das pessoas que os faziam. Embora importante em termos históricos, seu trabalho mostrou-se limitado, pois não estudou as diferenças individuais dos sujeitos. Em 1895, Binet e Henri desenvolveram uma aplicação de forma mais metodológica no campo da Psicologia Experimental, associando processos de imaginação e fantasias dos indivíduos, mediante a confecção de borrões de tinta. Depois deles, outros autores também desenvolveram estudos com manchas de tinta em várias localidades (Sousa, 1982; Vaz, 1997).

Hermann Rorschach foi o responsável por uma sistematização brilhante a respeito do trabalho com manchas de tinta, focalizando tanto aspectos formais como outros que envolviam as manchas. Iniciou os estudos com os borrões em 1910. Em 1918, o próprio Rorschach confeccionou e elaborou as pranchas do teste e passou a aplicá-las experimentalmente no Hospital de Herisau (Vaz,1987).

A confecção de tais formas fortuitas é muito simples: fazem-se alguns borrões grandes sobre uma folha de papel. Este papel será dobrado uma vez e os borrões deverão ser espalhados entre as folhas do mesmo. No entanto, nem toda figura assim obtida se prestará ao uso; sua utilização está sujeita a algumas condições. Em primeiro lugar, as formas deverão ser relativamente simples; as figuras complexas dificultam demais o cômputo dos fatores do teste. Além, disto, é preciso que o enquadramento dos borrões no espaço da prancha obedeça a certas condições de ritmo espacial; se isso não se der, a prancha carecerá de força plástica e, consequentemente, muitos indivíduos rejeitarão as figuras como 'simples borrões' e não se deixarão convencer a interpretá-las (Rorschach, 1921/1978, p.15) 
A primeira edição completa do trabalho de Rorschach data de 1921 no livro Psychodiagnostik, sendo denominado pelo autor como métodos e resultados de uma experiência diagnóstica de percepção por meio da interpretação de formas fortuitas, o livro ainda é considerado um clássico do gênero (Cabral \& Nick, 1997).

Desde 1921 quando foi publicado o Psicodiagnóstico (Rorschach, 1921/1978), que mais tarde recebeu o nome de seu idealizador, inúmeros trabalhos foram desenvolvidos e vários autores destacaram-se num movimento constante de pesquisas e aprimoramento com o instrumento.

Desde então, o teste tem suscitado um grande interesse e foi muito utilizado e pesquisado. Pelo menos durante duas décadas, as de 1940 e 1950, seu nome foi quase sinônimo de Psicologia Clínica. Naqueles anos, a principal função do clínico consistia na avaliação, no psicodiagnóstico, principalmente quando se tratava de diagnóstico diferencial. Durante as décadas de 1960 e 1970, o Rorschach se constituiu entre os testes mais utilizados no contexto clínico e segue ocupando este lugar até hoje (Exner, 1993/1994, p.3).

Diversos pesquisadores desenvolveram intensos e profundos trabalhos com o material deixado por Rorschach (1921/1978). A maioria dos trabalhos foi de natureza empírica e marcou a técnica com importantes descobertas. Pode-se destacar os estudos de Beck (1945, 1950), Beizmann (1974), Hertz (1951), Klopfer e Ainsworth (1954), Klopfer e Davidson (1962/1977), Klopfer e Kelly (1946/1972), Loosli-Usteri (1962), Piotrowski (1974), Rapaport (1946/1977), Silveira (1985), Traubenberg (1970/1998), dentre outros.

Desse modo, cada pesquisador acrescentou um aspecto próprio à técnica e à codificação dos escores, desenvolvendo o que se chama de Sistema de Classificação, que identifica uma determinada forma de trabalhar com o Método de Rorschach e diferenciam-se entre si no que tange aos aspectos de análise das respostas e compreensão das vivissitudes do sujeito no momento do teste. 
O sistema compreensivo (que será utilizado neste estudo) foi desenvolvido por Exner (1993/1994), nos Estados Unidos da América (EUA), baseado no estudo de vários sistemas de classificação existentes à época e sob intensa e grandiosa investigação empírica dos resultados.

Ao observar os procedimentos de aplicação e codificação propostos por Beck, Hertz, Klopfer, Piotrowski e Rapaport, Exner propôs um modelo integrador dos principais aspectos apresentados pelos influentes autores americanos até então, não perdendo, contudo, a característica central de cada um de seus colaboradores. Optou por abandonar as configurações muito pessoais e sem qualquer comprovação empírica, mantendo os índices e os procedimentos que as investigações mostravam ser relevantes e cientificamente aplicadas e comprovadas. Com esse procedimento, objetivava uniformizar a linguagem dos rorschachistas, permitindo maior comunicação entre os que pesquisavam e empregavam clinicamente o instrumento. Assim, fundou organizações especializadas no instrumento e em pesquisas e utilizou recursos empíricos e controlados para poder propor o sistema compreensivo (Nascimento \& Güntert, 2000).

A escolha de um sistema de classificação a ser adotado depende da afinidade e da identificação do clínico ou do pesquisador. Todos os sistemas possuem seus importantes pontos para a história do desenvolvimento do Método de Rorschach e não têm supremacia um sobre o outro. Assim, pode-se dizer que todos os sistemas de classificação estão corretos. Trata-se apenas de uma escolha técnico-metodológica do uso do instrumento.

Pérez (1995) expõe sobre o crescimento do emprego do sistema compreensivo na Europa, sobretudo na Espanha, e justifica tal crescimento pelo caráter empírico e integrador dos procedimentos assinalados pelo sistema.

No Brasil, a primeira discussão científica sobre o Método de Rorschach é datada de 1929 em Minas Gerais, dirigida por Helena Antipoff. Os primeiros registros de aplicação do 
Rorschach são de 1932, por Leme Lopes no Rio de Janeiro e a primeira publicação científica brasileira com o teste é de janeiro de 1934, escrita por T. Bastos com o título 'Aplicações do Método do Dr. Rorschach aos casos clínicos de endocrinologia’ (Yazigi, 1987).

Assim, em relação ao Rorschach, o Brasil sempre acompanhou o desenvolvimento e estudo sobre a técnica. Esta característica pode ser percebida, inclusive, a partir da fundação de sociedades científicas brasileiras com o intuito de agregar profissionais interessados no instrumento.

Em 1952, Aníbal Silveira fundou a Sociedade de Rorschach de São Paulo que, basicamente, agregava profissionais que utilizavam o sistema de classificação desenvolvido pelo seu fundador. Em 1993, André Jacquemin fundou a Sociedade Brasileira de Rorschach e outros métodos projetivos; esta última agregou os profissionais e os pesquisadores de todos os sistemas de classificação do Rorschach, bem como os profissionais e pesquisadores que utilizam outros instrumentos projetivos de investigação.

Tabela 1. Levantamento dos trabalhos apresentados nos eventos da SBRo que utilizaram o sistema compreensivo

\begin{tabular}{lccc}
\hline Evento & Data & $\begin{array}{c}\text { Número de } \\
\text { trabalhos }\end{array}$ & $\begin{array}{c}\text { Porcentagem } \\
\text { dos trabalhos }\end{array}$ \\
\hline I Encontro SBRo & $23-24$ / outubro / 1995 & 2 & $6 \%$ \\
II Encontro SBRo & $19-20$ / outubro / 1996 & 5 & $11 \%$ \\
I Congresso SBRo & $13-16$ / julho / 1997 & 5 & $14 \%$ \\
III Encontro SBRo & $9-12$ / dezembro / 1998 & 9 & $14 \%$ \\
II Congresso SBRo & $3-6$ / maio / 2000 & 11 & $16 \%$ \\
IV Encontro SBRo & $14-17$ / novembro / 2001 & 13 & $16 \%$ \\
III Congresso SBRo & $8-11$ / outubro / 2004 & 21 & $17 \%$ \\
IV Congresso ASBRo & $10-14$ / junho / 2006 & 16 & $12 \%$ \\
\hline
\end{tabular}

A partir da década de 1990, observou-se um crescimento na utilização clínica e de pesquisas do sistema compreensivo no Brasil. O fato pode ser observado nos dados da Tabela 1, que apresentam um levantamento da quantidade de trabalhos científicos que utilizaram o sistema compreensivo e foram apresentados nos eventos científicos da Sociedade Brasileira de Rorschach e outros métodos projetivos (SBRo 1995, 1996, 1997, 1998, 2000, 2001 e 
2004), apesar da pequena diminuição no IV Congresso da Associação Brasileira de Rorschach e métodos projetivos (ASBRo, 2006).

Dentre um grande conjunto de instrumentos projetivos, o Psicodiagnóstico de Rorschach ocupa, realmente, uma posição de grande destaque, enfatizada quer pela prática clínica dos profissionais da área, quer pela bibliografia e eventos científicos especializados nas discussões sobre avaliação psicológica.

\section{Aspectos Projetivos do Método de Rorschach}

Van Kolck (1981) assinala critérios de classificação das provas projetivas, baseado na proposta de vários autores, designando-as, conforme suas propriedades e características. Nestes termos, o Rorschach pode ser enquadrado como uma prova:

-constitutiva, quanto ao uso funcional do material, em que o sujeito organiza suas respostas com base em um material não estruturado;

-perceptivo-estrutural, quanto aos processos e aspectos de personalidade envolvidos, no qual o sujeito utiliza recursos de percepção para a projeção de suas características baseado na organização de suas respostas e

-visual, quanto à natureza do material empregado para estímulo, pois o sujeito usa a visão como meio de entrar em contato com os borrões-estímulo.

Para Coelho (1980), pode-se descrever o que acontece com o sujeito quando se defronta com as pranchas e seus estímulos no momento da aplicação do Rorschach. Em razão de suas características, o indivíduo utiliza predominantemente as sensações visuais, embora possa fazer referência a outras modalidades sensoriais durante a aplicação, como: táteis, movimentos, tensões, etc., dependendo dos aspectos personalógicos envolvidos. A organização dos perceptos é resultante do dinamismo psíquico e da projeção pautada em 
imagens subjetivas observadas em um contexto concreto (identificação e descrição do que foi percebido) e abstrato (apreensão dos elementos abstratos e essenciais).

Assim, o sujeito seleciona aspectos da prancha, segundo referenciais de atenção e afetivos, manifestando-os ao examinador por meio das respostas verbais e dos comportamentos que ele manifesta, oferecendo um rico material de análise, pois, apoiado nesse material é possível avaliar todo esse mecanismo e as características que foram envolvidas (Coelho, 1980).

Diante do contato visual com os estímulos organizados nas dez pranchas e utilizando os recursos perceptivos, os sujeitos organizam suas respostas que revelam importantes elementos de sua personalidade, possibilitando uma análise aprofundada desses elementos da personalidade, oferecendo bom material para encaminhamentos e ao trabalho psicoterapêutico.

O material de interpretação mostra-se bastante eficiente, pois os dados obtidos de forma sistematizada e controlada pelas propriedades da técnica, organizados na codificação e análise das respostas dadas podem ser medidos e quantificados, possibilitando um trabalho estatístico e objetivo (Adrados, 1982).

Desse modo, resultados claros de comparação são oferecidos, além de possibilitar uma análise simbólica dos dados psicodinâmicos das respostas, informando a respeito da dinâmica da personalidade do paciente de forma contextualizada, oferecendo subsídios psicodiagnósticos e prognósticos para o trabalho clínico.

É importante salientar que o instrumento oferece dados por intermédio de índices de adaptação e psicopatológicos, fornecendo um parâmetro de comparação frente à realidade externa e suas vivências que, por sua vez, disponibilizam ao psicólogo uma possibilidade de um diagnóstico diferencial, adaptativo e prognóstico, entre outros. 
Como citam Cunha et al. (1993), o Método de Rorschach pode ser indicado para o diagnóstico da personalidade em diferentes contextos clínicos, para o planejamento do processo terapêutico, para um recurso na seleção profissional, para investigação psicológica na área forense e para traçar elementos prognósticos em qualquer uma dessas situações.

Embora neste estudo tenha sido enfocado o trabalho clínico, é necessário esclarecer que o instrumento é multifacetado na prática em Psicologia, subsidiando uma série de possibilidades muito maior do que possa ter sido difundido até hoje.

As técnicas de exame psicológico constituem-se em excelente instrumento para coleta de dados em pesquisas e/ou objeto direto de investigação em pesquisas, demonstrando o crescente interesse de profissionais e pesquisadores no desenvolvimento de investigações na área (Jacquemin , 1997).

Dentre outros atributos, o Método de Rorschach é sistematicamente empregado em pesquisas científicas. Seus dados possibilitam importantes perspectivas no desenvolvimento de investigações sobre avaliação psicológica (Weiner, 1986).

Há muito tempo o teste garantiu seu caráter científico, por causa de intensas pesquisas nos mais diferentes níveis, configurando-se como um importante objeto e instrumento para a investigação da personalidade dos indivíduos (Yazigi, 1997).

Com base no exposto, salienta-se novamente que o Psicodiagnóstico de Rorschach ocupa cada vez mais um lugar de destaque entre as técnicas projetivas no trabalho clínico, mostrando-se sempre atual e de extrema valia aos profissionais que se preocupam em realizar um psicodiagnóstico apoiado em dados que ofereçam subsídios para uma interpretação contextualizada, profunda e dinâmica da personalidade dos sujeitos.

O Método de Rorschach foi publicado no início do século XX e cada vez mais se mostra um instrumento atual, com qualidades e possibilidades que transcendem à sua época e à sua posição atual. 
As Sociedades Científicas diretamente relacionadas ao Método de Rorschach (Associação Brasileira de Rorschach e outros métodos projetivos, por exemplo) são responsáveis pela formação especializada de vários profissionais que se interessam pelo instrumento e garantem, apoiados em seus cursos e eventos científicos, um excelente intercâmbio entre clínicos e pesquisadores. O aumento e a valorização do uso da técnica também estão relacionados às atividades dessas sociedades. 


\subsection{O Método de Rorschach na Investigação do Pânico}

O Método de Rorschach organizou-se e configurou-se como uma das mais importantes técnicas de investigação psicológica, pautando-se em sua base fundamentalmente clínica. Oriundo do desenvolvimento da psiquiatria e da psicanálise na época de sua criação, despertou grande interesse científico na área, conquistando ampla confiabilidade entre os profissionais de saúde mental no período, “mantendo a nomenclatura e nosologia clássica das doenças mentais” (Vaz, 1997, p.115).

Assim, o Rorschach é, tradicionalmente, classificado como um instrumento para avaliação de condições normais ou patológicas dos indivíduos (Weiner, 1986).

É constituído com base nas comparações entre pacientes que apresentavam um sofrimento mental e pessoas da população comum; pode-se dizer que o Método proposto por Rorschach nasceu fundamentado em informações obtidas em funcionamentos psicopatológicos, por isso, talvez, nenhuma outra técnica de avaliação psicológica possa, com tanta precisão, avaliar a psicopatologia de pacientes.

É importante ressaltar o grande número de pesquisas que foram (e são) desenvolvidas na área de psicopatologia com o método. Desde sua publicação, um grande número de clínicos e pesquisadores desenvolveu trabalhos com o Rorschach e as mais diferentes formas de psicopatologias.

\section{O Rorschach na Investigação de Aspectos Psicopatológicos}

O conhecimento acumulado sobre a aplicação do Rorschach nas mais variadas psicopatologias permite uma constante revisão dos conceitos de seus diagnósticos diferenciais, acompanhando a evolução dos quadros e as descobertas científicas da área. Todo clínico ou pesquisador que utiliza o Rorschach para investigar a psicopatologia espera que 
seus estudos auxiliem nas próximas investigações e esperam incentivar os jovens clínicos e pesquisadores a usar também o Método de Rorschach, mantendo aceso o interesse e o desenvolvimento do instrumento (Campo, 1995).

O Rorschach permite uma investigação dos funcionamentos específicos da personalidade, podendo ser um importante instrumento para avaliação dos aspectos psicopatológicos (Chabert, 1987/1993). Com este instrumento, é possível tipificar e diferenciar quadros diagnósticos, levando o psicólogo a uma conclusão mais fiel e a um planejamento terapêutico mais direcionado ou o pesquisador a delineamentos mais precisos e a considerações mais claras de seu trabalho.

Esta característica pode ser observada em vários trabalhos como, por exemplo, o de Laicardi, Nuovo e Tobino (1988) que empregaram o método para diferenciação de dois tipos específicos de síndromes esquizofrênicas, expondo a diferença sutil dos dados que esclareceram os dois diagnósticos.

Segundo Frank (1997), a possibilidade do uso clínico do Rorschach, como instrumento no psicodiagnóstico diferencial transcende seus dados psicométricos. Os aspectos quantitativos constituem um importante referencial quando se precisa realizar um diagnóstico que tem como objetivo avaliar as diferenças significativas entre um funcionamento típico e um patológico. Além disso, a possibilidade de uma leitura simbólica das verbalizações possibilita uma compreensão psicodinâmica bastante específica, necessária para a contextualização individual do paciente que está sendo avaliado.

Para que os dados quantitativos do Rorschach em um contexto clínico sejam usados na realização do psicodiagnóstico diferencial, são necessárias investigações anteriores que fundamentem os dados para uma comparação precisa, sobretudo, no que se refere à avaliação de estruturas psicopatológicas. Necessita-se de pesquisas específicas, cujo objeto de estudo seja as mais diferentes patologias e, com base em investigações empíricas, levantar os dados 
e os índices específicos, para que as futuras avaliações apóiem-se em proposições testadas e comprovadas e não em especulações sem sua devida constatação (Weiner, 1986).

Por todas essas razões o Rorschach é um dos testes mais utilizados para investigação de aspectos psicopatológicos e do diagnóstico diferencial (Cunha, 1996).

Conforme esclarece Vaz (1997), pela estreita relação entre o Método de Rorschach e as mais diferentes patologias, há um grande número de trabalhos clínicos e de pesquisas envolvendo a investigação do método nos mais diferentes quadros psicopatológicos.

Na literatura sobre o tema, observa-se que a possibilidade de descrição precisa dos índices do teste e sua objetividade de investigação e análise proporcionaram, ao longo do tempo, a descrição de vários quadros clínicos por meio de um conjunto de variáveis que podem auxiliar no diagnóstico diferencial das patologias, sempre apontado nos procedimentos necessários ao uso clínico da técnica (Santos, 1996).

Em relação ao tema, existem estudos a respeito da ansiedade, que podem subsidiar uma investigação sobre o pânico, em trabalhos integrando os índices observados no Rorschach com comportamentos ansiosos e diagnósticos prévios de condutas ansiosas, concluindo que existe uma estreita relação entre os índices observados nos protocolos de Rorschach e a vivência de estruturas ansiogênicas nos indivíduos (Gacono \& Meloy, 1991; Gacono, Meloy \& Weber, 1992).

Em específico no que tange ao transtorno de pânico, pelos trabalhos realizados por Andersen e Rosenberg (1990) e Adrados e Figueiredo (1995), percebe-se que o Rorschach é um instrumento capaz de caracterizar com precisão a síndrome e suas motivações psíquicas, tanto estruturais como inconscientes.

Em se tratando de transtornos de pânico, os estudos clínicos e de pesquisa envolvendo a avaliação de ansiedade e do transtorno propriamente dito, podem ser destacados. 


\section{O emprego do Rorschach na investigação da ansiedade}

Apoiados em seu significado de interpretação, os índices de avaliação do Rorschach permitem assinalar vários aspectos componentes da personalidade dos indivíduos. Dentre estes, no caso deste estudo, pode-se destacar a ansiedade.

Hurvich, Benveniste, Howard e Coonerty (1993) apresentaram um estudo com vinte colaboradores, comparando os índices de ansiedade obtidos no Hurvich Experience Inventory (um instrumento baseado na estrutura de auto-relato que visa a avaliação da ansiedade de aniquilação) e os índices de ansiedade de aniquilação obtidos das respostas do Rorschach e das histórias do TAT. Observaram alto grau de correlação $(0,94)$ entre o material objetivo do inventário e a manifestação de ansiedade nos índices do Rorschach.

Indicaram alta incidência de respostas que, segundo os autores, denotaram ansiedade de aniquilação em todos os protocolos, sobretudo nas pranchas IV e IX (15 vezes) e II e III (13 vezes). Pautados nesse estudo, os autores evidenciaram a possibilidade do uso do Rorschach na investigação de ansiedade de aniquilação de forma precisa (Hurvich et al., 1993).

Coelho e Costa (1987/1988) indicaram, apoiadas nas proposições do sistema de classificação de Silveira, que indivíduos ansiosos mostram sinais específicos no Rorschach. $\mathrm{Na}$ análise de 30 pacientes diagnosticados clinicamente como ansiosos pela Escala de Ansiedade de Cattell, demonstraram, quando comparados à amostra normativa, que esses indivíduos respondiam em maior freqüência aos determinantes com características de sombreado L e l'. Segundo as autoras, a determinante L proposta pelo sistema de Silveira, indica, quando em número elevado, excesso de cautela nos contatos interpessoais. As respostas classificadas como l' indicam reações emocionais muito primárias, como: ansiedade, insegurança ou conflitos. 
Além dessas determinantes, as autoras observaram a incidência de choque à luminosidade em 100\% dos protocolos e choque cromático em $70 \%$ dos protocolos, indicando falta de controle diante dos elementos ansiógenos e afetivos, respectivamente (Coelho \& Costa, 1987/1988).

Diante dos dados, as autoras citadas findam seu estudo concluindo que "o fenômeno psíquico interpretado como ansiedade parece traduzir-se de modo específico nos fatores da Prova de Rorschach” (p.33).

Outros estudos propuseram-se a analisar da ansiedade fundamentados nos dados do Rorschach, como o estudo de Douville e Ventura-Abramson (1992) que estudaram as manifestações de fobia em 15 protocolos de crianças e pré-adolescentes de ambos os sexos, apoiados no sistema de classificação francês e na análise psicodinâmica das respostas.

O referido estudo encontrou acentuados sinais de ansiedade nas crianças analisadas, como: aumento no uso de pequenos detalhes para localizar suas respostas, indicando uma atitude de evitar e afastar-se da realidade objetiva, preferindo elaborar os conteúdos de forma pessoal e particularizada; respostas fragmentadas e pouco elaboradas que revelam dificuldade de articulação interna.

A incidência de respostas do tipo Clob é associada à vivência da ansiedade de forma mais primitiva. Além de outros fatores inconscientes que desencadearam o comportamento fóbico, observados com base na leitura psicodinâmica das verbalizações dos sujeitos. Neste contexto, enfatizaram que o Rorschach pode ser sensível às variações de ansiedade do tipo fóbica dos pacientes (Douville \& Ventura-Abramson, 1992).

Gacono e Meloy (1991) descreveram um estudo a respeito da ansiedade, utilizando o sistema compreensivo para o Método de Rorschach. Desenvolveram sua pesquisa com 42 homens adultos com transtorno de personalidade anti-social, sem qualquer tipo de comorbidade e com quoeficiente intelectual médio, que cumpriam pena na Califórnia, divididos 
igualmente em dois subgrupos denominados pelos autores de psicopatas graves e psicopatas moderados. Elegeram cinco variáveis relacionadas à ansiedade para o estudo, sendo respostas de textura, vista e sombreado difuso, além da nota D e D ajustado.

Comparando-se os resultados obtidos com a tabela normativa de não pacientes norteamericanos e com os dados de pacientes não internados com outros quadros, foram observadas duas variáveis com diferenças significativas: como a diminuição das respostas T, nos dois grupos ( $\left.\mathrm{p}<0,01 / \mathrm{x}^{2}=5,56\right)$, indicando um certo temor, desconforto ou desprazer no contato interpessoal mais próximo (Gacono \& Meloy, 1991).

No que se refere às respostas $\mathrm{Y}$, houve uma diminuição da emissão desse tipo de determinante no grupo de psicopatas graves e aumento na emissão das respostas dos psicopatas moderados, indicando que o primeiro grupo apresentou menos desconforto emocional e ansiedade do que o grupo normativo. Por outro lado, o grupo dos psicopatas moderados, mostrou extremo sofrimento, desconforto, ansiedade e tensão $\left(p<0,005 / x^{2}=\right.$ 7,71). Tal aspecto, segundo os pesquisadores, está relacionado aos elementos narcisistas presentes nos psicopatas graves que podem inibir sentimentos de sofrimento (Gacono \& Meloy, 1991).

Diante dos resultados, Gacono e Meloy (1991) concluíram que o Método de Rorschach possibilita recursos psicométricos precisos para avaliar a ansiedade nos indivíduos com transtorno anti-social, permitindo verificar a intensidade psicopatológica do quadro.

Em outra pesquisa, Gacono, Meloy e Weber (1992) realizaram um estudo comparativo entre 48 adolescentes com desordem de conduta e 30 adolescentes com distimia, visando compreender os estados de ansiedade apoiados nos dados do Rorschach, segundo a classificação do sistema compreensivo. Os sujeitos não indicavam nenhum outro quadro psicopatológico e possuíam inteligência média. Elegeram também para seu estudo as respostas de sombreado $\mathrm{T}$ e $\mathrm{Y}$. 
Após a comparação dos dados obtidos com a tabela normativa norte-americana para adolescentes não pacientes e com a tabela de pacientes com depressão, observaram que as duas variáveis destacadas indicaram diferenças significativas:

Diminuição das respostas T - para o grupo de adolescentes com desordem de conduta $\left(\mathrm{p}<0,01 / \mathrm{x}^{2}=7,49\right)$; aumento das respostas $\mathrm{Y}$ - para os sujeitos com desordem de conduta e distimia ( $\left.<<0,05 / \mathrm{x}^{2}=5,02\right)$ (Gacono, Meloy \& Weber, 1992).

A partir da proposta de classificação de Klopfer, Vaz (1997) também descreve um conjunto específico de dez sinais associados ao transtorno por ansiedade generalizada, classificando o Rorschach como um instrumento importante e necessário para o diagnóstico do nível de ansiedade dos pacientes, sendo: ausência de FC; ausência ou presença pouco significativa de M; R - rebaixado; presença de choques acromático ou cromático; tempo médio de reação ou de duração curto; $\mathrm{k}$ + kF > Fk; m + mF > Fm; confabulação e/ou idéia de referência; F\% - dentro dos escores para a população normativa e elevação de S.

Para que o quadro de ansiedade generalizada seja identificado, Vaz (1997) enfatiza que se faz necessário dentre os dez sinais expostos a existência de, pelo menos, confabulação, elevação de S, k + kF > Fk, ausência de M e ausência de FC.

O autor também expôs um conjunto de sinais no Rorschach para identificação do transtorno de ansiedade social, sendo choques generalizados às áreas vermelhas nos Cartões II e III; dificuldades do examinando em cartões onde, usualmente, são vistas figuras A, observadas pelo tempo de reação e duração curto ou rejeição do Cartão VIII.

Eells e Boswell (1994) estudaram a relação de Y e m - à incidência de frustração e ansiedade em um estudo com 48 estudantes universitários, realizado em um ambiente totalmente controlado em laboratório. Não encontraram relação significativa entre as determinantes Y e m nesse estudo da frustração e ansiedade. Embora os dados sejam bastante conclusivos, levantaram a hipótese das características assinaladas terem sido amenizadas pela 
manipulação das variáveis no ambiente controlado do laboratório e indicaram a necessidade de ampliação do estudo, em especial, fora desse espaço.

Apesar da relação entre as determinantes de sombreado e ansiedade ser comum entre os vários sistemas de classificação do Rorschach, existe a necessidade, como assinala o estudo de Frank (1993), de se especificar com precisão os critérios de classificação para se considerar uma resposta como sendo de sombreado e a importância de uma análise comparativa para que não se incorram erros de investigação. Salienta-se que os cuidados metodológicos sempre devem estar presentes em estudos comparativos.

A seguir são expostos alguns estudos que buscam uma descrição da personalidade dos pacientes com pânico, utilizando, o emprego de diferentes técnicas projetivas para isso.

\section{Estudo do pânico por técnicas projetivas e Rorschach}

Estudos sobre o pânico e as técnicas projetivas foram desenvolvidos por pesquisadores em vários contextos. Inicialmente, apresentam-se três estudos com outras técnicas, no sentido de uma ilustração dos possíveis dados a serem observados:

Utilizando o Teste de Relações Objetais de Phillipson, outro estudo sobre o assunto foi desenvolvido por Echávarri, O’Ryan, Rapaport, Lira e Gloger (1994) que investigaram vinte pacientes com transtorno de pânico e puderam observar:

- predomínio de angústia persecutória e de angústia depressiva;

- utilização de mecanismos de defesa arcaicos, como cisão entre o negativo persecutório e o positivo idealizado, negação dos conteúdos persecutórios, idealização dos aspectos positivos desejados, projeção de conteúdos persecutórios e agressivos, além de isolamento afetivo; e 
- no que se refere às relações objetais, observaram a necessidade de vínculos afetivos primários e dependentes. Os vínculos são configurados de forma insegura e frustrante, levando os pacientes ao estabelecimento de vínculos distantes e inconsistentes.

Outro trabalho foi desenvolvido por Morais e Souza (1996) que realizaram a aplicação de um conjunto de técnicas projetivas em um grupo de 16 pacientes com distúrbios de pânico. Realizaram a aplicação do T.P.C. de Pfister, H.T.P., Desenho da Família e o T.A.T. - forma reduzida. Observaram que a maioria dos pacientes demonstrou:

- dificuldades significativas de ajustamento;

- juízo de realidade precária;

- sentimento de impotência e abandono;

- afetividade mal canalizada;

- indícios de agressividade latente;

- conflitos na área da sexualidade; e

- fortes tendências regressivas.

Villemor-Amaral, Farah e Primi (2004) realizaram um estudo sobre o pânico, utilizando o Teste das Pirâmides Coloridas de Pfister (TPC). Aplicaram a técnica em 15 pacientes diagnosticados com Transtorno de Pânico e compararam os resultados com 109 sujeitos da amostra normativa brasileira para o mesmo teste. Os dados estatisticamente mais significativos indicaram que os pacientes com pânico empregaram mais pirâmides com formação simétrica. Além disso, observaram um aumento da porcentagem de uso para a cor azul.

Baseado no modelo compreensivo, o Rorschach foi objeto de pesquisa de Andersen e Rosenberg (1990) no estudo comparativo entre 41 pacientes com transtorno de pânico, 14 com depressão maior e 18 com desordens de ansiedade generalizada, cujos dados foram comparados com 18 sujeitos normais. 
Após a comparação dos dados, nos protocolos dos pacientes com Transtorno de Pânico foram observadas diferenças significativas nos seguintes itens: diminuição de R, diminuição de $\mathrm{M}$, diminuição de WsumC, diminuição de $\mathrm{D} \%$, rebaixamento de $\mathrm{F}+\%$, aumento de H\%, diminuição de Z, e diminuição dos Blends (Andersen \& Rosenberg,1990).

Os autores concluíram o trabalho, expondo que os pacientes com transtorno de pânico indicaram um comprometimento na estrutura da personalidade e implicações na habilidade dos processos cognitivos. Como os resultados mostraram-se muito relevantes no estudo do pânico, salientaram que o emprego do Rorschach é de extrema valia no diagnóstico diferencial das diferentes psicopatologias, inclusive do Transtorno de Pânico (Andersen \& Rosenberg, 1990).

Em estudo utilizando o Método de Rorschach, Balbi, Iannucci e Italia (1994) descreveram a semelhança observada na estrutura de personalidade de um paciente que apresentou ataques de pânico quando comparado a um indivíduo que sofria ataques de raiva, indicando que ambos os sujeitos tinham fortes vivências de ansiedade de separação, associadas a uma estrutura borderline de personalidade, que geravam perda da consciência de si e do contato afetivo com o ambiente.

Na pesquisa clínica realizada, os autores citados pautaram suas conclusões em leituras psicanalíticas obtidas nas respostas do Rorschach. Compararam as análises de dois protocolos, um de um homem com ataques recorrentes de raiva com um de uma mulher com transtorno de pânico e observaram semelhanças na interpretação psicodinâmica das respostas. Indicaram que as verbalizações de ambos os pacientes apresentaram conteúdos de personalidade com estrutura mais primitiva, relacionada a falhas nas primeiras relações objetais, o que levaria esses indivíduos a uma estrutura borderline de personalidade. Além disso, puderam observar fortes vivências de ansiedade de separação nos colaboradores; no 
caso da paciente com pânico, essa ansiedade traduz-se em um medo incontrolável de morrer (Balbi, Iannucci \& Itália, 1994).

Especificamente com o emprego do Rorschach no estudo do pânico, no levantamento da literatura especializada foram obtidos os seguintes trabalhos de pesquisa:

Cohen e Ruiter (1992) testaram 22 pacientes, com idade entre 24 e 50 anos, com transtorno de pânico associado à agorafobia, empregando o Rorschach segundo o sistema compreensivo. Compararam seus resultados com os dados de outros quadros clínicos publicados (esquizofrenia, distúrbios de sono e depressão), além de dados publicados de não pacientes. Os dados da pesquisa revelaram um rebaixamento de Afr, rebaixamento do WsumC, quando comparados aos indivíduos não pacientes. Tal aspecto revelou características de fuga diante do contato afetivo, gerando certa restrição na vida afetiva dos pacientes, fazendo com que estes usassem um mecanismo de formação reativa para se defender da necessidade de afeto que sentiam.

No ano seguinte, os mesmos autores desenvolveram uma investigação com 18 pacientes holandeses com pânico associado à agorafobia e quatro pacientes holandeses com pânico sem agorafobia. Usaram também o Rorschach baseado no sistema compreensivo, identificando uma dificuldade na habilidade dos pacientes em lidar com emoções negativas e ansiogênicas, associadas a uma falha dos processos defensivos (Cohen \& Ruiter, 1993).

MacFadden (1994) estudou nove pacientes do sexo feminino com diagnóstico de pânico, por meio do Método de Rorschach, segundo o sistema de classificação de Silveira. Após a análise das médias obtidas nos protocolos das pacientes, comparou os resultados aos valores normativos propostos pelo sistema, obtendo-se as seguintes diferenças: aumento de \%R, diminuição da \%F, aumento da \%A, diminuição do elab/R , aumento do Af , aumento do Imp , diminuição de Com , diminuição de (MacFadden, 1994).

A autora conclui sua exposição referindo que: 
a análise dos resultados indicou que as pacientes em estudo são portadoras de intensas e profundas dificuldades psicológicas, decorrentes de uma falha no processo de desenvolvimento bio-psico-social. As primeiras relações interpessoais foram insuficientes e inadequadas para favorecer a construção de um referencial interno que, por sua vez, possibilitasse a aquisição de papéis necessários ao convívio social (MacFadden, 1994, p.52).

Outro estudo empregando o Método de Rorschach, usou o sistema de classificação de Klopfer, foi desenvolvido por Adrados e Figueiredo (1995) a partir de um levantamento de 85 protocolos de pacientes diagnosticados clinicamente como portadores de Síndrome do Pânico, de ambos os sexos.

Para as autoras, a maioria dos pacientes que participou do estudo, percebeu: F\% adequada, posição vivencial extratensiva, F+ extenso dentro dos padrões para a população, FM > M, C + CF > FC, Sombreado aumentado (Adrados \& Figueredo, 1995).

A exposição foi terminada com a citação “os pacientes portadores da doença do pânico parecem mais emotivos e sugestionáveis ... e portadores de um maior volume de ansiedade do que grupos do mesmo nível cultural e idade” (Adrados \& Figueredo, 1995, p.49).

Em estudo desenvolvido por Sarvasi (1999), foram investigadas as características das relações objetais estabelecidas por cinco pacientes com pânico; para tanto, foi usado o Método de Rorschach sob dois enfoques: a aplicação segundo o modelo proposto por Klopfer e a atualização dos procedimentos baseados no Rorschach Temático,que foi introduzido, no Brasil, por Jacquemim. A autora notou que quatro dos pacientes apresentaram $\mathrm{M}<\mathrm{FM}+\mathrm{m}$.

No estudo dos fenômenos especiais, a autora observou a incidência em quatro sujeitos dos seguintes aspectos: giro instantâneo do cartão, que revela desconfiança e conflito entre autonomia e dependência, mobilizando de forma prematura condutas de oposicionismo e atuação; respostas de par, indicando certo narcisismo e por fim, choque ao vazio, traduzindo fantasias de abandono da mãe e uma percepção negativa da imagem materna (Sarvasi, 1999). 
Pautada em uma leitura das relações objetais, percebeu, a partir da articulação das histórias narradas, que os pacientes apresentaram um funcionamento específico das configurações das relações objetais, como necessidade de apoio da figura materna, gerando uma percepção negativa dessa figura, com base nas vivências de abandono; uso de identificação projetiva como mecanismo de defesa principal; conflito entre autonomia e dependência (Sarvasi, 1999). 


\subsection{Objetivos}

Apoiado nos conceitos expostos nas considerações teóricas apresentadas, o presente estudo tem como objetivo geral: caracterizar os aspectos comuns observados no estudo da personalidade de pacientes com transtorno de pânico, obtidos por meio do Psicodiagnóstico de Rorschach, segundo o sistema de classificação compreensivo proposto por Exner (1993/1994).

Para atingir o objetivo geral descrito, foi necessário atentar para os seguintes objetivos específicos:

- Comparar, por meio de análises estatísticas, os resultados quantitativos apresentados por 30 pacientes adultos, com transtorno de pânico com os resultados apresentados por 30 indivíduos adultos não pacientes;

- Discutir os significados das variáveis que apresentaram diferenças estatisticamente significativas entre os dois grupos de sujeitos, 30 pacientes adultos com transtorno de pânico e 30 indivíduos adultos não pacientes;

- Identificar os aspectos qualitativos dos protocolos que caracterizam pacientes com transtorno de pânico; e

- Descrever os aspectos de personalidade observados nos dados do Método de Rorschach dos indivíduos com transtorno de pânico. 


\section{MÉTODO}

A importância de um estudo empírico está em proporcionar a análise de um fenômeno a ser pesquisado de forma coerente e real, considerando-se todos os aspectos apresentados pelos sujeitos sob influência de variáveis ambientais, fundamentadas na intercorrelação que estes fenômenos podem apresentar (Hernández, 1993).

A interpretação dos dados empíricos, baseada no estudo das variáveis que serão indicadas, possibilita uma intensa articulação entre o lógico e o real, ou seja, entre o conhecimento acumulado e descrito nos pressupostos teóricos e a apresentação 'viva' do fenômeno a ser estudado nos resultados apresentados pelos sujeitos, proporcionando uma efetivação e um crescimento do conhecimento científico (Hübner-D’Oliveira, 1984; Severino, 2001).

Nesse sentido, buscou-se na presente pesquisa uma descrição detalhada dos aspectos psicológicos presentes na personalidade de pacientes com transtorno de pânico, com base nas informações obtidas pelo Método de Rorschach.

\subsection{Colaboradores}

Participaram da pesquisa um total de 60 pessoas, divididas em dois grupos homogêneos e equivalentes para o estudo da personalidade dos pacientes com pânico: o Grupo I, denominado Grupo de Pacientes e o Grupo II, para efeitos de controle, que foi chamado Grupo de Não pacientes.

Para compor o Grupo de Pacientes (Grupo I), fizeram parte da amostra 30 sujeitos, sendo 15 do sexo feminino e 15 do sexo masculino, todos com diagnóstico de transtorno de pânico sem co-morbidade, inscritos em programas existentes em um Ambulatório de Saúde Mental de uma cidade da Grande São Paulo, para o atendimento dessa patologia. 
Para compor o Grupo de Não pacientes (Grupo II) 30 sujeitos foram analisados, sem qualquer tipo de queixa, com idade, nível de escolaridade e nível socioeconômico equivalentes aos obtidos no Grupo I, divididos em 15 do sexo feminino e 15 do sexo masculino.

Os dados da equivalência entre idade e escolaridade dos colaboradores da pesquisa estão descritos no Quadro 2:

Quadro 2. Dados sobre idade e escolaridade dos participantes da pesquisa

\begin{tabular}{|c|c|c|c|c|c|}
\hline \multicolumn{6}{|c|}{ Sexo Feminino } \\
\hline \multicolumn{3}{|c|}{ Grupo I - Pacientes } & \multicolumn{3}{|c|}{ Grupo II - Não-pacientes } \\
\hline Código & Idade & Escolaridade & Código & Idade & Escolaridade \\
\hline PF 01 & 31 & Fundamental Incompleto & CF 01 & 29 & Fundamental Incompleto \\
\hline PF 02 & 60 & Fundamental Incompleto & CF 02 & 55 & Fundamental Incompleto \\
\hline PF 03 & 53 & Fundamental Incompleto & CF 03 & 55 & Fundamental Incompleto \\
\hline PF 04 & 60 & Fundamental Completo & CF 04 & 65 & Fundamental Completo \\
\hline PF 05 & 33 & Superior Incompleto & CF 05 & 33 & Superior Incompleto \\
\hline PF 06 & 52 & Fundamental Incompleto & CF 06 & 51 & Fundamental Incompleto \\
\hline PF 07 & 49 & Fundamental Incompleto & CF 07 & 48 & Fundamental Incompleto \\
\hline PF 08 & 42 & Fundamental Incompleto & CF 08 & 41 & Fundamental Incompleto \\
\hline PF 09 & 39 & Fundamental Completo & CF 09 & 37 & Fundamental Completo \\
\hline PF 10 & 43 & Fundamental Incompleto & CF 10 & 46 & Fundamental Incompleto \\
\hline PF 11 & 55 & Fundamental Incompleto & CF 11 & 55 & Fundamental Incompleto \\
\hline PF 12 & 45 & Fundamental Incompleto & CF 12 & 50 & Fundamental Incompleto \\
\hline PF 13 & 52 & Fundamental Completo & CF 13 & 51 & Fundamental Completo \\
\hline PF 14 & 31 & Fundamental Incompleto & CF 14 & 31 & Fundamental Incompleto \\
\hline PF 15 & 34 & Médio Completo & CF 15 & 33 & Médio Completo \\
\hline \multicolumn{6}{|c|}{ Sexo Masculino } \\
\hline \multicolumn{3}{|c|}{ Grupo I - Pacientes } & \multicolumn{3}{|c|}{ Grupo II - Não-pacientes } \\
\hline Código & Idade & Escolaridade & Código & Idade & Escolaridade \\
\hline PM 01 & 24 & Fundamental Incompleto & CM 01 & 26 & Fundamental Incompleto \\
\hline PM 02 & 36 & Fundamental Incompleto & CM 02 & 40 & Fundamental Incompleto \\
\hline PM 03 & 28 & Fundamental Incompleto & CM 03 & 21 & Fundamental Incompleto \\
\hline PM 04 & 21 & Médio Incompleto & CM 04 & 19 & Médio Incompleto \\
\hline PM 05 & 38 & Fundamental Incompleto & CM 05 & 49 & Fundamental Incompleto \\
\hline PM 06 & 43 & Médio Completo & CM 06 & 43 & Médio Completo \\
\hline PM 07 & 42 & Fundamental Incompleto & CM 07 & 42 & Fundamental Incompleto \\
\hline PM 08 & 62 & Médio Completo & CM 08 & 60 & Médio Completo \\
\hline PM 09 & 43 & Fundamental Incompleto & CM 09 & 47 & Fundamental Incompleto \\
\hline PM 10 & 40 & Fundamental Incompleto & CM 10 & 42 & Fundamental Incompleto \\
\hline PM 11 & 37 & Fundamental Completo & CM 11 & 37 & Fundamental Completo \\
\hline PM 12 & 23 & Médio Completo & CM 12 & 22 & Médio Completo \\
\hline PM 13 & 52 & Superior Incompleto & CM 13 & 52 & Superior Incompleto \\
\hline PM 14 & 35 & Fundamental Incompleto & CM 14 & 34 & Fundamental Incompleto \\
\hline PM 15 & 65 & Fundamental Incompleto & CM 15 & 62 & Fundamental Incompleto \\
\hline
\end{tabular}


Como pode ser observado, houve um pareamento direto quanto à escolaridade. No que se refere à idade dos sujeitos, a média geral das idades dos pacientes foi de 42,2 anos e dos não pacientes 42,5. Quando o sexo dos colaboradores é considerado, para o sexo feminino tem-se média em 45,2 às pacientes e 45,3 às não pacientes; para o sexo masculino, as médias de idade foram 39,2 aos pacientes e 39,7 aos não pacientes. As médias obtidas a partir da idade dos colaboradores evidenciam que esta variável foi controlada.

\subsection{Material e Instrumentos para a Coleta de Dados}

Para o levantamento dos dados com vistas à organização geral da pesquisa, foram utilizados três instrumentos distintos: os roteiros de entrevista, um para o Grupo I - pacientes (Apêndice 1) e outro para o Grupo II - não pacientes (Apêndice 2); para a triagem dos participantes do Grupo II, foi empregado, também, o Questionário de Saúde Geral de Goldberg - QSG, no sentido de se verificar o estado psicológico saudável de cada não paciente; por fim, foi usado o Método de Rorschach em todos os participantes.

Foram necessárias 30 folhas do questionário-padrão (Apêndice 1) para o registro dos dados de cada um dos sujeitos de pesquisa que compôs o Grupo I, bem como do levantamento de aspectos relacionados aos sintomas e às crises de pânico. Além destas, foram necessárias 32 de folhas do mesmo questionário, adaptado para a organização dos dados dos sujeitos que participaram do grupo de não pacientes (Apêndice 2).

Os roteiros das entrevistas foram desenvolvidos com a finalidade de levantar dados de caracterização da amostra, tanto de pacientes como de não pacientes. Nesse sentido, foram levantadas informações gerais de cada sujeito como: idade, sexo, escolaridade, profissão, ocupação e estado civil. As questões que compuseram os questionários foram desenvolvidas baseadas no quadro dos sintomas de pânico apresentados pelo DSM-IV (A.P.A, 1994/1995), explicitado e detalhado pelo material bibliográfico estudado, sobretudo de Barlow e Cerny 
(1999) e López (2000). Estes autores foram escolhidos por tratarem especificadamente de procedimentos psicológicos no diagnóstico do pânico.

Em razão de sua grande eficácia e utilidade para a análise do pânico, optou-se pela estrutura aplicada em alguns inventários que objetivam uma caracterização clara deste quadro (Gentil, Ito \& Roso 1987; Ito \& Ramos, 1998; López, 2000), pois a proposta foi de que cada um dos sintomas investigados siga um modelo de graduação o que possibilita a investigação não só dos sintomas específicos, mas também de suas intensidades. O roteiro para os sujeitos não pacientes foi desenvolvido, pautando-se no original para os pacientes, adaptando-se a investigação para indivíduos que não sofreram crises de pânico (Apêndices 1 e 2).

No roteiro do questionário, empregou-se uma estrutura similar a de uma escala, com base em itens distribuídos no tipo Likert pela sua objetividade, o que permite uma padronização a respeito das informações a serem coletadas, facilitando a análise quantitativa dos elementos investigados. Assim, os questionamentos distribuídos em uma escala de investigação diagnóstica podem apresentar um padrão sintomatológico do quadro, possibilitando comparar os resultados ao grupo controle (Ito \& Ramos, 1998).

O Questionário de Saúde Geral de Goldberg (QSG) é um instrumento de avaliação psicológica, com estrutura de auto-relato, composto por 60 questões fechadas. A tarefa do indivíduo avaliado é responder cada um dos itens em uma folha de respostas, comparando seu estado psicológico usual com uma das alternativas propostas em uma escala do tipo Likert de quatro pontos. Segundo Cunha (2000), o QSG foi delineado para avaliar a gravidade do estado psicopatológico sem características psicóticas em indivíduos para efeito de triagem.

Para a aplicação do QSG foram utilizadas 32 folhas de registro das respostas dos colaboradores, além de um caderno onde estavam expressas as questões a serem respondidas. 
Nesta pesquisa, o material necessário para aplicação do Rorschach foi composto por um conjunto de pranchas do teste, 60 folhas de localização das respostas e folhas para o registro literal das respostas.

\subsection{Procedimentos para a Coleta de Dados}

No início, foram contatadas instituições que mantêm um programa de atendimento para transtorno ou síndrome do pânico no sentido de obter autorização para a coleta dos dados da pesquisa. Conseguiu-se a autorização para a coleta de dados em um Ambulatório de Saúde Mental situado na Grande São Paulo, onde foi possível utilizar a estrutura da instituição para o contato com os pacientes, bem como para aplicação do questionário e do Método de Rorschach.

O prontuário dos pacientes do Ambulatório foi consultado no sentido de separar os que sofriam de Transtorno de Pânico, sem co-morbidades, que foram convidados, por telefone ou por correspondência, a participar da pesquisa.

Para os que aceitaram, foi agendado um dia para as atividades. Em um primeiro momento, a Carta de Informação sobre a Pesquisa e o Termo de Consentimento Livre e Esclarecido (Apêndice 3) foi entregue, conforme normas estabelecidas para pesquisas envolvendo seres humanos dispostas pelo Ministério da Saúde (Brasil, 1996).

Após as explicações necessárias e diante do aceite dos colaboradores, foi realizado o preenchimento do questionário sobre os dados gerais e o levantamento de sintomas (Apêndice 1), bem como a aplicação do Método de Rorschach, de acordo com a disponibilidade de cada um dos colaboradores. A maior parte dos pacientes agendou as atividades para um dia em que tinha alguma atividade no Ambulatório.

A aplicação do Método de Rorschach seguiu, rigorosamente, todas as especificações técnicas propostas pelo sistema compreensivo (Exner, 1993/1994, 1995 e 1995/1999). 
A coleta de dados dos colaboradores do Grupo I (pacientes) ocorreu nas dependências do Ambulatório de Saúde Mental, em ambiente adequado às aplicações, segundo as especificações técnicas. A instituição cedeu uma sala para que ocorressem as aplicações. A coleta de dados do sexo feminino terminou antes que todos os dados fossem levantados. Dessa forma, durante um período final de levantamento esperou-se a colaboração apenas de pacientes do sexo masculino.

Após o término da coleta de dados dos pacientes, procedeu-se ao levantamento da idade e escolaridade para o convite aos colaboradores do Grupo II (não pacientes). Os indivíduos que preenchiam os requisitos de idade e escolaridade eram submetidos ao QSG para verificação do estado psicológico geral.

Para fazer parte da pesquisa, os participantes do Grupo II foram submetidos individualmente ao Questionário de Saúde Geral - QSG (Goldberg, 1972/1996) para verificação das características psicológicas gerais, garantindo-se que estes não possuíam nenhum quadro de sofrimento psicológico, quer leve ou severo.

O referido instrumento avalia cinco aspectos específicos de saúde geral, sendo estresse psíquico, desejo de morte, desconfiança no desempenho, distúrbios do sono e distúrbios psicossomáticos. Quando os escores desses cinco fatores são somados, compõe-se o escore de saúde geral (Goldberg, 1972/1996). Para efeito deste estudo, foi utilizado o escore geral do QSG de cada um dos participantes.

Como foi necessário garantir que os participantes do Grupo II (não pacientes) apresentassem um estado psicológico saudável, o QSG mostrou-se como uma estratégia eficaz para a seleção dos indivíduos.

As normas do QSG para a população brasileira, baseadas em escores brutos e percentílicos, são diferentes para cada um dos sexos. A pontuação bruta máxima que garante 
um estado psicológico saudável é de 2,30 às mulheres e 2,13 aos homens, correspondendo a um percentil máximo de 85 (Goldberg, 1972/1996).

Na composição do Grupo II (não pacientes), foram convidados 32 indivíduos para a seleção da amostra de não pacientes que se submeteram ao QSG; dois deles, um do sexo masculino e um do sexo feminino, obtiveram escores que revelaram algum tipo de problema psicológico e, por esse motivo, foram descartados da amostra.

Os dados dos testes dos participantes estão expostos no Quadro 3:

Quadro 3. Resultados do Questionário de Saúde Geral de Goldberg dos participantes do Grupo de Não pacientes

\begin{tabular}{|c|c|c|c|c|c|}
\hline \multicolumn{3}{|c|}{ Sexo feminino } & \multicolumn{3}{c|}{ Sexo masculino } \\
\hline Código & Escore Obtido & Decisão & Código & Escore Obtido & Decisão \\
\hline CF 01 & 1,40 & Aceito & CM 01 & 1,45 & Aceito \\
\hline CF 02 & 1,95 & Aceito & CM 02 & 1,56 & Aceito \\
\hline CF 03 & 2,20 & Aceito & CM 03 & 1,68 & Aceito \\
\hline CF 04 & 1,35 & Aceito & CM 04 & 1,95 & Aceito \\
\hline CF 05 & 2,05 & Aceito & CM 05 & 1,71 & Aceito \\
\hline CF 06 & 1,78 & Aceito & CM 06 & 1,93 & Aceito \\
\hline CF 07 & 1,76 & Aceito & CM 07 & 1,48 & Aceito \\
\hline CF 08 & 2,05 & Aceito & CM 08 & 1,45 & Aceito \\
\hline CF 09 & 1,96 & Aceito & CM 09 & 1,46 & Aceito \\
\hline CF 10 & 1,73 & Aceito & CM 10 & 1,66 & Aceito \\
\hline CF 11 & 1,51 & Aceito & CM 11 & 2,10 & Aceito \\
\hline CF 12 & 1,51 & Aceito & CM 12 & 1,58 & Aceito \\
\hline CF 13 & 1,58 & Aceito & CM 13 & 1,73 & Aceito \\
\hline CF 14 & 2,18 & Aceito & CM 14 & 1,25 & Aceito \\
\hline CF 15 & 1,35 & Aceito & CM 15 & 1,48 & Aceito \\
\hline F extra & 2,81 & Recusado & M extra & 2,55 & Recusado \\
\hline
\end{tabular}

Outros aspectos controlados na investigação foram a idade e a escolaridade de todos os sujeitos. No sentido de minimizar, ao máximo, a influência desses fatores na emissão das respostas ao Método de Rorschach, inicialmente foram realizadas as aplicações nos pacientes com transtorno de pânico, conforme apresentado anteriormente. Após o período de avaliação desses participantes do grupo I, houve a procura de indivíduos sem qualquer tipo de queixa psicológica (não pacientes) com idade e escolaridade equivalentes com os apresentados pelos pacientes. Estes se submeteram ao QSG, como foi descrito. 
Após a seleção da amostra, os participantes eram submetidos ao Método de Rorschach. A aplicação para os colaboradores não pacientes ocorreu na Clínica Psicológica de uma Universidade situada na Grande São Paulo, em ambiente adequado para as atividades.

Para a aplicação do Método de Rorschach, foram rigorosamente seguidas as normas de aplicação para o sistema compreensivo apresentadas nos manuais técnicos do teste (Exner, 1993/1994, 1995 e 1995/1999).

Todos os participantes assinaram o Termo de Consentimento Livre e Esclarecido, de acordo com as normas de pesquisa com seres humanos. Cabe ressaltar que todos os procedimentos da pesquisa foram avaliados e aprovados pelo Comitê de Ética em Pesquisa com Seres Humanos do Instituto de Psicologia da Universidade de São Paulo, conforme Ofício Of. 1206/CEPH, datado de 11 de agosto de 2006.

\subsection{Procedimentos de Análise dos Dados}

As respostas obtidas nas aplicações foram codificadas, considerando-se todos os aspectos propostos pelo sistema compreensivo (Exner, 1993/1994 e 1995/1999), sendo:

- localização;

- qualidade evolutiva;

- determinantes;

- $\quad$ qualidade formal;

- conteúdos;

- pares;

- populares;

- $\quad$ valor de elaboração; e

- $\quad$ escores especiais. 
Toda a codificação das respostas foi realizada por dois juízes, sendo um deles o autor da pesquisa e o outro, professor de Rorschach, membro da Associação Brasileira de Rorschach e Métodos Projetivos e com formação no sistema compreensivo. Ambos codificaram, independentemente, cada protocolo. A análise da incidência dos itens de codificação realizada pelos juízes seguiu à seguinte estratégia:

- Concordância entre os dois juízes - item de codificação foi aceito diretamente para análise;

- Discordância entre os dois juízes - o item foi analisado por um terceiro juiz, igualmente especializado no sistema compreensivo que decidiu entre as duas posições diferentes.

Foram obtidos 60 protocolos, perfazendo um total de 1.133 respostas que foram analisadas pelos dois juízes. Após a comparação da codificação realizada, observou-se que, em 29 protocolos (48,3\%) houve concordância total entre os dois avaliadores e, em 1.072 respostas (94,6\%), também, ocorreu uma concordância total nas codificações. Dessa maneira, quando as respostas foram consideradas separadamente, observou-se que a discrepância das codificações entre os avaliadores foi mínima.

Dos protocolos analisados, 31 (51,7\%) apresentaram algum tipo de discordância, perfazendo um total geral de 61 respostas $(5,4 \%)$ com algum tipo de diferença entre os dois avaliadores. Os dados do Quadro 4 apresentam a quantidade de discordâncias por respostas em relação ao número de protocolos:

Quadro 4. Quantidade de discordância de respostas por protocolo

\begin{tabular}{|c|c|c|}
\hline $\begin{array}{c}\text { Número de Respostas } \\
\text { com discordância }\end{array}$ & $\begin{array}{c}\text { Protocolos com } \\
\text { discordância }\end{array}$ & Total \\
\hline 1 & 16 & 16 \\
\hline 2 & 3 & 6 \\
\hline 3 & 10 & 30 \\
\hline 4 & 1 & 4 \\
\hline 5 & 1 & 5 \\
\hline Total & 31 & 61 \\
\hline
\end{tabular}


No que se refere ao tipo de discordância observada, tem-se que os itens de maior diferença foram relacionados às determinantes e aos códigos especiais (21 diferenças cada um), seguidos da divergência de conteúdos (12 diferenças) e qualidade evolutiva (11 diferenças). Os itens com menor quantidade de divergências foram: a localização (duas diferenças) e respostas em par (uma diferença). Os itens de codificação relacionados à qualidade formal, respostas populares e valor de elaboração não indicaram diferença na codificação entre os dois avaliadores.

As diferenças foram analisadas por um terceiro juiz que optou entre as duas codificações apontadas. Dessa forma, foi possível diminuir a interferência pessoal na codificação das respostas. Após a decisão do terceiro juiz, as respostas foram cotadas para a organização do Sumário Estrutural de cada um dos protocolos.

Os dados foram avaliados de acordo com os agrupamentos sugeridos no Sumário Estrutural do sistema compreensivo, divididos em quatro grupos definidos como: PF, PM, CF e CM para o tratamento estatístico.

Para descrever o perfil da amostra segundo as variáveis em estudo, foram feitas tabelas de freqüência das variáveis categóricas (classificação dos parâmetros de personalidade), com valores de freqüência absoluta (N) e porcentual (\%), e estatísticas descritivas das variáveis contínuas (escores dos testes), com valores de média, desvio-padrão, valores mínimo, máximo e mediana (Levin, 1987; Pereira, 1999; Siegel, 1975).

Para comparação das variáveis categóricas entre os quatro grupos foi utilizado o teste Qui-Quadrado ou, quando necessário, o teste exato de Fisher (presença de valores esperados menores que 5). Para comparar as variáveis numéricas ou contínuas entre os quatro grupos, foi empregado o teste de Kruskal-Wallis, em razão do tamanho dos grupos e da ausência de distribuição Normal das variáveis. As comparações múltiplas entre os quatro grupos foram feitas por meio do teste post-hoc de Dunn (Levin, 1987; Pereira, 1999; Siegel, 1975). 
O nível de significância adotado para os testes estatísticos foi de $5 \%$, ou seja, $p<0.05$.

Os aspectos mais significativos que caracterizaram o grupo de pacientes foram identificados. Após isso foram feitos os agrupamentos para a interpretação proposta pelo sistema compreensivo (Acklin, 1995; Exner, 1993/1994; Exner \& Sendín, 1998/1999; Weiner, 1998/2000), traçando-se, com base nessas informações, interpretações psicológicas dos agrupamentos apresentados.

De acordo com as proposições para pesquisas com o Método de Roschach no sistema compreensivo, apresentadas por Exner (1995), foram destacadas variáveis que, pelas suas características e descrição na literatura, podem apresentar variações, de acordo com o quadro de pânico. Neste estudo, essas variáveis foram denominadas de ‘variáveis principais’. A sistematização dos dados quantitativos e qualitativos do teste pode oferecer subsídios para a descrição detalhada do transtorno do pânico, possibilitando a avaliação de personalidade desses pacientes (Exner, 1995).

A descrição e a compreensão do significado de cada variável basearam-se nas explicações contidas nos manuais técnicos do teste (Exner, 1993/1994; Exner, 1995/1999; Exner \& Sendín, 1998/1999).

A seguir, optou-se por uma apresentação geral do significado de cada variável, o detalhamento interpretativo será exposto no item dos resultados. Para o desenvolvimento da presente investigação, foram destacadas, como 'variáveis principais', os seguintes itens observados no Método de Rorschach:

- DEPI ,

- CDI ,

- L ,

- EB (Erlebnistypus),

- EA - Experiência Efetiva , 
- EBPer - EB Persistente ,

- eb - Experiência de Base ,

- $\quad$ es - Estimulação Sentida ,

- D - Nota D ,

- Adj D - Nota D Ajustada ,

- FM,

- $\mathrm{m}$,

- $\Sigma C^{\prime}$,

- $\Sigma \mathrm{V}$,

- $\quad \Sigma \mathrm{T}, \mathrm{e}$

- $\Sigma \mathrm{Y}$,

A seguir, realizou-se um estudo exploratório das demais variáveis obtidas pautadas na codificação das respostas do Rorschach, verificando-se a existência de diferenças estatisticamente significativas entre os dois grupos pesquisados. Estas variáveis foram denominadas de 'variáveis secundárias'.

Pela importância do aspecto simbólico apresentado por um instrumento projetivo, sobretudo quando é realizada uma leitura psicodinâmica dos quadros apresentados (Augras, 1980), as verbalizações dos pacientes foram analisadas qualitativamente.

Para a análise qualitativa das respostas, foram observadas as semelhanças das respostas apresentadas pelos pacientes com pânico, destacando-se os cartões em que estas respostas surgiram. Procedeu-se uma análise das imagens temáticas destas respostas, fundamentando-se na proposta de Weiner (1998/2000). Quando do surgimento de dúvidas quanto ao material temático apresentado, recorreu-se aos exemplos encontrados em outros autores que também se propuseram a realizar esta análise (Lerner, 1991; Schafer, 1954). 


\section{RESULTADOS E DISCUSSÕES}

Os resultados obtidos na presente investigação foram classificados como quantitativos, referentes aos dados levantados na codificação das respostas do Método de Rorschach que receberam tratamento estatístico; e qualitativos, resultantes da análise das verbalizações dos participantes nas mesmas respostas do citado método.

\subsection{Dados Quantitativos}

Como descrito anteriormente, os resultados quantitativos são compostos pelas variáveis principais e secundárias. As variáveis principais foram destacadas, de acordo com o que é sugerido por Exner (1995), com base nas hipóteses previamente levantadas no estudo, apoiando-se na literatura existente e nas pesquisas anteriores. As variáveis secundárias são resultado de uma investigação exploratória dos demais itens de codificação apresentados.

Nesta discussão, as descrições dos índices e seus respectivos significados interpretativos apresentados foram baseados nos manuais técnicos sobre o Método de Rorschach, segundo o sistema compreensivo (Exner, 1993/1994; Exner, 1995/1999; Exner \& Sendín, 1998/1999). Quando as variáveis de análise foram do tipo contínuas, os valores apresentados foram comparados com os dados obtidos na tabela geral da pesquisa normativa brasileira, desenvolvida por Villemor-Amaral, Silva Neto \& Nascimento (2003).

\section{Variáveis principais}

As seguintes variáveis principais foram destacadas para análise: DEPI - Índice de Depressão, CDI - Índice de Déficit Relacional, L - Índice Lambda, EB (Erlebnistypus) - Tipo de Vivência, EA - Experiencia Efetiva, EBPer - EB Persistente, eb - Experiência de Base, es Estimulação Sentida, D - Nota D, Adj es - Estimulação Sentida Ajustada, Adj D - Nota D 
Ajustada, FM - Movimento Animal, m - Movimento Inanimado, C’ - Cor Acromática, V Sombreado Vista, T - Sombreado Textura e Y - Sombreado Difuso.

Os resultados obtidos foram os seguintes:

O Índice de Depressão - DEPI, foi obtido pela observação de 15 variáveis que se articularam em sete elementos de análise. O índice seria considerado positivo, se houvesse a presença de, pelo menos, cinco desses elementos. Quando positivo, o DEPI avalia a presença de depressão ou algum tipo de transtorno afetivo, indicando ainda que a organização psicológica do indivíduo é bastante vulnerável à depressão ou alterações de humor.

No que se refere à comparação dos valores obtidos em DEPI, expostos nos dados das Tabelas 2 e 3, foram verificadas diferenças significativas entre os grupos pesquisados.

Tabela 2. Presença de DEPI nos quatro grupos

\begin{tabular}{|c|c|c|c|c|c|}
\hline \multirow{2}{*}{ DEPI } & \multicolumn{2}{|c|}{ Sim } & \multicolumn{2}{|c|}{ Não } & Sig \\
\hline & $\mathrm{N}$ & $\%$ & $\mathrm{~N}$ & $\%$ & \\
\hline PF & 7 & 46,67 & 8 & 53,33 & \\
\hline PM & 8 & 53,33 & 7 & 46.67 & $p=0,009$ \\
\hline CF & 2 & 13,33 & 13 & 86,67 & \\
\hline CM & 1 & 6,67 & 14 & 93,33 & \\
\hline
\end{tabular}

Como é possível verificar nos dados da Tabela 2, os grupos de pacientes apresentaram maior incidência de DEPI positivo, 46,67\% ( $\mathrm{N}=7)$ nos pacientes do sexo feminino e 53,33 $(\mathrm{N}=8)$ nos pacientes do sexo masculino. Na observação dos dados do grupo-controle, esta incidência caiu para 13,33\% (N=2) no controle feminino e 6,67\% (N=1) no masculino.

Após comparação das variáveis categóricas do Índice de Depressão pelo teste Exato de Fischer, obteve-se a diferença $\mathrm{p}=0,009$, indicando que houve uma diferença estatisticamente significativa entre os dois grupos, sendo maior a incidência do Índice de Depressão no grupo de pacientes. 
Tabela 3. Incidência de indicadores de DEPI nos quatro grupos

\begin{tabular}{lcccccc}
\hline Indic. & Média & D.P. & Min & Mediana & Máx & Sig \\
\hline PF & 4,40 & 0,63 & 3,00 & 4,00 & 5,00 & \\
PM & 4,40 & 0,99 & 2,00 & 5,00 & 6,00 & \\
CF & 3,47 & 0,83 & 2,00 & 3,00 & 5,00 & p $<0,001$ \\
CM & 3,33 & 0,72 & 2,00 & 3,00 & 5,00 & \\
\hline
\end{tabular}

Os dados da Tabela 3 mostram a incidência das variáveis que compõem o DEPI nos quatro grupos. Observou-se que a média dos indicadores de DEPI no grupo de pacientes foi 4,40 e no grupo controle de 3,47 às mulheres e 3,33 aos homens. Comparando-se os resultados das variáveis contínuas pelos testes de Kruskal-Wallis e pos-hoc de Dunn para a comparação dos escores entre os quatro grupos, obteve-se $p<0,001$, o que revelou uma diferença estatisticamente significativa entre eles, pois o grupo de pacientes possui um maior número de indicadores de DEPI quando comparado ao grupo-controle.

Desta maneira, é possível afirmar que os pacientes com Transtorno de Pânico que compuseram a amostra possuíam maior vivência depressiva do que os colaboradores do grupo-controle. Assim, verificou-se que pacientes com pânico tendem a apresentar DEPI positivo quando avaliados pelo Rorschach, em virtude de uma possível vivência depressiva ou de uma propensão a alteração de humor com tendência à depressão.

O índice de DEPI positivo, foi observado também por Exner e Erdberg (2005) em um estudo de um caso de pânico de um homem de 23 anos de idade, revelando que este sujeito encontrava-se vulnerável a situações de depressão e sofrimento afetivo.

A relação entre pânico e depressão também foi notada no estudo de Montiel, Capovilla, Berberian e Capovilla (2005) que observaram, baseados no Inventário de Beck, grande incidência de sintomas depressivos em pacientes com pânico. Os autores concluíram que existe uma forte relação entre os transtornos de ansiedade, sobretudo o pânico, com o desenvolvimento de sintomas depressivos. Explicaram que quanto maior a vivência de ansiedade maior seria a possibilidade do desenvolvimento de sintomas depressivos. 
Em trabalho anterior, Caetano (1985) descreveu a grande ocorrência de sintomas depressivos em pacientes com transtornos fóbico-ansiosos, em especial, o transtorno de pânico. Entretanto, relatou que a depressão desenvolvida por pacientes com pânico é produzida quando o quadro é crônico e limitante. Resultados semelhantes foram observados por Andersen e Rosenberg (1990) que perceberam grande presença de sintomas depressivos em pacientes com pânico.

O Índice de Déficit Relacional - CDI é um escore obtido com base na observação de 11 variáveis que se agrupam em cinco elementos de análise com presença de, pelo menos, quatro desses elementos. Avalia a existência de dificuldades para enfrentar eficientemente as demandas comuns do meio social onde o indivíduo insere-se, revelando certa falta de aptidão ou dificuldade para os elementos relacionais, levando-os a problemas na interação com os demais sujeitos que o rodeiam. Apresentam características de distância dos demais, pouca sensibilidade às necessidades dos outros, levando-os a fracassos nos contatos interpessoais.

Quando os resultados do CDI dos quatro grupos foram comparados, nos dados das Tabelas 4 e 5, não houve diferenças estatisticamente significativas entre os dados de pacientes e não pacientes.

Tabela 4. Presença de CDI nos quatro grupos

\begin{tabular}{|c|c|c|c|c|c|}
\hline \multirow{2}{*}{ CDI } & \multicolumn{2}{|c|}{ Sim } & \multicolumn{2}{|c|}{ Não } & Sig \\
\hline & $\mathrm{N}$ & $\%$ & $\mathrm{~N}$ & $\%$ & \\
\hline PF & 11 & 73,33 & 4 & 26,67 & \\
\hline PM & 11 & 73,33 & 4 & 26,67 & $p=0,891$ \\
\hline CF & 11 & 73,33 & 4 & 26,67 & \\
\hline $\mathrm{CM}$ & 9 & 60,00 & 6 & 40,00 & \\
\hline
\end{tabular}

Os dados expostos na Tabela 4 demonstram que 73,33 ( $\mathrm{N}=11)$ dos pacientes com pânico, bem como os não pacientes do sexo feminino indicaram CDI positivo, 60\% (N=9) do grupo controle masculino também apresentaram a mesma indicação. Quando os dados das variáveis categóricas do CDI foram comparados pelo teste Exato de Fischer, obteve-se a 
diferença $\mathrm{p}=0,891$, revelando que não houve diferenças estatisticamente significativas entre os grupos.

Tabela 5. Incidência de indicadores de CDI nos quatro grupos

\begin{tabular}{lcccccc}
\hline Indic. & Média & D.P. & Min & Mediana & Máx & Sig \\
\hline PF & 3,73 & 1,10 & 1,00 & 4,00 & 5,00 & \\
PM & 3,73 & 0,88 & 2,00 & 4,00 & 5,00 & \\
CF & 3,73 & 0,88 & 2,00 & 4,00 & 5,00 & $\mathrm{p}=0,979$ \\
CM & 3,67 & 0,98 & 2,00 & 4,00 & 5,00 & \\
\hline
\end{tabular}

As médias de variáveis positivas para CDI nos quatro grupos foram muito semelhantes. De acordo com a Tabela 5, encontraram-se 3,73 para os pacientes e controle feminino e 3,67 para controle masculino. Depois dos testes Kruskal-Wallis e pos-hoc de Dunn para a análise das variáveis contínuas do CDI, obteve-se um escore $p=0,979$, que indica a ausência de diferenças significativas.

Nesses dados, a maioria dos indivíduos que compôs a amostra, indicou algum tipo de dificuldade de interação com outras pessoas. Como diferenças não foram observadas, esse aspecto não foi considerado como característica dos pacientes com pânico. Embora não tenha sido alvo da presente investigação, conjecturou-se que outros fatores desenvolvimentais ou sociais podem ter interferido na dificuldade de interação presente nos componentes da amostra.

O Índice Lambda - L, índice avalia a intensidade do controle intelectual exercido pelo indivíduo, ou seja, a disposição para se abrir a novos campos de estimulação.

Tabela 6. Valores de $L$ apresentados nos quatro grupos

\begin{tabular}{lcccccc}
\hline L & Média & D.P. & Min & Mediana & Máx & Sig \\
\hline PF & 0,53 & 0,48 & 0,00 & 0,45 & 2,00 & \\
PM & 0,49 & 0,64 & 0,06 & 0,17 & 2,40 & \\
CF & 1,09 & 0,74 & 0,27 & 1,00 & 3,00 & $\mathrm{p}=0,008$ \\
CM & 1,46 & 2,59 & 0,07 & 0,67 & 10,50 & \\
\hline
\end{tabular}


Os dados da Tabela 6 revelam que os testes Kruskal-Wallis e pos-hoc de Dunn aplicados aos valores de L nos quatro grupos, demonstraram uma diferença estatisticamente significativa em $\mathrm{p}=0,008$ observada apenas no grupo de pacientes do sexo masculino, com uma menor incidência. Na análise geral, verificou-se o valor de L menor para os grupos de pacientes, quando comparados ao grupo de não pacientes.

Os dados normativos para a população brasileira apresentam valor de L com média em 1,05. Dessa maneira, os dados dos pacientes foram classificados como rebaixados, enquanto os valores do grupo controle mostraram-se compatíveis com a população brasileira.

Valores reduzidos de L indicam falta de discriminação entre informações importantes e irrelevantes. Aqueles que possuem tais valores reduzidos, são indivíduos facilmente invadidos pela estimulação emocional que pode interferir com freqüência na eficiência do julgamento de suas condutas e daquilo que é percebido.

No estudo de Exner e Erdberg (2005), o valor de L também se encontrava rebaixado, dado compatível com a presente pesquisa.

Os pacientes com pânico atravessam essa dificuldade, sendo submetidos a uma ampla variação de estímulos emocionais que interferem diretamente na articulação de seus conteúdos. Por outro lado, a pesquisa de Cohen e Ruiter (1992) demonstrou exatamente o contrário. Na investigação, 86\% dos 22 pacientes com pânico associado à agorafobia apresentaram L elevado, com valores acima de 0,99, cuja interpretação é exatamente oposta, ou seja, os indivíduos conseguem processar adequadamente as informações do meio. Nesse sentido, é possível hipotetizar que a presença do quadro de agorafobia pode alterar a maneira pela qual os pacientes processam componentes emocionais que podem interferir no julgamento de suas percepções.

Os dados relativos ao Tipo de Vivência - EB (Erlebnistypus) avalia o estilo pelo qual o indivíduo responde às demandas do meio externo. 
Se houver predomínio das respostas $\mathrm{M}$, o indivíduo será classificado como introvertido, caracterizando uma conduta mais ideacional, ou seja, considera todas as alternativas no momento de tomar uma decisão e não utiliza emoções para solucionar problemas, baseando-se em sua avaliação interna.

Quando há predomínio de WsumC é um indicador que o sujeito avaliado tem EB do tipo extratensivo, representando um estilo mais emocional, misturando afetos e pensamentos na resolução de problemas. Suas opiniões são influenciadas pelas informações externas.

Para segurança na avaliação, há necessidade de pelo menos dois pontos de diferença na proporção, tanto para a classificação do EB introvertido como para o EB extratensivo.

Quando essa diferença for menor do que dois pontos ou os valores encontrarem-se iguais, classifica-se o indivíduo como ambigual, que representa uma maior vulnerabilidade diante das dificuldades. As decisões são tomadas de forma vacilante e são mais demoradas do que nos outros dois estilos de reação, levando esses sujeitos a serem mais imprevisíveis.

Eventualmente, acontece de os dois lados da proporção serem zero, ou seja, nenhuma resposta de movimento humano ou de cor cromática. Nessas situações, o indivíduo é classificado como coartado, revelando um rígido esforço defensivo ocasionado por afetos paralisados e dificuldade de reflexão, não conseguindo refletir internamente nem ser influenciado por estimulações afetivas nas tomadas de decisões.

Tabela 7. Classificação de EB nos quatro grupos

\begin{tabular}{|c|c|c|c|c|c|c|c|c|c|}
\hline EB & \multicolumn{2}{|c|}{ Introvertido } & \multicolumn{2}{|c|}{ Extratensivo } & \multicolumn{2}{|c|}{ Ambigual } & \multicolumn{2}{|c|}{ Coartado } & Sig \\
\hline & $\mathrm{N}$ & $\%$ & $\mathrm{~N}$ & $\%$ & $\mathrm{~N}$ & $\%$ & $\mathrm{~N}$ & $\%$ & \\
\hline $\mathrm{PF}$ & 2 & 13,33 & 1 & 6,67 & 12 & 80,00 & 0 & 0,00 & \\
\hline PM & 2 & 13,33 & 1 & 6,67 & 12 & 80,00 & 0 & 0,00 & \\
\hline CF & 2 & 13,33 & 1 & 6,67 & 12 & 80,00 & 0 & 0,00 & 000 \\
\hline CM & 1 & 6,67 & 2 & 13,33 & 12 & 80,00 & 0 & 0,00 & \\
\hline
\end{tabular}


Os dados da Tabela 7 apresentam os tipos de EB demonstrados pelos sujeitos desta pesquisa. Observa-se que não existem diferenças entre os quatro grupos, pacientes com pânico feminino e masculino e controle feminino e masculino.

O teste Exato de Fisher teve significância de p = 1,000. Houve um grande predomínio do Tipo de Vivência ambigual em 80\% (N=12) da amostra investigada, pelo fato da maioria dos valores não apresentarem dois pontos ou mais de diferença na proporção M para WsumC. No trabalho de Exner e Erdberg (2005), o EB do paciente avaliado também foi classificado como ambigual.

Este aspecto merece maiores investigações pois em pesquisas anteriores não houve predomínio de resultados ambiguais. Nos trabalhos, observou-se predomínio do estilo extratensivo (MacFadden, Duarte \& Guimarães, 1986/87; MacFadden,1994; Adrados e Figueiredo, 1995 e Sarvasi, 1999).

É importante salientar que nenhum dos estudos utilizou o sistema compreensivo para a análise das respostas. Pode-se levantar a hipótese de que os diferentes sistemas tenham normas de classificação próprias para identificação do Tipo de Vivência, o que explicaria as diferenças. Por outro lado, uma vez que esse fator é muito importante na análise no Rorschach, se realmente forem observadas diferenças de orientação, segundo os sistemas de classificação, levanta-se um relevante aspecto a ser estudado.

Os dados relativos à Experiência Efetiva - EA, avaliam os recursos disponíveis que o indivíduo possui para tomar decisões e colocá-las em prática.

Tabela 8. Valores de EA apresentados nos quatro grupos

\begin{tabular}{lcccccc}
\hline EA & Média & D.P. & Min & Mediana & Máx & Sig \\
\hline PF & 3,57 & 2,37 & 1,00 & 2,50 & 9,00 & \\
PM & 4,20 & 2,84 & 0,50 & 4,00 & 10,00 & \\
CF & 4,17 & 2,81 & 0,50 & 3,50 & 10,50 & $\mathrm{p}=0,864$ \\
CM & 3,43 & 2,43 & 0,50 & 2,00 & 8,00 & \\
\hline
\end{tabular}


Nos dados da Tabela 8, é possível verificar que após cálculo de comparação pelos testes de Kruskal-Wallis e pos-hoc de Dunn o valor obtido foi $\mathrm{p}=0,864$, o que indicou que não existem diferenças estatisticamente significativas entre os quatro grupos. As médias de EA observadas foram de 3,57 aos pacientes do sexo feminino e 4,20 aos de sexo masculino, enquanto os colaboradores não pacientes indicaram média de 4,17 às mulheres e 3,43 aos homens. Os dados normativos brasileiros apresentam média de EA igual a 4,96 com desviopadrão de 3,49, o que indica que os valores mostrados pelos colaboradores desta pesquisa encontram-se compatíveis com os dados normativos.

O EB Persistente - EBPEr indica como o indivíduo tolera, de forma ágil e consistente, o enfrentamento de novas situações estressantes, visando a sua adaptação. Este índice é presente e calculado apenas quando os valores de EA são bem definidos, ou seja, quando o estilo de EB é introvertido ou extratensivo.

A maior parte dos sujeitos que participou da presente pesquisa caracteriza-se como ambigual, conforme descrito anteriormente. No trabalho de Exner e Erdberg (2005) não houve cálculo de EBPer, pelo fato do paciente ter um tipo de vivência ambigual. Apenas três colaboradores de cada grupo apresentaram um estilo definido. Os dados desses indivíduos são expostos na Tabela 9.

Tabela 9. Valores de EBPer apresentados nos quatro grupos

\begin{tabular}{lccccccc}
\hline EBPer & N & Média & D.P. & Min & Mediana & Máx & Sig \\
\hline PF & 3 & 3,50 & 1,50 & 2,00 & 3,50 & 5,00 & \\
PM & 3 & 4,50 & 2,78 & 1,50 & 5,00 & 7,00 & \\
CF & 3 & 3,47 & 1,36 & 2,40 & 3,00 & 5,00 & $\mathrm{p}=0,521$ \\
CM & 3 & 2,13 & 0,51 & 1,70 & 2,00 & 2,70 & \\
\hline
\end{tabular}

Os testes de Kruskal-Wallis e pos-hoc de Dunn demonstraram p = 0,521, assim, não houve diferenças significativas nos valores dos quatro grupos. O número de colaboradores com índice de EBPer definido foi de três por grupo, perfazendo $20 \%$ da amostra total dos pesquisados. 
Há uma outra proporção de análise, a Experiência de Base - eb , que avalia as fontes principais de tensão e desconforto internos, de acordo com o lado predominante na comparação da proporção. Sendo assim, há três condições de proporção: Predomínio de $\mathrm{FM}+\mathrm{m}$, predomínio de $\Sigma \mathrm{C}^{\prime}+\Sigma \mathrm{T}+\Sigma \mathrm{V}+\Sigma \mathrm{Y}$ ou igual valor dos dois lados.

Tabela 10. Classificação de eb nos quatro grupos.

\begin{tabular}{lccccccc}
\hline \multirow{2}{*}{ eb } & \multicolumn{2}{c}{$\begin{array}{c}\text { Predomínio } \\
\text { FM }+\mathrm{m}\end{array}$} & \multicolumn{2}{c}{$\begin{array}{c}\text { Predomínio } \\
\Sigma \mathrm{C}^{\prime}+\sum \mathrm{T}+\Sigma \mathrm{V}+\Sigma \mathrm{Y}\end{array}$} & \multicolumn{2}{c}{ Valores Iguais } & \multirow{2}{*}{ Sig } \\
\cline { 2 - 6 } & $\mathrm{N}$ & $\%$ & $\mathrm{~N}$ & $\%$ & $\mathrm{~N}$ & $\%$ & \\
\hline $\mathrm{PF}$ & 2 & 13,33 & 13 & 86,67 & 0 & 0,00 & \\
$\mathrm{PM}$ & 1 & 6,67 & 13 & 86,67 & 1 & 6,67 & \\
$\mathrm{CF}$ & 7 & 46.67 & 7 & 46,67 & 1 & 6,67 & $\mathrm{p}=0,010$ \\
$\mathrm{CM}$ & 8 & 53,33 & 6 & 40,00 & 1 & 6,67 & \\
\hline
\end{tabular}

Na Tabela 10, é possível verificar, com base nos dados obtidos no teste Exato de Fisher, que o valor $\mathrm{p}=0,010$, indicou diferença significativa entre os quatro grupos, pacientes feminino e masculino, controle feminino e masculino.

No grupo dos pacientes com pânico, prevaleceu o somatório $\Sigma C^{\prime}+\Sigma T+\Sigma V+\Sigma Y$ em 86,67\% ( $\mathrm{N}=13)$ em ambos os sexos, o que revelou um aumento da tensão interna, ocasionando aumento na liberação de afetos com pouco controle. Estes afetos sobrepujam os recursos disponíveis para a organização pessoal, causando uma sobrecarga emocional e condutas impulsivas. Esse processo interno não pode ser controlado pela vontade dos sujeitos, gerando extremo mal-estar e desconforto emocional, levando-os a experimentar dor e sofrimento psíquico em demasia.

No grupo de não pacientes, houve um predomínio da soma $\mathrm{FM}+\mathrm{m}$ em 46,67\% (N=7) do grupo feminino e 53,33\% (N=8) do grupo masculino. Os resultados indicaram um predomínio dos elementos ideacionais periféricos, ou seja, a elaboração ideativa pode ser disparada sem a vontade do sujeito, levando-o a uma atividade mental provocada por experiências de solicitações. Diante disso, as idéias do indivíduo são geradas com base nas demandas internas. 
O transtorno de pânico leva os pacientes a uma sobrecarga afetiva interna, desconforto e sofrimentos emocionais. Os fatores de sofrimento emocional, nas mais diferentes maneiras de serem vividos, podem ser verificados de diferentes formas nas investigações sobre a personalidade e pânico. A maior parte dos textos e das pesquisas anteriores apresentou, de alguma forma, a descrição de sofrimento emocional e dor psíquica, elementos que podem, inclusive, caracterizar o quadro de pânico.

O material teórico, de fundamentação psicanalítica e de outras abordagens teóricas em psicologia, bem como o material que se dedica a uma descrição nosológica indica extremo sofrimento e vivência angustiante nos pacientes, cuja experiência com o quadro é tão marcante em termos de dor psíquica que o temor de outros ataques é incontrolável (Adrados \& Figueiredo, 1995; Dunker, 1997; Arbona \& Arnal, 1995; Cartocci, 1998; Barlow \& Cerny, 1999; D’Oliveira, 1997; Gabbard, 1998; Gentil \& Roso, 1987; Gentil, 1996; Gentil, 1997b; López, 2000; Pereira, 1997; Schwartzman, 1997; Trinca, 1997; Troyano, 2001; Ventura, 1991).

Esse aspecto é descrito teoricamente, e pode ser observado, de forma empírica nas pesquisas com pacientes com pânico, em que são sempre freqüentes as indicações de sofrimento e dor psicológica vividas pelos sujeitos. Independente da estratégia metodológica que tenha sido adotada, os componentes de sofrimento psicológico são sempre presentes (Andersen \& Rosenberg, 1990; Balbi, Iannucci \& Italia, 1994; Caetano, 1985; Cohen \& Ruiter, 1992; Cohen \& Ruiter, 1993; Dias, Del Porto \& Miranda, 1990; Echávarri et al., 1994; Ito \& Ramos, 1998; MacFadden, 1994; MacFadden, Duarte \& Guimarães, 1986/87; Montiel, Capovilla, Berberian \& Capovilla, 2005; Morais \& Souza, 1996; Sarvasi, 1999; Villemor-Amaral, Farah \& Primi, 2004).

Apesar desses dados, na avaliação de Exner e Erdberg (2005), observou-se predomínio das respostas de movimento sobre as de cor acromática e sombreado que pode ser 
decorrente de elementos culturais ou de formação (o sujeito estava cursando ensino superior). Dessa forma, a condição cultural pode ter interferido na maneira pela qual esse paciente organizou seu sofrimento diante do quadro de pânico.

O índice denominado de Estimulação Sentida ou Estimulação Vivenciada - es, avalia os disparadores de tensão interna que levam o indivíduo à ação, cumprindo uma função de alerta, diante das dificuldades emocionais que o sujeito possa sentir.

Tabela 11. Valores de es apresentados nos quatro grupos

\begin{tabular}{lcccccc}
\hline es & Média & D.P. & Min & Mediana & Máx & Sig \\
\hline PF & 13,40 & 4,53 & 7,00 & 12,00 & 25,00 & \\
PM & 13,40 & 4,97 & 6,00 & 12,00 & 25,00 & \\
CF & 5,93 & 2,34 & 2,00 & 6,00 & 9,00 & $\mathrm{p}<0,001$ \\
CM & 9,93 & 8,46 & 1,00 & 7,00 & 30,00 & \\
\hline
\end{tabular}

Pelos dados da Tabela 11, verifica-se que o resultado baseado nos testes de KruskalWallis e pos-hoc de Dunn indicou p < 0,001 na comparação dos quatro grupos, demonstrou diferenças significativas entre pacientes e não pacientes. A média encontrada para os grupos de pacientes de ambos os sexos foi de 13,40 contra 5,93 ao grupo-controle feminino e 9,93 ao masculino. Os valores normativos para esse índice apresentam média em 8,57 com desviopadrão de 5,01, revelando que os pacientes que sofrem de pânico têm valores de es aumentados.

Dessa maneira, esses pacientes possuem uma vivência de extrema irritação, desconforto e incômodo internos. São sensações desagradáveis decorrentes de estímulos internos que são acionados, sem que os sujeitos possam deliberadamente controlá-los. Em valores adequados, podem ser compreendidos como sinais internos de alerta, que levam o indivíduo a ações para recuperar seu equilíbrio; entretanto, com índices aumentados, como é o caso dos pacientes da amostra, que revelaram uma sensação extrema de alerta, ativada por um desequilíbrio constante.

A Nota D avalia tolerância ao estresse, bem como elementos de controle. 
Tabela 12. Valores de $D$ apresentados nos quatro grupos

\begin{tabular}{lcccccc}
\hline D & Média & D.P. & Min & Mediana & Máx & Sig \\
\hline PF & $-3,33$ & 1,72 & $-7,00$ & $-3,00$ & $-1,00$ & \\
PM & $-3,07$ & 1,62 & $-6,00$ & $-3,00$ & $-1,00$ & \\
CF & $-0,40$ & 0,83 & $-2,00$ & 0,00 & 1,00 & $\mathrm{p}<0,001$ \\
CM & $-2,33$ & 3,58 & $-11,00$ & $-1,00$ & 0,00 & \\
\hline
\end{tabular}

Os valores expressos nos dados da Tabela 12 indicam a média da Nota D diminuída para os pacientes da amostra, sendo $-3,33$ para o sexo feminino e $-3,07$ para o sexo masculino. Quando os valores foram comparados com as médias obtidas nos sujeitos não pacientes, obteve-se $-0,40$ para o grupo feminino e $-2,33$ para o grupo masculino. Por meio dos testes de Kruskal-Wallis e pos-hoc de Dunn, obteve-se $\mathrm{p}<0,001$, o que revelou uma diferença significativa entre os grupos, com valores menores para os pacientes.

Este dado mostrou que os pacientes com transtorno de pânico vivenciam mais estresse do que os demais, além de não disporem de mecanismos de controle que assegurem um enfrentamento desse estresse. O dado pode ser corroborado pela pesquisa de Magalhães e Loureiro (2005) que conclui existir uma grande relação entre pânico e estresse. Todos os pacientes investigados demonstraram indicadores de estresse (7\% em fase de alerta e $93 \%$ em fase de resistência), desenvolvendo, tanto sintomas físicos como psicológicos.

Os valores da Nota D Ajustada - Adj D permite isolar a possível influência de elementos situacionais sobre a tolerância ao estresse e recursos disponíveis para essa tolerância.

Tabela 13. Valores de Adj D apresentados nos quatro grupos

\begin{tabular}{lcccccc}
\hline Adj D & Média & D.P. & Min & Mediana & Máx & Sig \\
\hline PF & $-1,20$ & 1,97 & $-6,00$ & 0,00 & 1,00 & \\
PM & $-0,67$ & 1,91 & $-3,00$ & $-1,00$ & 5,00 & \\
CF & $-0,13$ & 0,74 & $-1,00$ & 0,00 & 1,00 & p $=0,329$ \\
CM & $-1,60$ & 2,92 & $-9,00$ & 0,00 & 1,00 & \\
\hline
\end{tabular}


Os dados da Tabela 13 mostram a comparação entre os quatro grupos no que tange aos valores de Adj $\mathrm{D}$, foram observadas as médias de -1,20 para o grupo de pacientes femininos, $-0,67$ aos pacientes masculinos, $-0,13$ aos não pacientes femininos e $-1,60$ aos não pacientes masculinos. Após cálculos baseados nos testes de Kruskal-Wallis e pos-hoc de Dunn obteve-se $\mathrm{p}=0,329$, indicando que não houve diferenças significativas entre os quatro grupos nesse item. Os valores normativos brasileiros apontam média de Adj D em -0,50 com desvio padrão de 1,25. Assim, os valores apresentados nos quatro grupos estavam de acordo com o que se espera para a população brasileira.

Como os valores de D apresentam diferença e os valores de Adj D não indicaram diferenças estatisticamente significativas, pode-se afirmar que os pacientes com pânico sofrem de estresse sem que esse sofrimento seja advindo de questões situacionais, podendo ser compreendido como um estado psicológico mais interno.

Na investigação de Magalhães e Loureiro (2005), foi demonstrado que pacientes que sofrem de pânico, mostraram dificuldade para controlar e processar adequadamente as situações de estresse, nem conseguiram acessar recursos internos para esse enfrentamento.

No protocolo, as respostas FM avaliam o processo ideativo oriundo de pensamentos provenientes de estados abstratos e internos.

Tabela 14. Valores de FM apresentados nos quatro grupos

\begin{tabular}{lcccccc}
\hline FM & Média & D.P. & Min & Mediana & Máx & Sig \\
\hline PF & 3,27 & 3,24 & 0,00 & 3,00 & 11,00 & \\
PM & 3,27 & 1,98 & 0,00 & 3,00 & 7,00 & \\
CF & 2,07 & 1,10 & 0,00 & 2,00 & 4,00 & $\mathrm{p}=0,317$ \\
CM & 5,27 & 6,05 & 0,00 & 3,00 & 21,00 & \\
\hline
\end{tabular}

Ao se aplicar os testes de Kruskal-Wallis e pos-hoc de Dunn nos valores dispostos nos dados da Tabela 14, obteve-se $p=0,317$, o que indicou não haver diferença estatisticamente significativa entre os grupos. Os valores médios na emissão de respostas FM mostraram 3,27 para os pacientes do sexo feminino e do sexo masculino, comparados com 2,07 para controle 
feminino e 5,27 para controle masculino. Os índices normativos brasileiros apresentam média de FM 3,44 com desvio-padrão 2,33. Assim, observa-se que os valores das respostas de movimento animal foram compatíveis com o que se espera para a maioria da população e não diferenciou o grupo de pacientes com Transtorno de Pânico.

As respostas m refletem atividades cognitivas não deliberadas, resultado de um sentimento de perda de controle do curso do pensamento.

Tabela 15. Valores de $\mathbf{m}$ apresentados nos quatro grupos

\begin{tabular}{lcccccc}
\hline $\mathrm{m}$ & Média & D.P. & Min & Mediana & Máx & Sig \\
\hline PF & 0,53 & 1,06 & 0,00 & 0,00 & 3,00 & \\
PM & 0,67 & 0,90 & 0,00 & 0,00 & 3,00 & \\
CF & 0,67 & 0,90 & 0,00 & 0,00 & 3,00 & $\mathrm{p}=0,736$ \\
CM & 0,80 & 1,08 & 0,00 & 0,00 & 3,00 & \\
\hline
\end{tabular}

De acordo com os dados da Tabela 15, na amostra objeto desta pesquisa, as médias das respostas de movimento inanimado foram 0,53 ao grupo de pacientes femininos, 0,67 aos pacientes masculinos e não pacientes femininos e 0,80 aos não pacientes masculinos. Após a aplicação dos testes de Kruskal-Wallis e pos-hoc de Dunn, obteve-se $\mathrm{p}=0,736$, o que demonstrou que não existem diferenças significativas entre os quatro grupos. Os valores normativos brasileiros para m são 1,39 com desvio-padrão de 1,39. Os dados dos participantes são compatíveis com o esperado para a população normativa e os valores de m não se diferenciaram dos grupos de pacientes e não pacientes.

As respostas C’ avaliam uma forma de constrição afetiva, ou seja, dificuldade na expressão emocional. Neste estudo, as respostas C’ foram analisadas em sua totalidade, ou seja, $\Sigma C^{\prime}$.

Tabela 16. Valores de $\Sigma C^{\prime}$ apresentados nos quatro grupos

\begin{tabular}{lcccccc}
\hline$\Sigma C^{\prime}$ & Média & D.P. & Min & Mediana & Máx & Sig \\
\hline PF & 2,80 & 3,30 & 0,00 & 2,00 & 12,00 & \\
PM & 2,47 & 2,13 & 0,00 & 2,00 & 6,00 & \\
CF & 0,73 & 0,80 & 0,00 & 1,00 & 2,00 & $\mathrm{p}=0,089$ \\
CM & 1,40 & 1,35 & 0,00 & 1,00 & 4,00 & \\
\hline
\end{tabular}


A comparação dos quatro grupos para $\Sigma C^{\prime}$, Tabela 16 , indicou $p=0,089$. Após a aplicação dos testes de Kruskal-Wallis e pos-hoc de Dunn, foi revelado que não existem diferenças estatisticamente significativas entre eles. As médias foram: para o grupo de pacientes femininos 2,80 e aos pacientes masculinos de 2,47. Os dados do grupo-controle demonstraram médias de 0,73 às mulheres e 1,40 aos homens.

A média normativa brasileira para a $\Sigma C^{\prime}$ encontra-se em 1,13 com desvio-padrão de 1,29. Apesar da diferença entre os grupos não ter sido significativa, quando se observam os valores normativos, é possível verificar que os dados do grupo de pacientes estão ligeiramente acima do esperado. Apesar da quantidade das respostas de cor acromática não diferenciar o grupo de pacientes, notou-se que esse grupo apresentou uma maior vivência de componentes depressivos, com uma tendência ao desenvolvimento de sintomas psicossomáticos. O quadro somático é bastante comum em pacientes com pânico, observando-se uma grande variedade de sintomas que conduzem a uma perturbação orgânica nesses indivíduos (Arbona \& Arnal, 1995; Gabbard, 1998; Gentil \& Roso, 1987; Gentil, 1996; Gentil, 1997b; López, 2000; Pereira, 1997).

As V indicam aspectos relacionados à introspecção, mas são carregadas de uma identificação negativa. Neste estudo, as respostas V foram analisadas em sua totalidade, ou seja, $\Sigma \mathrm{V}$.

Tabela 17. Valores de $\Sigma V$ apresentados nos quatro grupos

\begin{tabular}{lcccccc}
\hline$\Sigma \mathrm{V}$ & Média & D.P. & Min & Mediana & Máx & Sig \\
\hline PF & 0,00 & 0,00 & 0,00 & 0,00 & 0,00 & \\
PM & 0,13 & 0,35 & 0,00 & 0,00 & 1,00 & \\
CF & 0,13 & 0,52 & 0,00 & 0,00 & 2,00 & $\mathrm{p}=0,564$ \\
CM & 0,07 & 0,26 & 0,00 & 0,00 & 1,00 & \\
\hline
\end{tabular}


Como é possível verificar na Tabela 17, os dados não indicaram diferenças estatisticamente significativas entre os quatro grupos. As médias obtidas foram 0,00 para o grupo de pacientes feminino, 0,13 para os pacientes masculinos e ao grupo-controle feminino e 0,07 ao controle masculino. Os testes de Kruskal-Wallis e pos-hoc de Dunn indicaram p = 0,564, ou seja, sem diferenças. A tabela normativa brasileira expõe o valor médio de $\Sigma \mathrm{V}$ em 0,51 com desvio padrão de 0,92. Dessa maneira, os dados da amostra foram compatíveis com os da população brasileira, indicando que $\Sigma \mathrm{V}$ não diferencia os grupos estudados.

As respostas T revelam as necessidades de proximidade e de contato emocional mais próximo. O somatório de T é obtido da mesma maneira dos demais.

Tabela 18. Valores de $\Sigma T$ apresentados nos quatro grupos

\begin{tabular}{lcccccc}
\hline$\Sigma$ T & Média & D.P. & Min & Mediana & Máx & Sig \\
\hline PF & 0,47 & 1,06 & 0,00 & 0,00 & 4,00 & \\
PM & 0,40 & 0,51 & 0,00 & 0,00 & 1,00 & \\
CF & 0,67 & 0,62 & 0,00 & 1,00 & 2,00 & $\mathrm{p}=0,164$ \\
CM & 0,27 & 0,59 & 0,00 & 0,00 & 2,00 & \\
\hline
\end{tabular}

A Tabela 18 traz os dados de $\Sigma$ T no estudo. Os valores são bem semelhantes, os testes de Kruskal-Wallis e pos-hoc de Dunn revelaram $\mathrm{p}=0,164$, demonstrando que não houve diferenças significativas entre os valores dos quatro grupos. As médias obtidas foram 0,47 para pacientes femininos, 0,40 para pacientes masculinos, 0,67 para não pacientes femininos e 0,27 para não pacientes masculinos. Os valores normativos brasileiros mostram média de 0,33 com desvio-padrão de 0,92 . Sendo assim, os valores dos sujeitos estão de acordo com o que se espera para os brasileiros. A variável $\Sigma$ T não diferencia o grupo de pacientes com pânico dos não pacientes.

No que tange ao $\Sigma Y$, , representa a dificuldade em se defender, levando o indivíduo a uma sensação de desamparo e ansiedade. 
Tabela 19. Valores de $\Sigma Y$ apresentados nos quatro grupos

\begin{tabular}{lcccccc}
\hline$\Sigma Y$ & Média & D.P. & Min & Mediana & Máx & Sig \\
\hline PF & 6,33 & 2,33 & 3,00 & 7,00 & 10,00 & \\
PM & 6,47 & 2,85 & 2,00 & 6,00 & 12,00 & \\
CF & 1,67 & 1,40 & 0,00 & 2,00 & 4,00 & $\mathrm{p}<0,001$ \\
CM & 2,13 & 2,20 & 0,00 & 1,00 & 7,00 & \\
\hline
\end{tabular}

Ao observar os dados da Tabela 19, é possível verificar um aumento na emissão de respostas $\mathrm{Y}$ nos pacientes, a média dos pacientes do sexo feminino foi de 6,33 e do sexo masculino de 6,47, contrapondo-se às médias do grupo-controle feminino que chegaram a 1,67 e masculino a 2,13. Após a aplicação dos testes de Kruskal-Wallis e pos-hoc de Dunn, obteve-se $\mathrm{p}<0,001$, revelando que o aumento das respostas de $\mathrm{Y}$ identificou o grupo de pacientes. Além disso, os valores normativos para $\Sigma Y$ estão com média 1,78 e desvio padrão 2,08, compatíveis com o grupo de não pacientes, mas bem menores do que os dados apresentados pelos sujeitos com pânico.

Nos pacientes da amostra, o aumento das respostas $\mathrm{Y}$ indicou extremo desconforto emocional e sofrimento interno, levando-os a experimentar uma sensação de incapacidade em se defender de situações emocionais perturbadoras, ou seja, desamparo emocional.

Em indivíduos não pacientes, há uma tendência desse sofrimento ser processado com relativa facilidade, já que a variável Y é bastante instável e suscetível à organização. No caso dos pacientes com pânico torna-se crônica diante da tensão desencadeada pelas crises e pelo temor de novas crises. A situação faz com que esses pacientes vivenciem a situação de desamparo de forma intensa. No pânico, os sentimentos de desamparo são observados nas investigações psicanalíticas sobre o quadro (Cartocci, 1998; Pereira, 1997; Schwartzman, 1997; Trinca, 1997). 


\section{Variáveis secundárias}

Além das variáveis principais já descritas, escolhidas com base nas propostas de pesquisas com o Método de Rorschach feitas por Exner (1995), foi realizado um estudo exploratório de todas os outros itens de codificação do método para verificar a existência de componentes com diferenças significativas que pudessem caracterizar o grupo de pacientes.

A seguir, são expostas as variáveis, com seus respectivos contextos, que apresentaram uma diferença estatisticamente significativa na comparação entre os quatro grupos. No contexto afetivo, as respostas CorSh. No contexto interpessoal, as análises de GHR:PHR e COP. No aspecto ligado à mediação, têm-se os índices XA\%, X-\% e X+\% .

Existem respostas com mais de um determinante em sua elaboração, que são chamadas de determinantes mistos ou blends. Uma das possíveis combinações existentes é identificadas por CorSh que indica que a vivência afetiva é também confusa e dolorosa, equivale a dizer que ao experimentar qualquer tipo de afeto, este vem carregado de ambivalência e sofrimento .

Tabela 20. Valores de CorSh apresentados nos quatro grupos

\begin{tabular}{lcccccc}
\hline CorSh & Média & D.P. & Min & Mediana & Máx & Sig \\
\hline PF & 2,20 & 2,14 & 0,00 & 2,00 & 7,00 & \\
PM & 1,93 & 1,79 & 0,00 & 1,00 & 6,00 & \\
CF & 0,47 & 0,64 & 0,00 & 0,00 & 2,00 & $\mathrm{p}=0,004$ \\
CM & 0,53 & 0,74 & 0,00 & 0,00 & 2,00 & \\
\hline
\end{tabular}

Os dados expostos na Tabela 20 indicam que a média de emissão de Mistos de CorSh foi de 2,20 às pacientes do sexo feminino e 1,93 aos pacientes do sexo masculino. Por outro lado, os sujeitos do grupo de não pacientes indicaram média de 0,47 para as mulheres e 0,53 para os homens. Após a aplicação dos testes de Kruskal-Wallis e pos-hoc de Dunn, obteve-se $p=0,004$, revelando que existe uma diferença estatisticamente significativa entre os grupos, que pode diferenciar o grupo de pacientes nesse aspecto. Ao se levantar os valores normativos, observa-se média 0,37 e desvio-padrão de 0,64 para a população brasileira. 
Assim, os pacientes com pânico apresentam maior índice de CorSh, revelando que suas vivências afetivas são carregadas de ambivalência e sofrimento.

No caso avaliado por Exner e Erdberg (2005), houve a incidência de um CorSh , que já é considerado como um sinal de perturbação afetiva. As demais pesquisas envolvendo a avaliação de pacientes com pânico também indicaram, de alguma forma, que os sujeitos passam por vivências de sofrimento emocional que acarretam sensação de ambivalência e pouca organização de componentes afetivos (Andersen \& Rosenberg, 1990; Balbi, Iannucci \& Italia, 1994; Caetano, 1985; Cohen \& Ruiter, 1992; Cohen \& Ruiter, 1993; Dias, Del Porto \& Miranda, 1990; Echávarri et al., 1994; Ito \& Ramos, 1998; MacFadden, 1994; MacFadden, Duarte \& Guimarães, 1986/87; Montiel, Capovilla, Berberian \& Capovilla, 2005; Morais \& Souza, 1996; Sarvasi, 1999; Villemor-Amaral, Farah \& Primi, 2004).

As respostas com representação humana também podem ser avaliadas e comparadas pela proporção entre elas GHR : PHR.

Tabela 21. Comparação GHR : PHR nos quatro grupos

\begin{tabular}{lccccccc}
\hline \multirow{2}{*}{ Proporção } & \multicolumn{2}{c}{$\begin{array}{c}\text { Predomínio } \\
\text { GHR }\end{array}$} & \multicolumn{2}{c}{ Predomínio } & \multicolumn{2}{c}{ Valores } & \multirow{2}{*}{ Sig } \\
\cline { 2 - 7 } & $\mathrm{N}$ & $\%$ & $\mathrm{~N}$ & $\%$ & $\mathrm{~N}$ & $\%$ & \\
\hline PF & 5 & 33,33 & 7 & 46,67 & 3 & 20,00 & \\
PM & 3 & 20,00 & 8 & 53,33 & 4 & 26,67 & \\
CF & 8 & 53,33 & 5 & 33,33 & 2 & 13,33 & $\mathrm{p}=0,011$ \\
CM & 13 & 86,67 & 1 & 6,67 & 1 & 6,67 & \\
\hline
\end{tabular}

No estudo da proporção GHR : PHR dos colaboradores, pelos dados da Tabela 21, após a aplicação do teste Exato de Fisher, obteve-se $\mathrm{p}=0,011$, houve uma diferença significativa na prevalência de uma das duas formas de processar a representação humana. Nos dados dos pacientes, houve predomínio em PHR em 46,67\% ( $\mathrm{N}=7$ ) das mulheres e 53,33\% (N=8) dos homens, expressando que os pacientes com pânico têm dificuldade de adaptação nas relações sociais, mostrando certa inaptidão no estabelecimento e manutenção das relações sociais. Entretanto, os dados do grupo-controle indicaram o contrário, 
prevalência de GHR em 53,33\% ( $\mathrm{N}=8)$ das mulheres e 86,67\% ( $\mathrm{N}=13)$ dos homens, revelando capacidade em estabelecer e manter contatos sociais de forma efetiva e consistente.

Os valores obtidos na avaliação de Exner e Erdberg (2005) foram 3:3, indicando que o sujeito submetido ao teste não possuía um estilo definido quanto ao contato social. Apesar dos valores não serem adaptados, nesse caso, recursos de formação podem ter interferido positivamente na articulação dos contatos sociais. MacFadden (1994) expôs que as pacientes que estudou, apresentaram dificuldade para perceber seu papel quando inseridas em um contexto social qualquer, ou seja, sentiam dificuldade para concretizar relações sociais com qualidade, o que impedia trocas sociais mais efetivas.

Além disso, estudos sobre as relações objetais estabelecidas por pacientes com pânico indicaram a presença de vínculos frágeis e inseguros, evitando o estabelecimento de relações mais próximas, o que acarreta contatos sociais superficiais e pouco consistentes. A dificuldade em estabelecer e manter bons contatos sociais pode levar esses indivíduos a uma conduta de retraimento afetivo-social (Echávarri et al., 1994; Sarvassi, 1999).

As emissões das respostas de movimento podem possuir escores especiais, de acordo com as propriedades narradas pelos sujeitos. Uma delas é a ocorrência de COP, identificado por respostas M, FM e m. Avalia a capacidade para estabelecer vínculos positivos, nos quais há um predomínio de amabilidade e acolhimento. Sua presença é bastante positiva e pode ser incluída como um dos indicadores de bom prognóstico em diversas situações.

Tabela 22. Valores de COP apresentados nos quatro grupos

\begin{tabular}{lcccccc}
\hline COP & Média & D.P. & Min & Mediana & Máx & Sig \\
\hline PF & 0,00 & 0,00 & 0,00 & 0,00 & 0,00 & \\
PM & 0,20 & 0,56 & 0,00 & 0,00 & 2,00 & \\
CF & 0,33 & 0,49 & 0,00 & 0,00 & 1,00 & $\mathrm{p}=0,006$ \\
CM & 0,67 & 0,72 & 0,00 & 1,00 & 2,00 & \\
\hline
\end{tabular}

De acordo com o que está exposto na Tabela 22, observa-se que as médias de COP nos grupos foram 0,00 aos pacientes femininos, 0,20 aos pacientes masculinos, 0,33 aos não 
pacientes femininos e 0,67 aos não pacientes masculinos. Após a aplicação dos testes de Kruskal-Wallis e pos-hoc de Dunn, foi obtido $\mathrm{p}=0,006$, indicando uma diferença significativa entre os grupos, e os pacientes com pânico revelaram escores menores. Os dados brasileiros apontam média de COP em 0,63 e desvio-padrão em 0,94, compatíveis com os dados do grupo controle, mas acima dos dados apresentados pelos pacientes com pânico.

Pode-se afirmar que a baixa incidência de COP caracterizou a amostra de pacientes com pânico, revelando dificuldades para estabelecer vínculos positivos e construtivos com outros indivíduos, o que prejudica suas relações interpessoais. Aspectos ligados à dificuldade de relacionamento também foram observados nas pesquisas sobre relações objetais (Echávarri et al., 1994; Sarvassi, 1999), revelando pobreza nos contatos interpessoais e certo retraimento nas relações humanas.

O índice de forma convencional - X+\% é uma proporção obtida com base na relação entre as respostas $\mathrm{F}+\mathrm{e}$ Fo.

Tabela 23. Valores de $\mathrm{X}+\%$ apresentados nos quatro grupos

\begin{tabular}{lcccccc}
\hline X+\% & Média & D.P. & Min & Mediana & Máx & Sig \\
\hline PF & 0,54 & 0,10 & 0,37 & 0,53 & 0,69 & \\
PM & 0,55 & 0,13 & 0,32 & 0,56 & 0,76 & \\
CF & 0,68 & 0,17 & 0,38 & 0,67 & 1,00 & $\mathrm{p}<0,001$ \\
CM & 0,75 & 0,18 & 0,36 & 0,75 & 1,00 & \\
\hline
\end{tabular}

A aplicação dos testes de Kruskal-Wallis e pos-hoc de Dunn, conforme dados expostos na Tabela 23, aponta $\mathrm{p}<0,001$, revelando diferenças estatisticamente significativas entre os grupos. Observa-se uma média para os pacientes femininos em 0,54 e para os pacientes masculinos em 0,55, além das médias de 0,68 para controle feminino e 0,75 para o controle masculino. A pesquisa normativa brasileira indica média de 0,44 com desvio-padrão em 0,12 .

O índice $\mathrm{X}+\%$ avalia o grau de convencionalidade perceptual que o indivíduo indica no contato com as estimulações do meio. Apesar dos dados dos pacientes serem 
estatisticamente menores do que os do grupo controle, os valores obtidos nos protocolos dos pacientes com pânico mostraram-se compatíveis com o que se espera para a população brasileira. Entretanto, os dados do grupo controle encontram-se elevados, quando comparados à amostra normativa nacional.

O aspecto de convencionalidade diferencia o grupo de pacientes com pânico do grupo de não pacientes. Revela que os pacientes ajustam-se à realidade de forma convencional, enquanto os colaboradores do grupo-controle indicam procura demasiada da exatidão, evitando serem originais no contato com a realidade, preferem submeterem-se passivamente às normas impostas.

O índice XA\% é uma proporção obtida baseada na relação entre as respostas F+ , Fo e $\mathrm{Fu}$.

Tabela 24. Valores de XA\% apresentados nos quatro grupos

\begin{tabular}{lcccccc}
\hline XA\% & Média & D.P. & Min & Mediana & Máx & Sig \\
\hline PF & 0,74 & 0,14 & 0,52 & 0,73 & 1,00 & \\
PM & 0,70 & 0,16 & 0,43 & 0,69 & 0,94 & \\
CF & 0,78 & 0,17 & 0,46 & 0,81 & 1,00 & $\mathrm{p}=0,010$ \\
CM & 0,88 & 0,11 & 0,71 & 0,91 & 1,00 & \\
\hline
\end{tabular}

O índice de forma convencional estendida interpreta como o indivíduo avalia as fontes externas de informações, captando os estímulos de forma convencional ou não. Os dados da Tabela 24 apresentam diferença significativa entre os grupos estudados, com $p=0,010$, obtido a partir dos testes de Kruskal-Wallis e pos-hoc de Dunn. As médias foram 0,74 para pacientes femininos e 0,70 para os pacientes masculinos, com valores inferiores do que 0,78 para o controle feminino e 0,88 ao controle masculino.

Os dados normativos brasileiros apresentam média em 0,74 com desvio padrão de 0,13. Sendo assim, apesar da diferença entre os grupos estudados, os valores apresentados pelos pacientes de pânico e não pacientes enquadraram-se no padrão da população brasileira, 
revelando que a interpretação desses dados foi igual para o grupo de pacientes e grupo controle.

O índice X-\%, é uma proporção obtida a partir da relação entre as respostas F-.

Tabela 25. Valores de $\mathrm{X}-\%$ apresentados nos quatro grupos

\begin{tabular}{lcccccc}
\hline X-\% & Média & D.P. & Min & Mediana & Máx & Sig \\
\hline PF & 0,26 & 0,14 & 0,00 & 0,27 & 0,48 & \\
PM & 0,32 & 0,19 & 0,06 & 0,31 & 0,73 & \\
CF & 0,19 & 0,13 & 0,00 & 0,16 & 0,42 & $\mathrm{p}=0,006$ \\
CM & 0,12 & 0,11 & 0,00 & 0,09 & 0,29 & \\
\hline
\end{tabular}

Nos dados expostos na Tabela 25, observa-se que as médias em relação a esta variável correspondem a 0,26 para pacientes de pânico do sexo feminino e 0,32 para os do sexo masculino, quando comparadas às médias de 0,19 para o grupo-controle feminino e 0,12 ao controle masculino. Após a aplicação dos testes de Kruskal-Wallis e pos-hoc de Dunn, obteve-se $\mathrm{p}=0,006$, o que revelou diferenças significativas entre os grupos.

Os valores esperados para a população brasileira indicam média em 0,25 com desvio padrão de 0,12. Embora existam diferenças estatísticas entre os grupos, todos os valores foram compatíveis com o que se espera para o brasileiro e mostraram que esse índice não diferencia os grupos estudados, quando estes são comparados aos dados normativos nacionais.

As três variáveis ligadas à mediação dos colaboradores (XA\%, X+\% e X-\%), embora com diferenças numericamente significativas entre os grupos, não serão incluídas nas conclusões finais, por não caracterizarem elementos próprios da personalidade dos pacientes com pânico. 


\subsection{Apreciações Qualitativas}

Apoiada em uma postura psicodinâmica para buscar um significado simbólico para as verbalizações apresentadas pelos sujeitos submetidos ao Método de Rorschach, a análise qualitativa das respostas possibilita uma compreensão individual dos dinamismos psicológicos apresentados pelos pacientes, permitindo uma análise de seus conteúdos internos de forma particular e contextualizada.

A análise qualitativa mostra-se muito importante nas aplicações clínicas do Método de Rorschach para facilitar a compreensão dos componentes pessoais dos indivíduos.

Neste estudo, objetivou-se uma análise dos componentes comuns observados nas imagens temáticas das respostas, fundamentando-se na proposta de Weiner (1998/2000) que propõe que as imagens temáticas referem-se aos componentes psicodinâmicos das respostas, observados nas verbalizações em que, por suas propriedades, há maior carga projetiva.

Em um primeiro momento, foram separadas todas as respostas cujo componente projetivo pudesse estar mais presente. A orientação para a seleção das respostas para a análise qualitativa foi retirada do que propõem Exner e Sendín (1998/1999) e Weiner (1998/2000), explicitados a seguir.

Os critérios utilizados incluíram as respostas com forma distorcida, pois não utilizam os componentes formais e objetivos das manchas e, por isso tendem a apresentar componentes mais pessoais do que as respostas com qualidade formal comum; as respostas com elaboração de movimento de qualquer tipo, visto que o estímulo apresentado é estático e a articulação de cinestesias é própria dos conteúdos dos indivíduos e, por fim, as respostas com superelaborações verbais. Nesses casos, incluem-se componentes verbais que são desencadeados por conteúdos que estão além do que é apresentado pelas manchas (Exner \& Sendín, 1998/1999; Weiner, 1998/2000). 
As respostas foram separadas por cartão, respeitando-se a proposta de que os estímulos apresentados em cada um dos cartões possuem componentes específicos que desencadeiam respostas, de acordo com demandas igualmente específicas (Weiner, 1998/2000).

Para que houvesse uma direção clara da análise das respostas, foram delineadas categorias de temas e variações para a leitura das verbalizações. A partir das proposições de Lerner (1991) e Schafer (1954), que apresentam um conjunto de categorias que pode ser aplicado na compreensão simbólica das respostas, foram criados os seguintes itens para a análise qualitativa:

- Orientação de dependência e oralidade;

- Orientação anal;

- Orientação sadomasoquista;

- Orientação autoritária;

- Conflitos de superego;

- Fragilidade geral e resistência;

- Atitude de medo ou rejeição diante da identidade masculina;

- Atitude de medo ou rejeição diante da identidade feminina;

- Atitude de rejeição diante de regras adultas, educacionais e parentais;

- Identidade negativa;

- Narcisismo e sensualidade;

- Aspectos de reprodução;

- Relacionado à idade ou morte; e

- Tom emocional e atmosfera interpessoal. 
As respostas separadas foram lidas e categorizadas, de acordo com os itens apresentados anteriormente, no sentido de observar a existência de um padrão comum nas verbalizações dos pacientes, conforme cada cartão.

Após a análise, foi possível verificar que não existe um padrão comum nas respostas apresentadas pelos pacientes, sendo assim parece não haver componentes qualitativos que diferenciem os grupos de pacientes.

Várias respostas foram destacadas com conteúdos projetivos e, em alguns casos, foi possível perceber uma uniformidade de temas ou categorias, quando a análise é feita por individuo separadamente. Dessa forma, os componentes projetivos observados no Método de Rorschach dos pacientes com pânico são diretamente relacionados aos conteúdos idiossincráticos desses indivíduos e, por isso, não podem ser analisados de forma coletiva.

Embora de grande importância para o estudo particular do dinamismo de cada paciente, podendo clarear os componentes ansiógenos de cada um, os elementos qualitativos e projetivos não fornecem informações seguras para diferenciar o grupo de pacientes com pânico, como foi observado nos dados quantitativos.

\subsection{Síntese dos Dados}

Na apresentação dos dados, após comparação daqueles fornecidos pelos pacientes com transtorno de pânico e dos indivíduos não pacientes, foi possível verificar diferenças estatisticamente significativas em um conjunto de variáveis quantitativas da codificação do Método de Rorschach. Os dados qualitativos não mostraram diferenças que pudessem caracterizar os componentes psicodinâmicos dos pacientes.

Os dados do Quadro 5, apontam uma síntese das variáveis que puderam diferenciar os dois grupos analisados, apoiadas na observância de diferenças estatisticamente significativas entre os grupos. 
Quadro 5. Síntese das variáveis com diferença estatisticamente significativa

\begin{tabular}{|l|l|l|}
\hline Item analisado & Classificação & Síntese do significado \\
\hline DEPI & Presença & $\begin{array}{l}\text { Possível vivência depressiva e alterações de } \\
\text { humor. }\end{array}$ \\
\hline L & Rebaixado & $\begin{array}{l}\text { Interferência de elementos emocionais nos } \\
\text { conteúdos pessoais e julgamentos. }\end{array}$ \\
\hline eb & $\begin{array}{l}\text { Predomínio } \\
\Sigma C^{\prime}+\Sigma T+\Sigma V+\Sigma Y\end{array}$ & $\begin{array}{l}\text { Aumento da tensão interna, indicação de } \\
\text { desconforto e sofrimento psíquico. }\end{array}$ \\
\hline es & Elevado & $\begin{array}{l}\text { Vivência de extrema irritação, desconforto } \\
\text { e incômodos internos. }\end{array}$ \\
\hline D & Rebaixado & $\begin{array}{l}\text { Vivência de estresse, sem recursos para } \\
\text { enfrentamento. }\end{array}$ \\
\hline$\Sigma Y$ & Elevado & $\begin{array}{l}\text { Extremo desconforto emocional e } \\
\text { sofrimento interno. }\end{array}$ \\
\hline CorSh & Elevado & $\begin{array}{l}\text { Vivências afetivas carregadas de } \\
\text { ambivalência e sofrimento. }\end{array}$ \\
\hline GHR : PHR & Predomínio PHR & $\begin{array}{l}\text { Dificuldade de adaptação nas relações } \\
\text { sociais. }\end{array}$ \\
\hline COP & Rebaixado & $\begin{array}{l}\text { Dificuldade em estabelecer vínculos } \\
\text { positivos e construtivos. }\end{array}$ \\
\hline
\end{tabular}

Após a análise quantitativa dos dados obtidos no Método de Rorschach, a partir da exposição dos dados no Quadro 5, observou-se que nove variáveis quantitativas podem diferenciar os grupos de pacientes com transtorno de pânico:

Presença de DEPI ( $p=0,009)$, indicando presença de depressão e de sintomas depressivos ou algum tipo de transtorno afetivo. O índice revela ainda que a organização psicológica do indivíduo é bastante vulnerável à depressão ou alterações de humor.

Rebaixamento de L ( $\mathrm{p}=0,008)$, demonstrando dificuldade acentuada na discriminação entre informações importantes e irrelevantes. Sujeitos com essas características sofrem facilmente invasão de componentes emocionais sobre a eficiência do julgamento de suas condutas e daquilo que é percebido. Estes pacientes são submetidos a uma ampla variação de estímulos emocionais que interferem diretamente na articulação de seus conteúdos pessoais.

Predomínio de $\Sigma C^{\prime}+\Sigma T+\Sigma V+\Sigma Y$ no eb (p = 0,010), caracterizando dor e sofrimento psíquicos em demasia, ocasionados pelo aumento da tensão interna. Nestes casos, há uma 
liberação de afetos com pouco controle, esses componentes afetivos sobrepõem-se aos poucos recursos disponíveis para a organização pessoal, levando o indivíduo a uma sobrecarga emocional e condutas impulsivas. É importante salientar que esse processo interno não pode ser controlado pela vontade dos sujeitos.

Elevação de es ( $<$ 0,001), indicando uma vivência de extrema irritação, desconforto e incômodo internos. Estas sensações desagradáveis são decorrentes de estimulação emocional acionada sem o controle deliberado dos indivíduos, levando-os a uma sensação extrema de alerta, ativada por um desequilíbrio constante.

Rebaixamento de $\mathrm{D}(\mathrm{p}<0,001)$ que revela grande vivência de estresse, associado à falta de recursos internos para enfrentá-lo.

Elevação da $\Sigma Y(p<0,001)$, que indica extremo desconforto emocional e sofrimento interno, associado à sensação de incapacidade em se defender de situações emocionais perturbadoras, ou seja, desamparo emocional. Em se tratando de pacientes com pânico, a sensação de desamparo é intensificada diante da tensão desencadeada pelas crises e pelo temor de novas crises.

Elevação de CorSh $(p=0,004)$, que propõem que as vivências afetivas experienciadas por esses indivíduos são carregadas de ambivalência e sofrimento, caracterizando um sinal de perturbação afetiva.

Predomínio de PHR ( $p=0,011)$, que demonstra dificuldade de adaptação nas relações sociais e expressa certa inaptidão no estabelecimento e manutenção destas relações, fazendo com que seus contatos sociais sejam difíceis e distanciados.

Rebaixamento de COP ( $\mathrm{p}=0,006)$, que permite afirmar que há dificuldade para estabelecer vínculos positivos e construtivos com outros indivíduos, prejudicando suas relações interpessoais. 
Os resultados expostos revelaram que existem variáveis quantitativas do Método de Rorschach que diferenciam os grupos de pacientes e não pacientes, mostrando-se sensíveis ao quadro de Transtorno de Pânico. 


\section{CONCLUSÕES}

Ao se retomar o objetivo geral deste estudo, foi possível concluir, a respeito do perfil de personalidade dos pacientes estudados:

Em síntese, os aspectos de personalidade observados nos dados do Método de Rorschach dos indivíduos com transtorno de pânico mostram que se trata de sujeitos que internamente sofrem de desconforto psicológico, vivenciam irritação, dor e sofrimento psíquico em demasia, ocasionados pelo aumento da tensão interna. Esta vivência interna causa sofrimento e não pode ser controlada deliberadamente por esses sujeitos.

É possível supor que a falta de controle sobre o sofrimento sentido seja causada por uma dificuldade acentuada na discriminação entre informações importantes e irrelevantes na articulação de seus conteúdos. Os pacientes sofrem facilmente invasão de componentes emocionais sobre a eficiência do julgamento de suas condutas e daquilo que é percebido, tanto interna como externamente. Provavelmente, por isso, sejam constantemente submetidos a uma ampla variação de estímulos emocionais que interferem de modo direto na articulação de seus conteúdos pessoais, levando-os a um estado de tensão sem a possibilidade de controle.

Os componentes afetivos sobrepõem-se aos poucos recursos disponíveis para a organização pessoal, levando o indivíduo a uma sobrecarga emocional interna e a condutas impulsivas. A liberação dos afetos é feita com pouco controle e baseada na tensão e no sofrimento sentidos.

Dessa forma, geram-se sensações emocionais desagradáveis que são decorrentes da estimulação emocional acionada sem o controle deliberado dos indivíduos, levando-os a uma sensação extrema de alerta, ativada por um desequilíbrio constante. A dificuldade em se defender das situações emocionais perturbadoras associadas à dor psicológica interna, gera 
uma vivência de desamparo emocional. Desse modo, as vivências afetivas experienciadas por esses indivíduos são carregadas de ambivalência e sofrimento, caracterizando um sinal de perturbação afetiva.

Diante desse processo de sofrimento interno e inadaptação emocional, que o paciente não consegue controlar por vontade própria, surge, reativamente, um quadro depressivo ou sintomas depressivos. Isso ocorre visto que a organização psicológica do indivíduo é bastante vulnerável à depressão, alterações de humor ou outro tipo de transtorno afetivo.

No que se refere aos relacionamentos humanos e sociais, observou-se dificuldade de adaptação nas relações sociais e falta de habilidade no estabelecimento e manutenção destas relações, fazendo com que os contatos sociais dos pacientes sejam difíceis e distanciados. Há, ainda, dificuldade para estabelecer vínculos positivos e construtivos com outros indivíduos, prejudicando suas relações interpessoais.

Todo esse quadro psicopatológico leva os pacientes a uma grande vivência de estresse, sem que tenham recursos internos para enfrentá-lo.

Em síntese, os pacientes que possuem um quadro de transtorno de pânico vivenciam extremo sofrimento causador de perturbação emocional, tensão interna, estresse e afastamento dos relacionamentos humanos positivos.

Neste estudo, as conclusões expressas referem-se à amostra investigada e não devem ser tomadas como finais. Há necessidade de constantes investigações sobre temas relacionados à psicopatologia e ao pânico, tais como: a influência da idade sobre os sintomas, elementos socioculturais e suas conseqüências sobre o quadro, aspectos relacionados ao gênero, estratégias de enfrentamento e tantos outros temas de suma importância.

Entretanto, só com a compreensão do funcionamento psicológico dos pacientes, será possível estabelecer critérios diagnósticos e estratégias terapêuticas que aliviem suas angústias e sofrimentos. 


\section{REFERÊNCIAS}

Acklin, M.W. (1995). Integrative Rorschach Interpretation. Journal of Personality Assessment, 64 (2), 235-238.

Adrados, I. (1982). Manual de psicodiagnóstico e diagnóstico diferencial (2a ed.). Petrópolis: Vozes.

Adrados, I. \& Figueiredo, N. (1995). Síndrome do Pânico. Boletim da Sociedade de Rorschach de São Paulo, 8 (1), 42-49.

Alarcón, R.D. (1995). Clasificación de la conducta anormal: El DSM-IV. In G. BuelaCasal; V.E. Caballo \& J.A. Carrobles (dirs.), Manual de psicopatología y transtornos psiquiátricos. (pp. 205-253). Madrid: Siglo Veintiuno de España.

American Psychiatric Association (1995). DSM-IV - Manual diagnóstico e estatístico de transtornos mentais (4a ed.). (D. Batista, trad.). Porto Alegre: Artes Médicas. (original publicado em 1994).

Andersen, R. \& Rosenberg, N.K. (1990). Rorschach-profile in panic disorder. Scandinavian Journal of Psychology, 31, 99-109.

Anderson, H.H. \& Anderson, G.L. (1978). Técnicas projetivas do diagnóstico psicológico. (E. Bennett, trad.). São Paulo: Mestre Jou. (original publicado em 1951).

Andrade, L.H.S.G.; Viana, M.C. \& Silveira, C.M. (2006). Epidemiologia dos transtornos psiquiátricos na mulher. Revista de Psiquiatria Clínica, 33 (2), 43-54.

Andreatini, R. \& Galduróz, J.C.F. (1995). Transtornos de pânico: uma proposta para o tratamento farmacológico. Temas, 25 (49), 72-82.

Anzieu, D. (1984). Os métodos projetivos (4a ed.). (M. L. E. Silva, trad.). Rio de Janeiro: Campus. (original publicado em 1961). 
Arbona, C.B. \& Arnal, R.B. (1995). Transtorno por pánico. In G. Buela-Casal; V.E. Caballo \& J.A. Carrobles (dirs.), Manual de psicopatología y transtornos psiquiátricos. (pp. 365-407). Madrid: Siglo Veintiuno de España.

Associação Brasileira de Rorschach e métodos projetivos (2006). Livro de Resumos, 4. Congresso Nacional da Associação Brasileira de Rorschach e métodos projetivos, 2006, Brasília: ASBRo.

Augras, M. (1980). A dimensão simbólica: O simbolismo nos testes psicológicos (2a ed.). Petrópolis: Vozes.

Balbi, A.; Iannucci, A, \& Italia, A. (1994). Attacchi de panico ed attachi di rabbia: separazione, vuoo e frammentazione. Psichiatria e Psicoterapia Analitica, 13 (3), 169-178.

Barlow, D.H. \& Cerny, J.A. (1999). Tratamento psicológico do pânico. (M. C. Monteiro, trad.). Porto Alegre: Artes Médicas. (original publicado em 1988).

Beck, S.J. (1945). Rorschach test - variety of personality pictures. New York: Grune \& Straton.

Beck, S.J. (1950). Rorschach’s test (2nd ed.). New York: Grune \& Straton.

Becker, E. \& Trinca, A.M.T. (1984). O pensamento clínico e a integração dos dados no diagnóstico psicológico. In W. Trinca e cols., Diagnóstico psicológico: A prática clínica. (pp. 82-94). São Paulo: EPU.

Beizmann, C. (1974). Le Rorschach de l'enfant à l'adulte (2a ed.). Neuchâtel: Delechaux 7 Niestlé.

Bell, J.E. (1992). Técnicas proyectivas: Exploración de la dinámica de la personalidad. (G. A. Maci, trad.). Cidade do México: Paidós. (original publicado em 1948).

Bradwejn, J.; Koszycki, D. \& Zacharko, R.M. (1996). Influence of personality on behavioral response to cholecystokin-tetrapeptide in patients with panic disorder. Psychiatry Research, 62, 131-1378. 
Brasil (1996). Ministério da Saúde. Conselho Nacional de Saúde. Fundação Nacional de Saúde. Diretrizes e Normas Regulamentadoras de Pesquisas Envolvendo Seres Humanos. Brasília.

Cabral, A. \& Nick, E. (1997). Dicionário técnico de psicologia (12a ed.). São Paulo: Cultrix.

Caetano, D. (1985). Relação entre ataque de pânico e depressão. Jornal Brasileiro de Psiquiatria, 31 (1), 17-24.

Caetano, J. (1997). Pânico tem solução em 80\% dos casos. Ciência Hoje, 22 (131), 60-63.

Campo, V. (1995). Estudios clínicos con el Rorschach en niños, adolescentes y adultos. Barcelona: Paidós.

Cartocci, L. (1998). Pânico, pane ... um divã para a queda. Percurso, 11 (21), 16-22.

Chabert, C. (1993). A Psicopatologia no Exame de Rorschach. (N. Silva Júnior, trad.). São Paulo: Casa do Psicólogo. (original publicado em 1987).

Coelho, L.M.S. (1980). Epilepsia e personalidade: Psicodiagnóstico de Rorschach, entrevistas e anamnese heredológica em 102 examinandos (2a ed.). São Paulo: Ática.

Coelho, L.M.S. \& Costa, L.C. (1987/1988). Sensibilidade dos ansiosos a estímulos específicos da Prova de Rorschach. Boletim da Sociedade de Rorschach de São Paulo, 6 (1), 10-36.

Cohen, L. \& Ruiter, C. (1992). Personality in Panic Disorder with Agoraphobia: a Rorschach study. Journal of Personality Assessment, 59 (2), 304-316.

Cohen, L. \& Ruiter, C. (1993). Persoonlijkheidskenmerken van patienten met agorafobie: een studie met het Comprehensive System voor de Rorschach. Nederlands Tijdschrift voor de Psychologie en haar Grensgebieden, 48 (1), 35-42.

Cunha, J.A. (1996). Avaliação psicológica. In E.D. Busnello; P. Prado-Lima; J.G.V Taborda e cols., Rotinas em psiquiatria. (pp. 50-57). Porto Alegre: Artes Médicas. 
Cunha J.A. (2000). Catálogo de técnicas úteis. In J.A. Cunha e cols., Psicodiagnóstico - V (5a ed.). (pp. 202-290). Porto Alegre: Artes Médicas.

Cunha, J.A.; Minella, D.M.L.; Werlang, B.G. \& Carneiro, T.F. (1993). Alguns tipos específicos de avaliação psicológica. In J.A. Cunha e cols., Psicodiagnóstico-R (4a ed. rev.). (pp. 101-134). Porto Alegre: Artes Médicas.

D’Oliveira, M.A.D. (1997). Fantasma do medo - Síndrome do Pânico: uma história real. Rio de Janeiro: Gryphus.

Deakin, J.F.W. \& Graeff, F.G. (1991). 5-HT and mechanisms of defense. Journal of Psychopharmacology, 5 (4), 305-315.

Dias, S.B.C.; Del Porto, J.A. \& Miranda, M.A. (1990). Distúrbio do pânico: aspectos clínicos e terapêuticos. Revista Brasileira de Clínica e Terapêutica, 19 (9), 365-372.

Douville, O. \& Ventura-Abramson, I. (1992). Utilisation diagnostique du Rorschach pour des symptomatologies majeures d'allure phobique chez l'enfant. Bulletin de Psychologie, 45 (406), 531-544.

Dunker, C.I.L. (1997). Psicanálise e teoria do valor: uma hipótese sobre a síndrome do pânico. Interações, 2 (3), 87-98.

Echávarri, O.; O’Ryan, F.; Rapaport, E.; Lira, F. \& Gloger, S. (1994). Ralaciones objetales en pacientes con trastorno de pánico: un estudio de seguimiento. Revista Chilena de Neuro-Psiquiatria, 32 (1), 37-43.

Eells, G.T. \& Boswell, D.L. (1994). Validity of Rorschach inanimate movement and diffuse shading responses as measures of frustration and anxiety. Perceptual and Motor Skills, 78 (2), 1299-1302.

Exner, J.E. (1994). El Rorschach: un sistema comprehensivo (3a ed.). (M. E. Ramírez, trad.). Madrid: Psimática. (original publicado em 1993).

Exner, J.E. (1999). Manual de classificação do Rorschach para o sistema compreensivo. (A. C. P. Silva Neto, trad.). São Paulo: Casa do Psicólogo. (original publicado em 1995). 
Exner, J.E. (ed.) (1995). Issues and Methods in Rorschach Research. New Jersey: Lawrence Erbaum Associates Publishers.

Exner, J.E. \& Erdberg, P. (2005). The Rorschach: a comprehensive system - advanced interpretation. (3rd ed.). New Jersey : John Wiley \& Sons, Inc.

Exner, J.E. \& Sendín, C. (1999). Manual de interpretacão do Rorschach para o sistema compreensivo. (L.Y. Massuh, trad.). São Paulo: Casa do Psicólogo. (original publicado em 1998).

Frank, G. (1993). On the validity of hypotheses derived from the Rorschach: the relationship between shading and anxiety, update 1992. Psychological Reports, 72, 519-522.

Frank, G. (1997). Research assessment of the clinical utility of the Rorschach. Psychological Reports, 81, 1255-1258.

Gabbard, G.O. (1998). Psiquiatria psicodinâmica (2a ed.). (L. N. A. Jorge \& M. R. S. Hofmeister, trad.).Porto Alegre: Artes Médicas. (original publicado em 1994).

Gacono, C.B. \& Meloy, J.R. (1991). A Rorschach investigation of attachment and anxiety in antisocial personality disorder. The Journal of Nervous and Mental Disease, 179 (9), 546-552.

Gacono, C.B.; Meloy, J.R. \& Weber, C.A. (1992). A Rorschach study of attachment and anxiety in inpatient conduct-disordered and dysthimic adolescents. Journal of Personality Assessment, 58 (1), 16-26.

Gentil, V. (1986). Fisiopatologia da síndrome do pânico. Revista da Associação Médica Brasileira, 32 (5/6), 101-107.

Gentil, V. (1996). Transtorno do pânico. In E.D. Busnello; P. Prado-Lima; J.G.V.Taborda e cols., Rotinas em psiquiatria. (pp. 171-177). Porto Alegre: Artes Médicas.

Gentil, V. (1997a). Ansiedade e transtornos ansiosos. In V. Gentil; F. Lotufo-Neto \& M.A. Bernik (orgs.), Pânico, fobias e obsessões: a experiência do Projeto ANBAM (3a ed.). (pp. 29-36). São Paulo: EDUSP. 
Gentil, V. (1997b). Transtorno de pânico. In V. Gentil; F. Lotufo-Neto \& M.A. Bernik (orgs.), Pânico, fobias e obsessões: a experiência do Projeto ANBAM (3a ed.). (pp. 101-111). São Paulo: EDUSP.

Gentil, V.; Ito, L.M. \& Roso, M.C. (1987). Problemas da deteminação de um perfil de personalidade em pacientes com síndrome do pânico. Revista Associação Brasileira de Psiquiatria - Asociacion Psiquiatrica de la America Latina, 9 (4), 140-144.

Gentil, V. \& Roso, M.C. (1987). Atualização sobre a síndrome do pânico: conceito e bases biológicas. Revista de Psiquiatria do Rio Grande do Sul, 9 (1), 49-58.

Gentil Filho, V.; Lotufo Neto, F. \& Maciel, L.M.A. (1995). Transtornos ansiosos. In H. Elkis et al., Psiquiatria básica. (pp. 233-246). Porto Alegre: Artes Médicas.

Goldberg, D. P. (1996). Questionário de saúde geral de Goldberg: Manual técnico. (L. Pasquali et al., trad. e adapt.). São Paulo: Casa do Psicólogo. (original publicado em 1972).

Grassano, E. (1996). Indicadores psicopatológicos nas técnicas projetivas. (L. S. L. P. C. Tardivo, trad.). São Paulo: Casa do Psicólogo. (original publicado em 1977).

Grünspun, H. (1990). Distúrbios neuróticos da criança (4a ed.). Rio de Janeiro: Livraria Atheneu.

Hernández, M.M. (1993). Metodología aplicada a la investigación en psicología. Madrid: Editorial Complutense.

Hertz, M.R. (1951). Frequency tables for scoring Rorschach responses (3rd ed.). Cleveland: Western Reserve University Press.

Hindmarch, I. (1998). Cognition and anxiety: the cognitive effects of anti-anxiety medication. Acta Psychiatrica Scandinavica, 98 (393), 89-94.

Hübner D’Oliveira, M.M. (1984). Ciência e pesquisa em psicologia: uma introdução. São Paulo: E.P.U.

Hurvich, M.; Benveniste, P.; Howard, J. \& Coonerty, S. (1993). Assessment of annihilation anxiety from projective tests. Perceptual and Motor Skills, 77 (2), 387-401. 
Ito, L.M. \& Ramos, R.T. (1998). Escalas de avaliação clínica: transtorno de pânico. Revista de Psiquiatria Clínica, 25 (6 - Edição Especial), 294-302.

Jacquemin, A. (1997). As técnicas de exame psicológico como instrumento na pesquisa e objeto de pesquisa. Boletim de Psicologia, 47 (107), 57-68.

Kaplan, H.I \& Sadock, B.J. (1993). Compêndio de psiquiatria: Ciências comportamentais e psiquiatria clínica (6a ed.). (D. Batista, trad.). Porto Alegre: Artes Médicas. (original publicado em 1991).

Klopfer, B. \& Ainsworth, M.D. (1954). Development in the Rorschach technique. New York: Word Book Company.

Klopfer B. \& Davidson, H.H. (1977). Técnica del Rorschach - Manual introductorio. (V.L.S. Campo, trad.). Buenos Aires: Paidós. (original publicado em 1962).

Klopfer, B. \& Kelly, D. (1972). Técnica del psicodiagnóstico de Rorschach. (D. Carnelli, trad.). Buenos Aires: Paidós. (original publicado em 1946).

Laicardi, C.; Nuovo, S. \& Tobino, C. (1988). Rorschach indices for discriminating between two schizophrenic syndromes. Perceptual and Motor Skills, 67, 399-406.

Lerner, P.M. (1991). Psychoanalytic theory and the Rorschach. New Jersey: The Analitic Press.

Levin, J. (1987). Estatística aplicada a Ciências Humanas (2a ed.). (S. F. Costa, trad). São Paulo: Harbra.

Loosli-Usteri, M. (1962). Manuel pratique du test de Rorschach. Paris: Hermann.

López, A.B. (1995). Agorafobia I: Naturaleza, etiologia y evaluación. Barcelona: Ediciones Paidós Ibérica.

López, A.B. (2000). Agorafobia y Ataques de Pánico. Madrid: Ediciones Pirámide.

MacFadden, M.A. (1994). Avaliação psicodinâmica de mulheres com transtorno de pânico. Boletim de Psicologia, 44 (100/101), 49-53. 
MacFadden, M.A.; Duarte, F. \& Guimarães, L.A.M. (1986/87). Um estudo preliminar de pacientes com crise de pânico, através da Prova de Rorschach. Arquivos de Saúde Mental de Estado de São Paulo, 66, 95-103.

Magalhães, S.H.T. \& Loureiro, S.R. (2005). Transtorno de pânico: nível de estresse e locus de controle. Estudos de Psicologia, 22 (3), 233-240.

Minerbo, M. (2003). Conhecimento e compreensão do Transtorno do Pânico pela classe médica: especialidades procuradas com maior freqüência pelos pacientes após as primeiras crises. São Paulo, Tese de Doutorado, Instituto de Psicologia, Universidade de São Paulo, São Paulo.

Montiel, J.M.; Capovilla, A.G.S.; Berberian , A.A. \& Capovilla, F.C. (2005). Incidência de sintomas depressivos em pacientes com transtorno de pânico. Psic, 6 (2), 33-42.

Morais, M.A.V. \& Souza, A.M. (1996). Avaliação da personalidade de pacientes do distúrbio do pânico, com o uso de técnicas projetivas (pp.101-107). In Anais, 1. Encontro da Sociedade Brasileira de Rorschach e outros métodos projetivos, 1996, Ribeirão Preto, SBRo.

Nascimento, R.S.G.F. \& Güntert, A.E.V. (2000). Novas tendências: introdução ao sistema compreensivo de Exner. In J.A. Cunha e cols., Psicodiagnóstico - V (5a ed.). (pp. 368377). Porto Alegre: Artes Médicas.

Niva, W. (1995). Projective techniques as psychotherapy. American Journal of Psychotherapy, 49 (2), 244-259.

Organização Mundial de Saúde (coord) (1993). Classificação de transtornos mentais e de comportamento da CID-10: Descrições clínicas e diretrizes diagnósticas. (D. Caetano, trad.). Porto Alegre: Artes Médicas. (original publicado em 1992).

Paul, A.M. (1998). The right (and left) way to look at anxiety. Psychology Today, 31 (1), 12-13.

Pereira, J.C.R. (1999). Análise de dados qualitativos - Estratégias metodológicas para as Ciências da Saúde, Humanas e Sociais. São Paulo: EDUSP. 
Pereira, M.E.C. (1997). O pânico e os fins da psicanálise: a noção de “desamparo” no pensamento de Lacan. Percurso, 10 (19), 29-36.

Pérez, J.F. (1995). Conocer el Rorschach. Valencia: Promolibro.

Piotrowski, Z.A. (1974). Perceptanalysis. (3rd ed.). Philadelphia: Ex Libris.

Poles, C. (2001). O medo que tortura. Veja, 34 (7), 104-111.

Ramos, R.T. (1995). Psicopatologia do Transtorno do Pânico: Efeito da terapêutica e delimitação diagnóstica. São Paulo, Tese de Doutorado, Faculdade de Medicina, Universidade de São Paulo, São Paulo.

Rapaport, D. (1977). Tests de diagnostico psicologico. (E. Loedel, trad.). Buenos Aires: Paidós. (original publicado em 1946).

Rorschach, H. (1978). Psicodiagnóstico (3a ed.). (M. S. V. Amaral, trad.). São Paulo: Mestre Jou. (original publicado em 1921).

Santos, M.A. (1996). Aplicações da Prova de Rorschach no campo da psicopatologia. (pp.257-281). In Anais, 1. Encontro da Sociedade Brasileira de Rorschach e outros métodos projetivos, 1996, Ribeirão Preto, SBRo.

Sarvasi, M.M.O.C. (1999). A Técnica de Rorschach na investigação das relações objetais de pacientes com Transtorno de Pânico. São Bernardo do Campo, Dissertação de Mestrado. Universidade Metodista de São Paulo. São Bernardo do Campo.

Schafer, R. (1954). Psychoanalitic interpretation in Rorschach Testing: Theory and application. New York: Grune \& Stratton.

Schrof, J.M.; Schultz, S.; Koerner, B.I. \& Svetcov, D. (1999). Social Anxiety. U. S. News \& World Report, 126 (24), 50-57.

Schwartzman, R.S. (1997). Síndrome de pânico: uma escuta psicanalítica. Percurso, 9 (18), 87-96.

Severino, A.J. (2001). Metodologia do trabalho científico (21a ed. rev. ampl.). São Paulo: Cortez Editora. 
Siegel, S. (1975). Estatística não-paramétrica para as Ciências do Comportamento. São Paulo: McGraw-Hill.

Silveira, A. (1985). Prova de Rorschach: elaboração do psicograma. São Paulo: Editora Brasileira Ltda.

Sociedade Brasileira de Rorschach e outros métodos projetivos (1995). Programa e Resumos, 1. Encontro da Sociedade Brasileira de Rorschach e outros métodos projetivos, 1995, Ribeirão Preto: SBRo.

Sociedade Brasileira de Rorschach e outros métodos projetivos (1996). Programa e Resumos, 2. Encontro da Sociedade Brasileira de Rorschach e outros métodos projetivos, 1996, Ribeirão Preto: SBRo.

Sociedade Brasileira de Rorschach e outros métodos projetivos (1997). Programa e Resumos, 1. Congresso da Sociedade Brasileira de Rorschach e outros métodos projetivos e 1. Congrès de la Société Internationale de Psycopathologie Phénoméno-Structurale, 1997, Ribeirão Preto: SBRo.

Sociedade Brasileira de Rorschach e outros métodos projetivos (1998). Programa e Resumos, 3. Encontro da Sociedade Brasileira de Rorschach e outros métodos projetivos, 1998, Ribeirão Preto: SBRo.

Sociedade Brasileira de Rorschach e outros métodos projetivos (2000). Programa e Resumos, 2. Congresso Nacional da Sociedade Brasileira de Rorschach e outros métodos projetivos, 2000, Porto Alegre: SBRo-Age Editora.

Sociedade Brasileira de Rorschach e outros métodos projetivos (2001). Anais, 3. Encontro da Sociedade Brasileira de Rorschach e outras técnicas de Avaliação Psicológica, 2001, Itatiba: SBRo.

Sociedade Brasileira de Rorschach e outros métodos projetivos (2004). Programação e Resumos dos Trabalhos, 3. Congresso Nacional da Sociedade Brasileira de Rorschach e outros métodos projetivos, 2004, Porto Alegre: SBRo.

Sousa, C.C. (1982). O Método de Rorschach (3a ed.). São Paulo: T.A. Queiroz - EDUSP. 
Taylor, S. \& Woody, S. (1997). Cognitive restructuring in the treatment of social phobia. Behavior Modification, 21 (4), 487-512.

Tice, T.N. (1990). Anxiety and phobia. Education Digest, 56 (4), 46-52.

Traubenberg, N.R. (1998). A prática do Rorschach. (J.A. Lelé, trad.). São Paulo: Vetor Editora. (original publicado em 1970).

Trinca, W. (1997). Fobia e pânico em psicanálise. São Paulo: Vetor.

Troiano, M. (2001). Guarire dagli attacchi di panico. Roma: Riuniti.

Van Kolck, O.L. (1981). Técnicas de Exame Psicológico e suas aplicações no Brasil. 2o volume - testes de personalidade. Petrópolis: Vozes.

Vaz, C.E. (1997). O Rorschach: Teoria e desempenho (3a ed.). São Paulo: Manole.

Ventura, P.R. (1991). Doença do pânico: perspectivas cognitivo-comportamental e biológica. Jornal Brasileiro de Psiquiatria, 40 (1), 13-25.

Vieira, W.C. (1997). A síndrome do pânico. Perfil, 10, 17-23.

Villemor-Amaral, A.E.; Farah, F.H.Z. \& Primi, R. (2004). O teste das pirâmides coloridas e o transtorno de pânico. Psicologia em Estudo, 9 (2), 301-307.

Villemor-Amaral, A.E.; Silva Neto, A.C.P. \& Nascimento, R.S.G.F. (2003). O Método de Rorschach no sistema compreensivo - Notas sobre estudos brasileiros - 1. São Paulo : Casa do Psicólogo.

Weiner, I.B. (1986). Conceptual end empirical perspectives on the Rorschach assessment of psychopathology. Journal of Personality Assessment, 50 (3), 472-479.

Weiner, I.B. (2000). Princípios de Interpretação do Rorschach. (M. C. V. Silva, trad.). São Paulo: Casa do Psicólogo. (original publicado em 1998).

Yazigi, L. (1987). Introduction. Rorschachiana, 16, 1-5.

Yazigi, L. (1997). O Rorschach: instrumento na pesquisa e objeto de pesquisa. Boletim de Psicologia, 47 (107), 73-83. 


\section{Apêndice 1. Roteiro de questões para entrevista dirigida a ser aplicada aos sujeitos} pacientes

Sujeito: Sexo: Idade:

Escolaridade:

Profissão/Ocupação

Idade primeira crise: Situação:

Processo Diagnóstico:

Freqüência das crises: Antes Tratamento:

Depois Tratamento:

Sintomas durante as crises:

\begin{tabular}{|l|c|c|c|c|c|}
\hline Sintoma & N & L & M & A & E \\
\hline aceleração do ritmo cardíaco & & & & & \\
\hline sudorese & & & & & \\
\hline tremores ou abalos & & & & & \\
\hline falta de ar ou sufocamento & & & & & \\
\hline sensações de asfixia & & & & & \\
\hline dor ou desconforto no tórax & & & & & \\
\hline náusea ou desconforto abdominal & & & & & \\
\hline sensação de tontura ou desmaio & & & & & \\
\hline desrealização & & & & & \\
\hline medo de perder o controle ou enlouquecer & & & & & \\
\hline medo de morrer & & & & & \\
\hline parestesias & & & & \\
\hline calafrios ou ondas de calor & & & & \\
\hline
\end{tabular}

Outras informações: 
Apêndice 2. Roteiro de questões para entrevista dirigida a ser aplicada aos sujeitos nãopacientes

Sujeito: Sexo: Idade:

Escolaridade:

Profissão/Ocupação

Em situações difíceis já sentiu:

\begin{tabular}{|c|c|c|c|c|c|}
\hline \multirow{2}{*}{\multicolumn{6}{|c|}{\begin{tabular}{|l|} 
Sintoma \\
aceleração do ritmo cardíaco
\end{tabular}}} \\
\hline & & & & & \\
\hline \multicolumn{6}{|l|}{ sudorese } \\
\hline \multicolumn{6}{|l|}{ tremores ou abalos } \\
\hline \multicolumn{6}{|l|}{ falta de ar ou sufocamento } \\
\hline \multicolumn{6}{|l|}{ sensações de asfixia } \\
\hline \multicolumn{6}{|l|}{ dor ou desconforto no tórax } \\
\hline \multicolumn{6}{|c|}{ náusea ou desconforto abdominal } \\
\hline \multicolumn{6}{|c|}{ sensação de tontura ou desmaio } \\
\hline \multicolumn{6}{|l|}{ desrealização } \\
\hline \multicolumn{6}{|c|}{ medo de perder o controle ou enlouquecer } \\
\hline \multicolumn{6}{|l|}{ medo de morrer } \\
\hline \multicolumn{6}{|l|}{ parestesias } \\
\hline calafrios ou ondas de calor & & & & & \\
\hline
\end{tabular}

Onde: Classificação $\mathbf{N}=$ nenhum; $\mathbf{L}=$ leve; $\mathbf{M}=$ moderado; $\mathbf{A}=$ acentuado; $\mathbf{E}=$ extremo.

Outras informações: 
Apêndice 3. Carta de Informação sobre Pesquisa e Termo de Consentimento Livre e Esclarecido.

\section{CARTA DE INFORMAÇÃO SOBRE A PESQUISA}

Meu nome é Paulo Francisco de Castro, psicólogo, CRP 06/33.976-9, tel 6464.1676, e estou desenvolvendo uma pesquisa que objetiva estudar o Transtorno de Pânico. Para isso, é necessário a realização de algumas perguntas e a aplicação de um reconhecido método de avaliação de personalidade. Todo e qualquer dado de identificação dos colaboradores será mantido em absoluto sigilo, guardado pela ética profissional e desenvolvimento de pesquisas. As atividades a serem desenvolvidas na pesquisa não oferecem nenhum risco ou desconforto aos participantes. Caso aceite, o colaborador poderá, a qualquer momento, retirar seu consentimento e deixar de participar da pesquisa que está sendo desenvolvida. Caso concorde colaborar com o desenvolvimento deste trabalho, solicito que preencha o termo abaixo:

\section{TERMO DE CONSENTIMENTO LIVRE E ESCLARECIDO}

Pelo presente instrumento, que atende as exigências legais, o(a) senhor(a) portador da cédula de identidade R.G. , sujeito de pesquisa realizada pelo psicólogo Paulo Francisco de Castro, CRP 06/33.976-9, após ter lido a Carta da Informação sobre Pesquisa (acima), ciente dos procedimentos que serão adotados para a coleta de dados na referida pesquisa, não restando nenhuma dúvida a respeito do lido e do explicado, firma seu Consentimento Livre e Esclarecido de concordância em participar da pesquisa proposta.

Data: 